I N T ER N ATIONAL MONETARY FUND

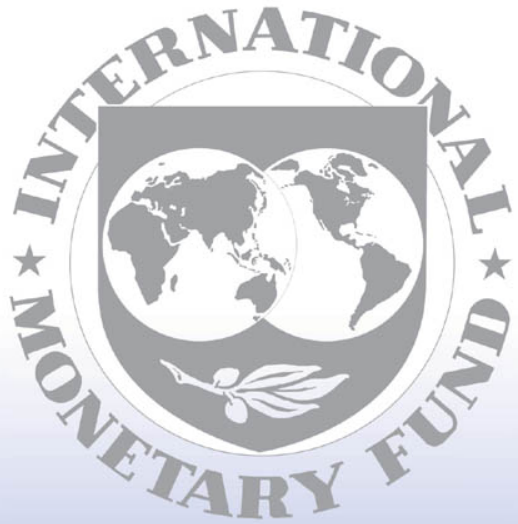

Staff

Country

Reports 


\section{Mexico: Report on the Observance of Standards and Codes_Data Module; Response by the Authorities; and Detailed Assessments Using Data Quality Assessment Framework}

This Report on the Observance of Standards and Codes on Data Module for Mexico was prepared by a staff team of the International Monetary Fund as background documentation for the periodic consultation with the member country. It is based on the information available at the time it was completed on May 23, 2003. The views expressed in this document are those of the staff team and do not necessarily reflect the views of the government of Mexico or the Executive Board of the IMF.

The Response by the Authorities on this report, and the Detailed Assessment Using the Data Quality Assessment Framework (DQAF) are also included.

The policy of publication of staff reports and other documents by the IMF allows for the deletion of market-sensitive information.

To assist the IMF in evaluating the publication policy, reader comments are invited and may be sent by e-mail to publicationpolicy@imf.org.

Copies of this report are available to the public from

International Monetary Fund $\bullet$ Publication Services

700 19th Street, N.W. • Washington, D.C. 20431

Telephone: (202) 6237430 • Telefax: (202) 6237201

E-mail: publications@imf.org • Internet: http://www.imf.org

Price: $\$ 15.00$ a copy

\section{International Monetary Fund \\ Washington, D.C.}


This page intentionally left blank

(C) International Monetary Fund. Not for Redistribution 
INTERNATIONAL MONETARY FUND

MEXICO

\section{Report on Observance of Standards and Codes (ROSC)—Data Module}

Prepared by the Statistics Department and the Western Hemisphere Department

Approved by Carol S. Carson and Anoop Singh

May 23, 2003

Contents

Acronyms $\underline{2}$

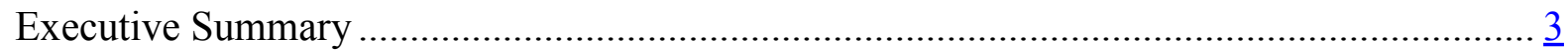

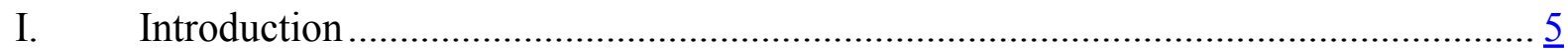

II. Data Dissemination Practices and the SDDS ......................................................... $\frac{5}{6}$

Data dimension: coverage, periodicity, and timeliness................................... $\underline{6}$

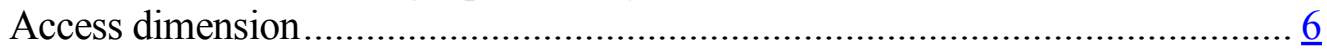

Integrity dimension .................................................................................... $\frac{6}{6}$

Monitoring of data and access dimensions ................................................. 7

III. Summary Data Quality Assessment................................................................... 7

Prerequisites of data quality .................................................................. 7

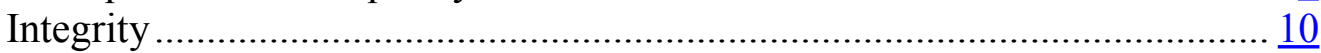

Accuracy and reliability ......................................................................

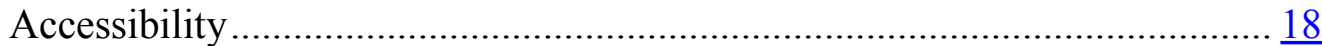

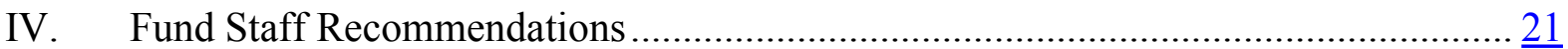

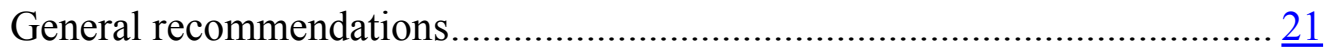

National accounts .................................................................................... $\frac{21}{21}$

National Consumer Price Index ........................................................... $\frac{22}{22}$

National Producer Price Index .............................................................. $\frac{22}{22}$

Balance of payments statistics …………………………………………. $\frac{22}{23}$

Government finance statistics ................................................................ $\frac{23}{23}$

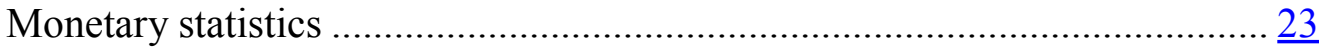

Text Table

1. Summary Data Quality Assessment .......................................................................... 20 


\section{ACRONYMS}

\begin{tabular}{|c|c|}
\hline 1993 SNA & System of National Accounts, 1993 \\
\hline AGA & Customs General Administration \\
\hline $\mathrm{BM}$ & Bank of Mexico \\
\hline BPM4 & Balance of Payments Manual, fourth edition \\
\hline BPM5 & Balance of Payments Manual, fifth edition \\
\hline CEMLA & Center for Latin American Monetary Studies \\
\hline CGT & General Conditions of Employment of the Bank of Mexico \\
\hline CMAP & Mexican Classification of Activities and Products \\
\hline CNBV & Banking and Securities National Commission \\
\hline COFOG & Classification of the Functions of Government \\
\hline COICOP & Classification of Individual Consumption by Purpose \\
\hline $\mathrm{CPC}$ & Central Product Classification \\
\hline $\mathrm{DCN}$ & National Accounts Directorate \\
\hline DED & Debt Statistics Department \\
\hline $\mathrm{DEH}$ & Government Finance Statistics Department \\
\hline DGCNESyP & $\begin{array}{l}\text { Directorate General of National Accounts, Socioeconomic Studies and } \\
\text { Prices }\end{array}$ \\
\hline DOF & Official Gazette of the Federation \\
\hline DPSP & Directorate of Prices, Wages, and Productivity \\
\hline DSBB & Dissemination Standards Bulletin Board \\
\hline ENIGH & National Survey of Household Income and Expenditure \\
\hline FDI & Foreign Direct Investment \\
\hline GAM & Office of the Manager of Macrofinancial Analysis \\
\hline GFSM 1986 & Government Finance Statistics Manual, 1986 \\
\hline IMSS & Mexican Social Security Institute \\
\hline INEGI & $\begin{array}{l}\text { National Institute of Statistics, Geography, and Information } \\
\text { Technology }\end{array}$ \\
\hline ISIC & $\begin{array}{l}\text { International Standard Industrial Classification of All Economic } \\
\text { Activities }\end{array}$ \\
\hline LIEG & Law on Statistics and Geographic Information \\
\hline MFSM & Monetary and Financial Statistics Manual \\
\hline NCPI & National Consumer Price Index \\
\hline NFPS & Nonfinancial public sector \\
\hline NPPI & National Producer Price Index \\
\hline $\mathrm{ODC}$ & Other depository corporations \\
\hline PSBR & Public sector borrowing requirements \\
\hline ROSC & Report on Observance of Standards and Codes \\
\hline SDDS & Special Data Dissemination Standard \\
\hline SCNM & Mexican System of National Accounts \\
\hline SHCP & Secretariat of Finance and Public Credit \\
\hline SBIB & Basic Banking Information System \\
\hline SII & Integrated Government Revenue and Expenditure Information System \\
\hline SIF & Financial Information System \\
\hline
\end{tabular}




\section{EXECUTIVE SUMMARY}

This data module of the Report on Observance of Standards and Codes (ROSC) for Mexico contains (1) a brief assessment of dissemination practices relative to the Special Data Dissemination Standards (SDDS) of the International Monetary Fund (IMF); (2) a summary assessment of the data quality dimensions underlying the national accounts, consumer price, producer price, balance of payments, government finance, and monetary statistics, based on the Data Quality Assessment Framework (DQAF) prepared by the IMF Statistics Department; and (3) the main recommendations of the IMF staff for improving the quality of macroeconomic statistics. The assessments have been prepared on the basis of information provided to the IMF by the Mexican authorities and official data available to the public.

The statistics-producing agencies assessed in this report are the National Institute of Statistics, Geography, and Information Technology (INEGI), the Bank of Mexico (BM), and the Secretariat of Finance and Public Credit (SHCP). This report was prepared by a mission that visited Mexico from February 20 to March 7, 2002. ${ }^{1}$

The mission's main general findings are as follows:

- Dissemination of data subject to the SDDS is in observance of all SDDS specifications, including data coverage, periodicity, and timeliness and the dissemination of advance data release calendars. In several cases, the periodicity and timeliness of these data exceed SDDS requirements.

- $\quad$ The overall quality of Mexican statistics is good. However, there are various areas where improvements could be made. The authorities are aware of this situation and are continuing work in this regard.

- $\quad$ The authorities maintain an open dissemination policy and make sufficient information available to the public in printed form and on the websites of the statistics-producing agencies. However, some of their statistics would be more useful if some improvements were made in coverage, dissemination of metadata (information on methodology, statistical techniques, and source data), and presentation of the data.

The mission's main findings regarding elements of the DQAF are as follows:

\footnotetext{
${ }^{1}$ The mission comprised: Peter L. Joyce (Deputy Director, Statistics Department), Segismundo Fassler (Senior Economist, Real Sector Division), Antonio Galicia Escotto (Senior Economist, Balance of Payments Division II), Alberto Jiménez de Lucio (Senior Economist, Government Finance Division), Teresa Villacrés (Senior Economist, Financial Institutions Division I), Dale Smith (Consultant, Real Sector), and Mabel Hollstein (Administrative Assistant).
} 
Prerequisites of data quality: The legal environment is generally adequate. The legal framework gives the SHCP the necessary powers to regulate and coordinate the national statistical system. It also makes it mandatory to provide information and establishes penalties to be imposed on those not complying with reporting requirements or not observing information confidentiality. However, the Bank of Mexico Law does not authorize the BM to collect statistics on the nonfinancial private sector. Coordination within and between the statistics-producing agencies is adequate, and all the agencies have sufficient human, financial, and information technology resources for carrying out their work.

Integrity: All the agencies demonstrate professionalism and provide their staff with ethical guidelines. The selection of data sources and methods is governed by statistical considerations. The agencies' statistics policies and practices are transparent.

Methodological soundness: Internationally accepted concepts and definitions have generally been applied or are being adopted, except in the case of government finance statistics, which follow national criteria that are similar but not identical to international criteria. The scope of some macroeconomic statistics and the classifications used in them do not follow international recommendations. The complete adoption of international standards and guidelines in the compilation of all statistics would improve their methodological soundness and facilitate international comparisons.

Accuracy and reliability: Although source data and statistical techniques are generally adequate for the compilation of the annual national accounts, the compilation of the quarterly estimates of GDP at current prices and the method of benchmarking the quarterly national accounts estimates to the outturn of the annual accounts should be refined. The regular preparation of revision studies would help improve the accuracy and reliability of statistics.

Serviceability: The periodicity and timeliness of the statistics are good. The intersectoral reconciliation of the statistics is adequate in most cases. A formal process of frequent user consultations and the dissemination of revision studies would improve the serviceability of statistics.

Accessibility: Statistics are disseminated simultaneously to all users in accordance with a calendar established in advance. The provision of detailed methodological notes on the compilation of the balance of payments and monetary statistics would facilitate a better understanding of these statistics.

The mission's main recommendations for improving the quality of Mexico's macroeconomic statistics are presented in the last section of the report. 


\section{INTRODUCTION}

1. This data module of the Report on Observance of Standards and Codes (ROSC) contains (1) a brief assessment of Mexico's practices with regard to the dissemination of macroeconomic statistics in comparison with the Special Data Dissemination Standards (SDDS) of the International Monetary Fund (IMF) (Section II); (2) a summary assessment of the quality of the main macroeconomic statistical datasets, based on the Data Quality Assessment Framework (DQAF) methodology prepared by the IMF Statistics Department staff (Section III) ${ }^{2}$ and (3) the main IMF staff recommendations for improving the quality of these data, based on the foregoing assessments (Section IV). The assessments have been prepared on the basis of information provided to the IMF by the Mexican authorities and official data in the public domain.

\section{Data Dissemination Practices AND the SDDS}

2. The SDDS is a set of standards, based on best practices, established in March 1996, that guide IMF member countries in the dissemination of their economic and financial data. ${ }^{3}$ Mexico subscribed to the SDDS on August 13, 1996; Mexico's data dissemination practices are therefore assessed against the SDDS.

3. Mexico observes the SDDS and complied on June 28, 2000 with the specifications on data coverage, periodicity, and timeliness, and on the dissemination of advance release calendars. The authorities started disseminating metadata on the Dissemination Standards Bulletin Board (DSBB) in September 1996. On April 24, 1997, they established a hyperlink between the national summary data page and the DSBB. Since April 17, 2000, they have been disseminating the Data Template on International Reserves and Foreign Currency Liquidity. On June 1, 2000, they established a hyperlink between this template and the DSBB.

4. Mexico provides access to the macroeconomic statistics covered by the SDDS in publications and on the websites of the National Institute of Statistics, Geography, and Information Technology (INEGI) (http://www.inegi.gob.mx/), the Bank of Mexico (BM) (http://www.banxico.org.mx/), and the Secretariat of Finance and Public Credit (SHCP) (http://www.shcp.gob.mx/index01.html).

\footnotetext{
${ }^{2}$ The SDDS focuses on the dissemination of information on the basis of which a user of statistics may assess the suitability of the data for a particular use; it does not directly assess the quality of the data. The ROSC, on the other hand, in addition to assessing data dissemination practices against the SDDS, assesses the quality of the data in detail using the DQAF, which draws heavily upon international best practices.

${ }^{3}$ A detailed description of the SDDS can be found on the IMF's Dissemination Standards Bulletin Board (DSBB) on the Internet at http://dsbb.imf.org.
} 


\section{Data dimension: coverage, periodicity, and timeliness}

5. Mexico observes SDDS data dimension requirements in all categories, using flexibility options for the timeliness of data on the operations of general government and central government. Data periodicity and timeliness exceed the requirements of the Standard with respect to labor market data (employment, unemployment, and wages/income), the analytical accounts of the central bank, and international reserves. Timeliness requirements are also exceeded with respect to national accounts, the consumer price index, the producer price index, central government debt, the analytical accounts of the banking system, the balance of payments, and the trade balance.

\section{Access dimension}

6. Mexico meets the SDDS requirements for public access to data. Advance release calendars, in observance of the SDDS requirements, are published in hardcopy or on the website of the agency responsible for disseminating the information. Dissemination dates are also shown on the DSBB three months in advance. Data are disseminated simultaneously to all interested parties, generally on the websites of the pertinent institutions.

\section{Integrity dimension}

7. The laws, regulations, and decrees governing the compilation and dissemination of official statistics in Mexico are available to the public - in printed and electronic form - in Spanish and in English. They provide a normative framework that supports the integrity of the statistical system.

8. The procedures for internal access to the data prior to their release are posted on the DSBB for the pertinent data categories. The government does not have internal access to the data before their dissemination in any of the categories covered by the SDDS. Data disseminated by the Mexican statistical agencies do not include ministerial commentaries except in the cases of central government operations and central government debt. In these two instances, ministerial commentaries are included in the Report on the Economic Situation, Public Finances, and Public Debt, which is submitted to the Congress once a quarter and published in the press on the same date.

\section{Quality dimension}

9. Summary methodological statements have been made available to the IMF for most data categories. Statements have not been made available for the labor market, interest rates, the stock exchange index, the balance of payments, or exchange rates. The eleven summary methodological statements received to date have been posted on the DSBB; nonetheless, some 
of them need updating. ${ }^{4}$ In addition, INEGI, the BM, and the SHCP disseminate methodological information in publications and on their websites.

10. The Mexican statistics-producing agencies also disseminate details on components of the statistics and additional data series for all of the data categories prescribed by the SDDS. This makes it possible to crosscheck data and verify the reasonableness of information reported.

\section{Monitoring of data and access dimensions}

11. In accordance with the third IMF Executive Board review of the SDDS, IMF staff began to monitor Mexico's observance of the standards in July 2000. This monitoring includes an examination of dissemination dates indicated in advance release calendars and metadata to ensure that data are published as announced in the calendar and that they match the metadata posted on the DSBB. During the July 2000-December 2001 period, Mexico's dissemination practices were in observance of SDDS requirements. ${ }^{6}$ In a few cases, and only in 2000 , there were brief delays in data dissemination on the country page.

\section{Summary Data Quality AsSessment ${ }^{7}$}

\section{Prerequisites of data quality}

This category of the DQAF identifies conditions within the agency in charge of producing statistics that have an impact on data quality. The elements within the category refer to the legal and institutional environment, resources, and quality awareness.

12. Mexico has a decentralized statistical system, even though a single federal agency is responsible for regulating and coordinating it. Generally speaking, the legal environment ${ }^{8}$ is adequate, although it suffers from considerable complexity. The legal framework establishes a National Statistical Service (SNE), national statistical systems, and arrangements for their organization and functioning. The agencies making up the national statistical systems are not

\footnotetext{
${ }^{4}$ Following the visit of the mission, an additional three summary methodological statements were posted on the DSBB, making 14 in all.

${ }^{5}$ Monitoring of the data dimension - data coverage, periodicity, and timeliness - and of advance release calendars in the access dimension has been under way since July 2000. For the other SDDS specifications, subscribing countries are asked to confirm on a quarterly basis that the description of their practices is accurate.

${ }^{6}$ The same pattern was observed in 2002.

${ }^{7}$ The staff assessment was supplemented by a survey of users of Mexican macroeconomic statistics undertaken to ascertain their views on selected aspects of the quality of the data. ${ }^{8}$ Based on the Federal Public Administration Organic Law, the Statistical and Geographic Information Law (and pertinent Regulations), the Federal Law on the Administrative Responsibilities of Civil Servants, and the Internal Regulations of the Secretariat of Finance and Public Credit, as well as on subsequent amendments thereof.
} 
identified specifically by name but are broadly defined in such a way that all statistical units of the public administration are included. The relevant law effectively empowers the SHCP ${ }^{9}$ to regulate and coordinate the integration of the various national statistical systems, the development of technical standards, and the collection, production, processing, and dissemination of statistical information.

13. All individuals and legal entities are required to provide statistical information requested by the units making up the national statistical systems, and significant penalties are provided for noncompliance. However, statistical units rarely impose such penalties, as they try to adopt measures conducive to voluntary reporting and provide technical assistance to reporting entities. At the same time, the latter are given assurances that any information they provide will be treated as confidential and used solely for statistical purposes. By law, civil servants who disclose confidential information are subject to penalties.

14. The legal framework establishes INEGI as a devolved body ${ }^{10}$ of the SHCP and gives it the authority to exercise the bulk of the powers granted to the SHCP as regards statistics. In particular, INEGI's responsibilities include planning, promoting, and implementing the organization and development of an integrated national and economic accounting system. Under these arrangements, INEGI is responsible for compiling the national accounts. The law contains no specific provisions governing the appointment of the President of INEGI and does not specify the professional qualifications for the position, although in practice the Secretary of Finance and Public Credit makes the appointment. Information sharing with other statistical units by means of agreements and working meetings is sufficient to ensure the availability of the necessary information and leads to arrangements that avoid the duplication of requests for information from reporting entities. Nevertheless, the various committees created through the legal framework, some of which have not yet been formally established, could facilitate closer coordination of statistical initiatives.

\section{INEGI has enough human, financial, and information technology resources for} compiling the statistics for which it is responsible. The level of its staff's academic training is deemed adequate, and all staff members participate in a continuous training program.

Measures are taken constantly, including the review of work programs and processes and the comprehensive use of available information technology, to improve the efficiency of the use of resources. Through the introduction of the INEGI quality program, the creation of groups of associates, and their systematic and continuous efforts to assess both the quality of statistical output and new needs, INEGI demonstrates its quality awareness. INEGI maintains contacts with a large number of users but has no systematic consultative process, such as periodic user surveys, to seek views on the quality of its statistics.

\footnotetext{
${ }^{9}$ Previously the Secretariat of Programming and Budget.

${ }^{10}$ Órgano desconcentrado. A devolved body has technical but not budgetary autonomy. At the time of the visit of the mission, plans were being considered for converting the INEGI into an autonomous body with its own budget in 2003 .
} 
16. The $\mathbf{B M}$, which is an autonomous body, is in practice responsible for compiling and disseminating monetary, balance of payments, consumer price, and producer price statistics. It also disseminates other macroeconomic statistics compiled by other statistics-producing agencies. According to the legal framework, ${ }^{11}$ the BM is responsible for compiling and disseminating monetary and consumer price statistics, as well as - in coordination with the other authorities concerned - other economic and financial statistics. The BM is also responsible for collecting data and operating information systems as necessary for these purposes. There is no specific stipulation that the BM should prepare balance of payments and producer price statistics. The National Banking and Securities Commission (CNBV), which is also established as a devolved body, disseminates statistical data for all entities under its supervision. Through arrangements both formal (primarily the establishment of committees) and informal (working meetings), the BM has ensured sufficient information interchange with other public agencies and private entities.

17. The law makes it mandatory for financial institutions to report to the BM, the SHCP, and the CNBV any data on their operations that these agencies may request and spells out the penalties to be applied for noncompliance. There is continuous communication between the $\mathrm{BM}$ and reporting entities to solve noncompliance problems and the BM provides adequate support for the preparation of information returns. As regards the nonfinancial institutions and other reporting entities, provisions specifically giving the BM power to require information are outdated, and penalties prescribed are insufficient. This sometimes makes it difficult to collect essential data. The BM cannot rely on the more general provisions to fill this vacuum, as the Law on Statistical and Geographical Information does not apply to the statistical units of autonomous agencies. On the other hand, the BM has adopted measures to encourage the voluntary reporting of necessary information. Legal provisions, including both those specific to the $\mathrm{BM}$ and the more general ones, guarantee the confidentiality of undisclosed information provided to the BM by reporting entities, and the BM has taken appropriate steps to assure this confidentiality.

18. Overall, the BM has enough human, financial, and information technology resources to compile the statistics for which it is responsible, although the transition from the fourth to the fifth edition of the Balance of Payments Manual may require additional resources. Efforts are continuously being made to upgrade the computer systems used in the compilation and analysis of the statistics. Over time, measures taken have included the use of the latest technological advances, with a consequent reduction in the number of staff members assigned to these activities, and the efficiency of the use of resources has thus improved. The BM demonstrates quality awareness through regular reviews of methodologies and data collection, processing, and dissemination procedures and through the introduction of internal

\footnotetext{
${ }^{11}$ Based on the Political Constitution of the United Mexican States, the Bank of Mexico Law, the Bank of Mexico Internal Regulations, the Credit Institutions Law, the General Law on Auxiliary Credit Organizations and Activities, the Financial Associations Law, the Credit Bureau Law, the National Banking and Securities Commission Law, the Tax Code of the Federation, and the Presidential Decree of December 31, 1952, as well as subsequent amendments thereof.
} 
process auditing. In addition, the national consumer price index (NCPI) is certified under ISO 9001. However, the BM does not conduct regular user surveys for the purpose of obtaining comments on data quality.

19. The SHCP has a generally adequate legal framework ${ }^{12}$ for the compilation and dissemination of government finance and public debt statistics. The legal framework gives the SHCP the power to regulate and coordinate national statistics, maintain the official record of federal public debt, and disseminate public debt statistics. Although the SHCP is responsible for keeping the Congress regularly informed about government finances, the law should require the SHCP to disseminate government finance statistics to the public on a regular basis. The SHCP maintains a close relationship with INEGI, the BM, and other public agencies in terms of sharing statistical information. In particular, close coordination with the BM facilitates reconciliation of financing data. The SHCP, the BM, and the Secretariat of Auditing and Administrative Development have cooperated to establish an integrated information system that avoids duplication in the reporting of information by reporting entities. The law states that any information requested by the competent authority (in this case, the SHCP) must be provided by the reporting entities, and the confidentiality of the information in question is guaranteed by law.

20. The SHCP has allocated sufficient human, financial, and information technology resources for the compilation of government finance and public debt statistics. Greater efficiency of resource use can be attributed mainly to the increasing use of automated processes for the compilation of government finance statistics. The SHCP is fully aware of the importance of the quality of statistics, which is being promoted through the establishment of common accounting standards for all budgetary agencies, the verification of the consistency of primary information with the output, and the automation of the compilation and verification of statistics. Every two years, the SHCP conducts user surveys with a view to obtaining comments on quality.

\section{Integrity}

Integrity identifies features that support firm adherence to objectivity in the collection, compilation, and dissemination of statistics so as to maintain users' confidence. Elements refer to the professionalism and ethical standards that should guide policies and practices, which should be reinforced by their transparency.

21. Professionalism is a guiding principle of INEGI, which has an integrated professionalization system that governs all aspects of its staff's professional careers and impedes any improper external influence on the content or dissemination of statistics. The selection of data sources and methods is dictated purely by statistical considerations.

\footnotetext{
${ }^{12}$ Based on the Federal Public Administration Organic Law, the General Law on Public Debt, the Law on Revenues, the Decree Approving the Expenditure Budget of the Federation (for each fiscal year), and the Internal Regulations of the Secretariat of Finance and Public Credit, as well as on subsequent amendments thereof.
} 
In addition, INEGI is authorized to make technical comments to any communications media that have made errors interpreting the data, and it exercises that authority. INEGI statistical policies and practices are transparent as INEGI informs the public of the terms and conditions under which statistics are compiled, does not allow any national authority access to statistics before their release, identifies itself as the statistics-producing agency, and announces in advance any substantial change in the methodology, statistical techniques, or source data used. As regards ethical standards, INEGI staff members are subject to the provisions of the Federal Law on the Administrative Responsibilities of Civil Servants and the INEGI code of General Terms of Employment. There is an induction process for new workers regarding their rights and duties. ${ }^{13}$

22. The BM is committed to maintaining the highest standards of professionalism. The legal framework governing the BM is adequate for ensuring the autonomy of staff members assigned to the compilation of statistics and professional competence is a key requirement in the hiring of employees and in staff promotions. The selection of data sources is dictated purely by statistical considerations, and staff members are encouraged to prepare studies on related topics. The BM holds periodic meetings with the communications media to avoid erroneous interpretations of statistics and, in major cases of improper interpretation, provides clarifications. In general, BM statistical policies and practices are transparent as the BM informs the public of the terms and conditions under which the statistics are compiled, does not give any national authority access to the statistics before their release, identifies itself as the statistics-producing agency, and announces in advance any substantial change in the methodology, statistical techniques, or source data used, ${ }^{14}$ except in the case of balance of payments statistics, changes in which are not disclosed in advance. As regards ethical standards, the Bank of Mexico Law states that BM staff members are subject to the provisions of the Federal Law on the Administrative Responsibilities of Civil Servants. In addition, the BM has drawn up General Terms of Employment, a copy of which is given to all new employees and which is posted on the BM's Intranet site. It also sets up committees on specific topics, with the participation of staff from the various BM departments, to deal with cases of noncompliance with the rules.

23. In practice, the SHCP maintains a high level of professionalism, even though technical independence in the compilation of statistics is not backed by laws or specific safeguards. Government finance and public debt statistics are compiled on the basis of accounting records and administrative reports, drawn up in accordance with the relevant charts of accounts and budgetary standards. The selection of sources and methods is free of any political influence. The SHCP tries to avoid any incorrect interpretation of statistics by providing explanatory notes along with the statistics. In cases of improper interpretation, the SHCP issues clarifications through its Press Office or its technical staff. SHCP statistical

\footnotetext{
${ }^{13}$ In addition, the preparation is currently under way of a code of institutional values and a code of values related to the compilation of statistics.

${ }^{14}$ In the case of the methodological revision of the monetary aggregates, the previous methodology co-existed for two years with the new one, to facilitate understanding of the scope of the changes.
} 
policies and practices are transparent as the SHCP informs the public of the terms and conditions under which the statistics are compiled, does not allow any national authority access to the statistics before their release, identifies itself as the statistics-producing agency, and announces in advance, usually in the Draft Expenditure Budget of the Federation or in General Economic Policy Criteria, any substantial change in the methodology used. SHCP staff members are subject to the provisions of the Federal Law on the Administrative Responsibilities of Civil Servants; there is no other set of ethical standards for the SHCP.

\section{Methodological soundness}

Methodological soundness refers to the application of international standards, guidelines, and agreed practices. Application of such standards, which are specific to the dataset, is indicative of the soundness of the data and fosters international comparability. Elements refer to the basic building blocks of concepts and definitions, scope, classification and sectorization, and basis for recording.

24. Mexico's national accounts are based on the conceptual framework of the System of National Accounts, 1993 (1993 SNA). The delimitation of the economy, production, and assets is generally in compliance with international recommendations, even though a few discrepancies, caused by the lack of relevant information of minor importance, may be noted. These discrepancies include nonrecording of a portion of production of manufactured goods for own-consumption, expenditure on research and development on own account, and production of computer software for own use. Also, historical monuments and original literary and artistic works are not recorded under assets. The classifications used in the national accounts for transactions, institutional sectors, economic activities, and consumption expenditure of households and general government are in conformity with international recommendations. The product classification used differs from that recommended internationally. In principle, all transactions are recorded at market prices and on an accrual basis.

25. The NCPI is based on internationally accepted concepts, practices, and standards. The index covers all urban areas with 20,000 or more inhabitants, all monetary consumption expenditure, the value of consumption of own-produced food, and imputed rents on owneroccupied dwellings. However, the classification system has not been adjusted to conform to the Classification of Individual Consumption by Purpose (COICOP). The overall structure of the national producer price index (NPPI) is based on internationally recommended concepts and definitions. However, international systems have not been adopted for the classification of economic activities and products. ${ }^{15}$ The index covers all economic activities except for the financial services sector and production of processing industries under special customs regimes.

\footnotetext{
${ }^{15}$ For the NPPI, the Mexican Chart of Economic Activities-80 (CMAE-80) is used for the classification of economic activities and products. This is not consistent with ISIC (Revision 3) or the North American Industry Classification System (NAICS).
} 
26. The structure and the classification of balance of payments statistics are in conformity with the methodological standards described in the fourth edition of the Balance of Payments Manual (BPM4). ${ }^{16}$ Considerable progress has been made in the transition to the methodology of the fifth edition of the Balance of Payments Manual (BPM5) and some BPM5 recommendations have already been implemented such as the incorporation of goods for processing into the goods account, the grouping of the income account headings in a single section, and the inclusion of the BM's liabilities to the IMF in the other investment account. The recommendations yet to be implemented using the BPM5 methodology include a finer breakdown of services in the current account and the identification of capital transfers (implementation of which is impeded by lack of source data), the accrual-based recording of the payment of interest on public external debt, and the separate identification of the financial transactions of foreign branches of Mexican banks using the residency criterion. A finer breakdown of services and the identification of capital transfers will require the development of enhanced data sources.

27. The Data Template on International Reserves and Foreign Currency Liquidity is generally compiled in accordance with the Operational Guidelines for the Data Template on International Reserves and Foreign Currency Liquidity. In addition to what is required, information has been included in Sections V and VI on the forecast of short-term flows that affect the international reserves and the composition, by foreign currencies, of gross international reserves. However, Section II, on predetermined short-term drains, is limited to presenting the net flows derived from the memorandum section, which includes items not related to Section II, such as placements of bonds contracted by the government or the BM and expected interest from investment of international reserves. ${ }^{17}$ Progress has also been made toward producing the international investment position. ${ }^{18}$

28. The methodology used to compile government finance statistics follows national concepts and definitions that are generally similar to the guidelines in A Manual on Government Finance Statistics, 1986 (GFSM 1986). The authorities will in due course assess the advisability and possible ways of migrating to the Government Finance Statistics Manual, 2001 (GFSM 2001). Government finance statistics are compiled and disseminated for the federal government (budgetary central government), consolidated central government, general government, budgetary public sector, nonfinancial public sector, and public sector borrowing requirement. Government finance statistics for general government are provided only on request. Institutional coverage of consolidated central government differs from international guidelines in that decentralized agencies engaged in nonmarket activities are not included (these receive the bulk of their revenues from the federal government, which records

\footnotetext{
${ }^{16}$ Mexico's balance of payments statistics are reported to the IMF Statistics Department using the BPM5 methodology.

${ }^{17}$ After the visit of the mission, the BM reclassified the interest from investment of international reserves according to the Operational Guidelines for the Data Template on International Reserves and Foreign Currency Liquidity.

${ }^{18}$ After the visit of the mission, the BM began compiling and disseminating the international investment position.
} 
as expenditure transfers and subsidies granted). This difference also affects the coverage of general government.

29. Revenues, expenditure, financing, and debt are classified in accordance with national criteria similar to those recommended in the GFSM 1986, but with significant presentational differences. Generally speaking, a link can be established between the national classifications and those in the GFSM 1986. The necessary information is available for compiling government finance statistics in accordance with international guidelines. Revenues, expenditure, and financing are shown on an amended cash basis, while debt is presented on a cash basis.

30. As regards monetary statistics, the monetary aggregates are compiled and disseminated, as are separate sectoral balance sheets for the BM, commercial banks, and development banks. These statistics are compiled, generally, in conformity with the methodology of the IMF's Monetary and Financial Statistics Manual (MFSM), for instance with respect to the concept of residency, the identification of institutional sectors, the valuation of financial assets at market prices, use of accrual-basis accounting, and the presentation of assets and liabilities on a gross basis. Commercial banks and development banks make up the other depository corporations (ODC) subsector. However, some groups of corporations currently considered as nonbanks issue broad money liabilities and perform functions similar to those of the $\mathrm{ODC}^{19}$ according to the MFSM definition. Indeed, these instruments are already taken into account in the measurement of broad money.

31. Monetary statistics are reviewed periodically to ensure that the methodology used to compile them reflects changes arising in the structure of the financial sector and in financial instruments. Statistics are presented once a year-in the section on flow of funds in the Annual Report of the Bank of Mexico — within an analytical framework where assets and liabilities of the BM and the ODC (as a subsector) are clearly identified by financial instrument. Although it is possible, based on the information currently disseminated, for a user to construct a Depository Corporations Survey (DCS) that provides data for depository corporations' claims on and liabilities to nonresidents and the resident sectors of the economy, dissemination of an analytical framework of this type would facilitate interpretation of monetary statistics. ${ }^{20}$

\footnotetext{
${ }^{19}$ After the visit of the mission, the BM developed and introduced a system with full coverage of the ODC.

${ }^{20}$ After the visit of the mission, the BM initiated a process for compiling and disseminating the surveys in question. Since August 8, 2002, the BM has been posting on its website surveys of the BM, ODC, depository corporations, other financial corporations, and financial corporations.
} 


\section{Accuracy and reliability}

Accuracy and reliability identifies features that contribute to the goal that data portray reality. Elements refer to identified features of the source data, statistical techniques, and supporting assessments and validation.

32. The compilation of national accounts is supported by a broad database derived from a regular program of economic censuses conducted every five years, annual and monthly economic surveys, and various administrative data that ensure full coverage of economic activities. Although some of these surveys are deterministic, they are adequately representative. Sampling errors for assessing the reliability of probabilistic surveys are not calculated. The variables obtained from the annual surveys are sufficient for compiling the production accounts, although a finer breakdown of production costs would enhance the accuracy of estimates. Monthly economic surveys, for their part, lack information on intermediate consumption, which means that assumptions have to be used. There are valuation problems with the source data on imports by tariff items and some production activities reported in the manufacturing sector survey are valued at producer prices, including certain special taxes on products, so that adjustments are necessary to convert to basic prices.

33. The base year for the national accounts is 1993, for which complete supply-and-use tables are available. Although these tables are also compiled annually, there is no matrix of intermediate consumption. The annual calculations include production accounts at current prices and at constant prices (fixed base, 1993) for 364 activities. Estimates are generally obtained by extrapolating the values for the base year with value and volume indices to obtain estimates at current and constant prices, respectively. Estimates for intermediate consumption of the manufacturing sector at current prices are inconsistent with the assumption used of fixed input/output ratios at constant prices. The procedure adopted for calculating taxes on products at constant prices is inappropriate. In the calculation of GDP by expenditure, there is no direct measurement of changes in inventories available. The methodology used for compiling quarterly GDP estimates at current prices is inadequate, as the assumption of fixed input/output ratios at current prices is inappropriate. In addition, the prorating method used to align quarterly GDP estimates with annual figures introduces breaks in the series.

34. Statistical techniques used for compiling the NCPI accord with internationally accepted practices. In addition, a system is used to audit the price survey and the processing of data for index quality control. However, the index weights are based on the results of the 1989 National Survey of Urban Household Income and Expenditure (ENIGH), which was conducted during only one quarter of that year. The age of these weights exceeds the international recommendation of five to seven years. ${ }^{21}$ In addition, use of data on household consumption collected during only one quarter of the year could introduce seasonal biases in

\footnotetext{
${ }^{21}$ After the visit of the mission, the BM updated the base period for the NCPI. The index is now compiled with the second half of June 2002 as the price reference period. It uses new expenditure weights from the year 2000, aligned to the second half of June 2002 for relative price changes.
} 
the weights. The NPPI is compiled in accordance with internationally accepted methods and procedures. A system is also used to audit the price survey and the processing of data for index quality control.

35. Balance of payments statistics are compiled with information received from an adequate mix of primary and secondary sources. In addition, there are specific procedures for improving the coverage, classification, and valuation of various accounts. In particular, these procedures include (1) coverage and valuation of the goods account, which complement the information received from customs; (2) coverage of the travel account, which provides reliable data; and (3) adjustments in the valuation of external public debt transactions that facilitate carrying them over at market prices to the balance of payments. Nevertheless, the financial transactions of foreign branches of Mexican banks in the balance of payments are not classified using the residency criterion as recommended in BPM5, although the monetary accounts are produced using this criterion. The source data are valued and the results are checked. However, revision studies and analyses are not performed regularly.

36. Adequate information sources are available for compilation of monthly and annual government finance statistics with the various coverages, including all institutions in the respective subsectors. Information is current and timely, except with respect to state and municipal governments. Budgetary and extrabudgetary charts of accounts are consistent with government finance statistics categories recommended in the GFSM 1986, but there is no automatic mechanism for directly deriving government finance statistics categories from budgetary accounts. Time of recording and valuation are generally consistent with the concepts in the GFSM 1986. Information in government finance statistics can be fully reconciled with information in the official annual accounts.

37. To check their accuracy, the principal sources of information on the federal public sector are cross-checked with other accounting and administrative documents. All government finance statistics are preliminary until the final revision is done with definitive audited information: this is indicated by including the word preliminary in the respective tables. If discrepancies are found later, corrections are made. Financing data in government finance statistics are reconciled every month with corresponding monetary data from the BM. Regular revision studies are made for government finance statistics. These are not disseminated but are used to improve the quality of government finance statistics.

38. With respect to monetary statistics, broad-based source data are available with sufficient breakdowns by sector and financial instrument to facilitate application of the methodology recommended in the MFSM. The sectoral balance sheet of the central bank is compiled on the basis of the accounting balance sheet of the BM. The sectoral balance sheet of ODC is based on the Accounting and Sectorization Report that ODC submit each month to the BM. Procedures for compiling source data and for checking and validating data are fully automated. These processes facilitate reporting by ODC and help ensure the quality of intermediate and final statistical products. Reliability of monetary statistics is under constant scrutiny by the BM and periodic revision studies are carried out. Despite constant communications between the BM and ODC, the failure of some ODC to submit the 
Accounting and Sectorization Report by the established deadline-within the first 10 business days of the month - impedes more timely dissemination (i.e., with a lag of less than 40 days) of the more detailed set of monthly monetary statistics.

\section{Serviceability}

Serviceability focuses on practical aspects of how well a dataset meets users' needs. Elements refer to the extent to which data are relevant, produced and disseminated in a timely fashion with appropriate periodicity, are consistent internally and with other datasets, and follow a predictable revisions policy.

39. Although no surveys are carried out among users of national accounts statistics, frequent consultations occur at meetings with users from a wide range of public and private institutions. In addition, the scope of the statistics compiled and disseminated is extensive. Periodicity and timeliness of national accounts are in conformity with international standards. The statistical series is coherent internally and over time. Revisions policy and practice follow a regularly established schedule known to users.

40. No regular user consultation process has been established for the NCPI and NPPI series. However, frequent consultative meetings are held with analysts from the press, the government, the private business sector, and academic circles. Periodicity is monthly and twice monthly for the NCPI and monthly for the NPPI. Each index is disseminated within 10 days of the end of the reference period. Time series are produced and disseminated with a breakdown by geographical area and expenditure component for the NCPI and by industry and purpose for the NPPI. The two series are coherent over time and as regards the order and type of aggregation.

41. Mexico compiles and disseminates quarterly balance of payments statistics, the periodicity and timeliness of which meet SDDS requirements. Preliminary annual data are disseminated two months after the reference period, and in April of the same year in which the Annual Report of the Bank of Mexico is published with revised data. Statistics are coherent over time and among the various external sector accounts and can be reconciled with monetary and government finance statistics. There is full consistency with national accounts statistics. The international investment position is not yet available and there is therefore no reconciliation between such information and balance of payments flows. ${ }^{22}$ Although there is no formal revisions policy, revisions are made on a predictable timetable related to the timetable for the dissemination of quarterly balance of payments data. Users are not consulted actively or systematically; however, user requests are met while following strict confidentiality criteria. No formal procedure has been established for the dissemination of revision studies and analyses.

42. Government finance statistics follow the same time frame as that used in budget preparation and monitoring. The timeliness of data on operations of central government and general government does not meet SDDS requirements, whereas the timeliness of data on central government debt meets SDDS requirements. The periodicity of all these data is as

\footnotetext{
${ }^{22}$ After the visit of the mission, the BM began compiling and disseminating the international investment position.
} 
required under the SDDS. Government finance statistics data on financing are consistent with monetary accounts and balance of payments; inconsistencies with national accounts arise only on account of differences in the basis of recording and coverage. The consistency between preliminary and final data is sufficient to warrant confident use of preliminary data in policy formulation and analysis. Analyses comparing preliminary with final data are not disseminated.

43. Consultations and meetings are held with users whenever there is a change of methodology for monetary statistics. However, the BM does not participate in user forums or engage in direct periodic consultations to assess the practical usefulness of the data. The BM is aware of innovations affecting financial markets and tries to incorporate relevant changes into the monetary statistics. The statistics are coherent internally and over time and can be reconciled with government finance and balance of payments statistics. Periodicity and timeliness of monetary statistics satisfy SDDS requirements. Data are disseminated in preliminary form in accordance with a calendar announced in advance to the public. Figures remain preliminary for two months and then become final. For internal purposes, studies are conducted on revisions and on consistency between preliminary and final data, but these studies are not disseminated.

\section{Accessibility}

Accessibility deals with the availability of information to users. Elements refer to the extent to which data and metadata are clear and easily available and the extent to which assistance to users is adequate to help them find and use the data.

44. National accounts statistics, regardless of their periodicity, are disseminated in a press release and simultaneously posted in full on the INEGI website. Presentation of the statistics in absolute values, indices, percentage distributions, and charts facilitates user understanding. Statistics are disseminated simultaneously to all users in accordance with a calendar announced in advance. Users also have access to metadata by Internet and in INEGI publications. In all publications and on the INEGI website, contact addresses are given for information on the statistics. INEGI has a catalogue of products and services that is updated every year.

45. The NCPI and the NPPI are disseminated, by press release and on the BM website, to all users simultaneously, in accordance with a calendar announced in advance. Monthly data are presented for both indices (plus twice-monthly data for the NCPI), broken down by major group, with tables, time-series charts, and a brief analysis. Detailed time series are available for the NCPI, starting with 1980 data, on the website. Also, NPPI data are disseminated in the same place, broken down by product, starting with 1981 data, and by service, starting with 1994 data. No contact addresses are given for information on the statistics.

46. Dissemination formats for balance of payments include statistical tables, notes on foreign trade, press releases, and the Annual Report of the Bank of Mexico, all found on the $\mathrm{BM}$ website. Information is disseminated with various levels of aggregation, and trends and salient points are analyzed separately in notes and bulletins. Data are sent simultaneously to all parties concerned on the date indicated in the release calendar. However, there are no methodological notes explaining the concepts, definitions, and classifications used in balance 
of payments statistics, and there is as yet no documentation on sources and statistical techniques used in compiling the main balance of payments components. The SHCP disseminates on its website metadata related to external public debt statistics.

47. The public is provided with a very large volume of information on government finance statistics. Formats used for presenting government finance statistics differ from the tables recommended by the GFSM 1986 but their content is similar. A link can generally be established between national classifications and those in the GFSM 1986 but the establishment of such a link requires detailed information not available to users. As a result, the current presentation of government finance statistics makes international comparisons difficult. Introduction of a few selected tables highlighting principal results and following the guidelines in the GFSM 1986 would facilitate general user understanding and international comparisons. Monthly, quarterly, and annual government finance statistics are disseminated through the SHCP website and other media. A data dissemination calendar is also released a year in advance on the SHCP website and in other media. The actual dissemination date usually coincides with the date announced.

48. Government finance statistics are disseminated simultaneously to all parties concerned without preferential treatment for any user. Three methodological notes are also disseminated on the SHCP website discussing concepts, sources, and methods. Also posted on the website and in other media are the name, telephone number, and e-mail address of the person who can be consulted regarding government finance statistics.

49. Presentation of monetary statistics is accompanied by tables and charts facilitating an accurate interpretation of the performance of the principal monetary aggregates. Statistics are disseminated simultaneously to all interested parties on the BM website, where recent data and time series with various levels of detail can also be consulted, although searching may be difficult because of the abundance of information and the complexity of the page. ${ }^{23}$ The BM website contains a brief description of the principal monetary variables but does not provide comprehensive documentation on the methodology currently used to compile monetary statistics. $^{24}$ The BM website does not identify the name of a contact person or the BM unit that compiles monetary statistics; however, users can send their comments and requests through a general electronic mailbox established for this purpose. The BM also responds to special requests from users, provided that such requests do not involve confidential information.

\footnotetext{
${ }^{23}$ In recognition of this limitation, the BM has started a project to simplify search procedures. ${ }^{24}$ After the visit of the mission, the BM added a comprehensive methodological note to its website.
} 
Table 1. Summary Data Quality Assessment

\begin{tabular}{|c|c|c|c|c|c|c|}
\hline \multirow[b]{3}{*}{ Dimension/element } & \multicolumn{6}{|c|}{$\begin{array}{l}\text { NA = Not applicable; } \mathrm{O}=\text { Practice observed; } \mathrm{LO}=\text { Practice largely observed; } \\
\text { LNO = Practice largely not observed; NO = Practice not observed. }\end{array}$} \\
\hline & $\begin{array}{l}\text { National } \\
\text { Accounts }\end{array}$ & $\begin{array}{l}\text { Consumer } \\
\text { Prices }\end{array}$ & $\begin{array}{l}\text { Producer } \\
\text { Prices }\end{array}$ & $\begin{array}{l}\text { Balance of } \\
\text { Payments }\end{array}$ & $\begin{array}{l}\text { Government } \\
\text { Finance }\end{array}$ & $\begin{array}{l}\text { Monetary } \\
\text { Statistics }\end{array}$ \\
\hline & & & & & & \\
\hline \multicolumn{7}{|l|}{ 0. Prerequisites } \\
\hline $\begin{array}{l}\text { 01. Legal and institutional } \\
\text { environment } \\
0.2 \text { Resources } \\
0.3 \text { Quality awareness }\end{array}$ & $\begin{array}{l}\mathrm{LO} \\
\mathrm{O} \\
\mathrm{O}\end{array}$ & $\begin{array}{l}\mathrm{O} \\
\mathrm{O} \\
\mathrm{O}\end{array}$ & $\begin{array}{l}\mathrm{LO} \\
\mathrm{O} \\
\mathrm{O}\end{array}$ & $\begin{array}{c}\mathrm{LO} \\
\mathrm{O} \\
\mathrm{O}\end{array}$ & $\begin{array}{l}\mathrm{O} \\
\mathrm{O} \\
\mathrm{O}\end{array}$ & $\begin{array}{l}\mathrm{O} \\
\mathrm{O} \\
\mathrm{O}\end{array}$ \\
\hline \multicolumn{7}{|l|}{ 1. Integrity } \\
\hline $\begin{array}{l}\text { 1.1 Professionalism } \\
\text { 1.2 Transparency } \\
\text { 1.3 Ethical standards }\end{array}$ & $\begin{array}{l}\mathrm{O} \\
\mathrm{O} \\
\mathrm{O}\end{array}$ & $\begin{array}{l}\mathrm{O} \\
\mathrm{O} \\
\mathrm{O}\end{array}$ & $\begin{array}{l}\mathrm{O} \\
\mathrm{O} \\
\mathrm{O}\end{array}$ & $\begin{array}{l}\mathrm{O} \\
\mathrm{O} \\
\mathrm{O}\end{array}$ & $\begin{array}{l}\mathrm{O} \\
\mathrm{O} \\
\mathrm{O}\end{array}$ & $\begin{array}{l}\mathrm{O} \\
\mathrm{O} \\
\mathrm{O}\end{array}$ \\
\hline \multicolumn{7}{|l|}{ 2. Methodological soundness } \\
\hline $\begin{array}{l}\text { 2.1 Concepts and definitions } \\
\text { 2.2 Scope } \\
\text { 2.3 Classification/sectorization } \\
\text { 2.4 Basis for recording }\end{array}$ & $\begin{array}{c}\mathrm{O} \\
\mathrm{O} \\
\mathrm{LO} \\
\mathrm{O}\end{array}$ & $\begin{array}{c}\mathrm{O} \\
\mathrm{O} \\
\mathrm{LNO} \\
\mathrm{O}\end{array}$ & $\begin{array}{l}\mathrm{O} \\
\mathrm{LO} \\
\mathrm{LNO} \\
\mathrm{O}\end{array}$ & $\begin{array}{l}\text { LO } \\
\text { LO } \\
\text { LO } \\
\text { LO }\end{array}$ & $\begin{array}{l}\text { LO } \\
\text { LNO } \\
\text { LNO } \\
\mathrm{O}\end{array}$ & $\begin{array}{l}\text { LO } \\
\text { LO } \\
\mathrm{O} \\
\mathrm{O}\end{array}$ \\
\hline \multicolumn{7}{|l|}{ 3. Accuracy and reliability } \\
\hline $\begin{array}{l}\text { 3.1 Source data } \\
\text { 3.2 Statistical techniques } \\
\text { 3.3 Assessment and validation of } \\
\quad \text { source data } \\
\text { 3.4 Assessment and validation of } \\
\quad \text { intermediate data } \\
\text { 3.5 Revision studies }\end{array}$ & $\begin{array}{c}\mathrm{LO} \\
\mathrm{LNO} \\
\mathrm{O} \\
\mathrm{LO} \\
\mathrm{LO}\end{array}$ & $\begin{array}{c}\mathrm{LO} \\
\mathrm{LNO} \\
\mathrm{O} \\
\mathrm{O} \\
\mathrm{LNO}\end{array}$ & $\begin{array}{c}\mathrm{O} \\
\mathrm{O} \\
\mathrm{O} \\
\mathrm{O} \\
\mathrm{LNO}\end{array}$ & $\begin{array}{c}\mathrm{LO} \\
\mathrm{O} \\
\mathrm{O} \\
\mathrm{O} \\
\mathrm{LO}\end{array}$ & $\begin{array}{l}\mathrm{O} \\
\mathrm{O} \\
\mathrm{O} \\
\mathrm{O} \\
\mathrm{O}\end{array}$ & $\begin{array}{c}\mathrm{LO} \\
\mathrm{O} \\
\mathrm{O} \\
\mathrm{O} \\
\mathrm{O}\end{array}$ \\
\hline \multicolumn{7}{|l|}{ 4. Serviceability } \\
\hline $\begin{array}{l}\text { 4.1 Relevance } \\
\text { 4.2 Timeliness and periodicity } \\
\text { 4.3 Consistency } \\
\text { 4.4 Revision policy and practice }\end{array}$ & $\begin{array}{l}\mathrm{O} \\
\mathrm{O} \\
\mathrm{O} \\
\mathrm{O}\end{array}$ & $\begin{array}{c}\mathrm{LO} \\
\mathrm{O} \\
\mathrm{O} \\
\mathrm{LNO}\end{array}$ & $\begin{array}{c}\text { LO } \\
\mathrm{O} \\
\mathrm{O} \\
\mathrm{LNO}\end{array}$ & $\begin{array}{l}\mathrm{LO} \\
\mathrm{O} \\
\mathrm{O} \\
\mathrm{LO}\end{array}$ & $\begin{array}{c}\mathrm{O} \\
\mathrm{LO} \\
\mathrm{O} \\
\mathrm{LO}\end{array}$ & $\begin{array}{c}\mathrm{LO} \\
\mathrm{O} \\
\mathrm{O} \\
\mathrm{LO}\end{array}$ \\
\hline \multicolumn{7}{|l|}{ 5. Accessibility } \\
\hline $\begin{array}{l}\text { 5.1 Data accessibility } \\
\text { 5.2 Metadata accessibility } \\
\text { 5.3 Assistance to users }\end{array}$ & $\begin{array}{l}\mathrm{O} \\
\mathrm{O} \\
\mathrm{O}\end{array}$ & $\begin{array}{c}\mathrm{O} \\
\mathrm{O} \\
\mathrm{LO}\end{array}$ & $\begin{array}{c}\mathrm{O} \\
\mathrm{O} \\
\mathrm{LO}\end{array}$ & $\begin{array}{c}\mathrm{O} \\
\mathrm{LNO} \\
\mathrm{LO}\end{array}$ & $\begin{array}{c}\mathrm{LO} \\
\mathrm{O} \\
\mathrm{O}\end{array}$ & $\begin{array}{c}\mathrm{O} \\
\mathrm{LNO} \\
\mathrm{LO}\end{array}$ \\
\hline
\end{tabular}




\section{Fund StafF RECOMMENdATIONS}

\section{General recommendations}

- Include in the relevant legislation a provision governing the appointment of the president of INEGI and specifying the professional qualifications for the position.

- $\quad$ Legally authorize the BM to compile balance of payments and producer price statistics and to collect statistical information from the public and private sectors for these purposes.

- $\quad$ Ensure that all the major statistical agencies are required, as well as authorized, to disseminate to the public macroeconomic statistics for which they are responsible.

- $\quad$ Begin an active, systematic process of consulting users on the quality of macroeconomic statistics.

- $\quad$ Establish procedures for informing users about data revision studies.

- $\quad$ Ensure easy user access to the statistics and related metadata, including through publication of the name of a contact person.

- As a minimum, disseminate on the statistical agencies' sites the metadata posted on the DSBB.

\section{National accounts}

- $\quad$ Introduce the central product classification (CPC).

- Improve and broaden information obtained through monthly and annual economic surveys.

- $\quad$ Request the processing of information already collected in manufacturing surveys on intermediate consumption by product.

- Ascertain whether prices used by reporting entities in economic surveys to value the consumption of raw materials conform to valuation principles described in the 1993 SNA.

- $\quad$ Assess the possibility of obtaining data on imports broken down by tariff item at c.i.f. prices.

- $\quad$ Review the calculation of taxes on products at constant prices.

- $\quad$ Extend the calculation of changes in inventories to include economic activities covered in surveys. 
- Use appropriate indicators for output and intermediate consumption to obtain the corresponding quarterly GDP estimates at current prices by economic activity and use a more appropriate method for benchmarking the quarterly estimates to annual data.

\section{National Consumer Price Index}

- Introduce the COICOP for the coding, classification, and dissemination of all data related to household consumption, for the NCPI and the ENIGH.

- $\quad$ Ensure that the ENIGH is carried out for a full year to minimize biases owing to seasonality problems in index weights.

- $\quad$ Establish a regular program for updating the basket of goods and services and their weights at least every five years. ${ }^{25}$

\section{National Producer Price Index}

- Introduce internationally accepted classification systems for the coding, classification, and dissemination of data on economic activities and products.

- Include processing industries under special customs regimes.

\section{Balance of payments statistics}

- $\quad$ Complete the transition to the BPM5 methodology.

- $\quad$ Compile the international investment position and reconcile it with the balance of payments. $^{26}$

- $\quad$ Make the Data Template on International Reserves and Foreign Currency Liquidity consistent with the format presented in the Operational Guidelines.

- Use information available in monetary accounts on the financial transactions of foreign branches of Mexican banks classified according to the residency criterion.

- $\quad$ To the extent possible, compile information on payments of interest on public external debt on an accrual basis.

- $\quad$ Document with methodological notes the concepts, definitions, and classifications used in the balance of payments, as well as sources and statistical techniques used to compile balance of payments.

\footnotetext{
${ }^{25}$ After the visit of the mission, the BM updated the base period for the NCPI. The index is now compiled with the second half of June 2002 as the price reference period. It uses new expenditure weights from the year 2000, aligned to the second half of June 2002 for relative price changes.

${ }^{26}$ After the visit of the mission, the BM began compiling and disseminating the international investment position.
} 


\section{Government finance statistics}

- $\quad$ Routinely compile and disseminate statistics for the various levels of government (including consolidated central government and general government) following classification and presentation formats recommended in the GFSM 1986.

- $\quad$ Consider adoption of the GFSM 2001 and develop a migration path for compiling and disseminating statistics in accordance with its guidelines.

- Compile and disseminate more timely statistics on state and local governments.

- Introduce a mechanism in the information system to facilitate derivation of government finance statistics directly and automatically from budgetary accounts.

- Improve the timeliness of statistics on central government and general government operations with a view to complying with SDDS requirements. ${ }^{27}$

\section{Monetary statistics}

- Develop a work plan to complete adoption of the MFSM in the following areas: ${ }^{28}$

- $\quad$ Compile and disseminate, in the short term, the central bank survey (CBS), the other depository corporations (ODC) survey, and the depository corporations survey (DCS) based on the sectoral balance sheets that are currently produced.

- Improve the coverage of the ODC subsector by including savings and loan associations, financial factoring enterprises, financial leasing firms, and credit unions.

- $\quad$ Compile and publish the other financial corporations survey and the financial corporations survey.

- $\quad$ Ensure compliance with deadlines established for submission of the Accounting and Sectorization Reports of the ODC.

- Implement, as soon as possible, the metadata and methodologies module project. ${ }^{29}$

\footnotetext{
${ }^{27}$ Mexico currently avails itself of a flexibility option under the SDDS in this regard. ${ }^{28}$ After the visit of the mission, the BM began working toward the adoption of these recommendations. Since August 8, 2002, the BM has been disseminating on its website the central bank survey, the ODC survey (with full coverage), the depository corporations survey, and the other financial corporations survey. The series are monthly and start from 1997.

${ }^{29}$ After the visit of the mission, the BM posted an extensive methodological note on its website.
} 


\section{INTERNATIONAL MONETARY FUND}

MEXICO

\section{Report on the Observance of Standards and Codes (ROSC)—Data Module \\ Response by the Authorities}

May 23, 2003

\section{Contents}

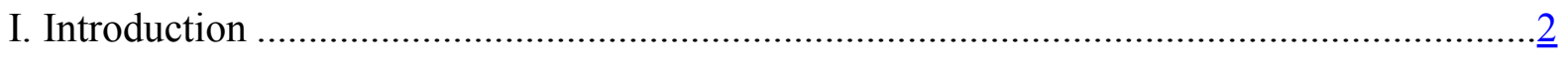

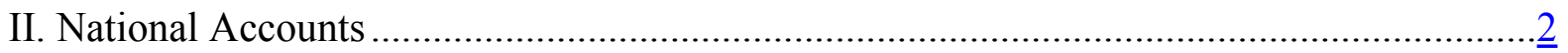

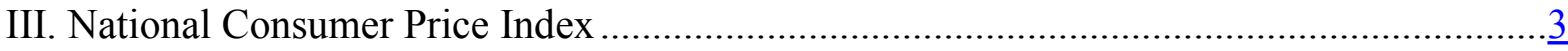

IV. Balance of Payments Statistics .....................................................................................

V. Monetary Statistics................................................................................................

VI. Government Finance Statistics .............................................................................. 


\section{INTRODUCTION}

The Mexican authorities concur with the mission's general findings on the quality of Mexican statistics: dissemination of data subject to the SDDS is in observance of all SDDS specifications, including data coverage, periodicity, and timeliness and the dissemination of advance data release calendars; the overall quality of statistics is good and the authorities are working to improve them; and the authorities maintain an open dissemination policy and make sufficient information available to the public in printed form and on the websites of the statistics-producing agencies.

Moreover, the Mexican authorities agree with the mission's main findings regarding the different elements of the Data Quality Assessment Framework: the legal environment is generally adequate; all the agencies demonstrate professionalism and provide their staff with ethical guidelines; the selection of data sources and methods is governed by statistical considerations; the agencies' statistical policies and practices are transparent; internationally accepted concepts and definitions have generally been applied or are being adopted; adequate source data are generally available; the periodicity and timeliness of the statistics are good; and statistics are disseminated simultaneously to all users in accordance with a calendar established in advance. The authorities agree with the need to provide detailed methodological notes on the compilation of the balance of payments and monetary statistics.

The lag between the mission's report on the Data Module of the ROSC for Mexico and its date of publication has enabled many of the mission's comments or recommendations for further improving the quality of Mexico's macroeconomic statistics to be carried out (as noted in footnotes in the mission documentation); these comments and recommendations, therefore, no longer apply.

\section{National Accounts}

As part of its ongoing work in the compilation of national accounts, the Mexican authorities agree in general with the mission's main findings: the adequate legal and institutional environment in which they unfold; the professionalism of human resources and the continuous implementation of training programs; the constant revision of work processes; the exhaustive utilization of data-processing technology to improve efficiency in the use of the resources; the extensive coverage of statistics and the open dissemination policy of information; the consistency of periodicity and timeliness with international standards; the simultaneous dissemination of statistics to all users in accordance with a calendar established in advance; the institution's internal ethical code and the methodological soundness with which international standards are implemented.

The authorities also coincide with the mission's assessment regarding the need to identify separately research and development expenditures, as well as the production of original literary or artistic works and the production of computer programs for internal use. 
Regarding the mission's comment on the non-adoption of the central product classification, Mexico has undertaken since 2000 an ambitious project with Canada and the US to establish a comparable set of business activity statistics. This set will complement the North American Industry Classification System (NAICS), which was implemented in 1997 after the subscription of the North American Free Trade Agreement (NAFTA) in 1994.

As the mission expresses in its report, the accuracy and confidence of the national accounts rests partially on monthly and annual sector surveys, as well as on 10-year censuses. In this context, the Mexican authorities have extended the conceptual coverage of these surveys since 2003 in order to obtain information about a greater number of variables that will be used in the development of the national accounts. New items include inputs, capital formation, and changes in stocks, among others.

Similarly, the frameworks for the existing surveys and censuses are being revised and adjusted to the System of National Accounts, 1993 (1993 SNA) in order to make them compatible with the informational requirements for the elaboration of macroeconomic indicators.

The supply-and-use tables that are compiled annually will be complemented for the period 1998-2003 with an input-output matrix. This matrix is already under development. The matrix will itemize intermediate consumption by main products and, as a result, will permit the disclosure of additional annual information that can be combined with the breakdown included in annual surveys.

Following the mission's recommendations, the calculation of taxes on products at constant prices is being revised for both quarterly and annual statistics. The quarterly revisions will be applied as soon as a new change of base year is implemented. The annual revisions will follow the Denton method to align the estimates of the quarterly Gross Domestic Product with the values that are obtained on an annual basis.

Finally, the Mexican authorities expect to include periodic and systematic consultations with users of the national accounts system of Mexico in their regular survey activity.

\section{National Consumer Price IndeX}

Regarding the mission's comment that the NCPI index weights, which are based on the results of the 1989 National Survey of Urban Household Income and Expenditure (ENIGH), exceed the international recommendation of updating them every five to seven years, Banco de México in July 2002 changed the NCPI base to second half of June $2002=100$.

\section{Balance of Payments Statistics}

As described in the mission's report, considerable progress has been made in moving from the fourth edition (BPM4) to the fifth edition of the Balance of Payments Manual (BPM5). The significant progress already achieved by Banco de México in the transition of the 
structure and classification of the balance of payments statistics makes it possible for the Banco de México to begin publishing official balance of payments statistics based on the BPM5 proposed methodology starting with the first quarter of 2003. Regarding more specific recommendations of the IMF mission, Banco de México would like to highlight the following:

- $\quad$ Regarding the recommendation to include a finer breakdown of services in the current account, Banco de México has been working towards the identification of new information sources that would eventually allow to meet the BPM5 required breakdown. However, as of today, there is no information available on such items as construction services, information technology, and cultural and recreational services. Nevertheless, Banco de México considers that the current breakdown reasonably approximates the BPM5 required breakdown, and plans to incorporate new concepts into the services account of the balance of payments statistics as soon as new information becomes available.

- $\quad$ Regarding the identification of capital transfers, transfers currently incorporate workers' remittances, donations, and pensions. Nevertheless, due to limitations in the compilation process, it is virtually impossible to distinguish current from capital transfers. However, given the general characteristics of the operations, Banco de México presumes that capital transfers are not significant.

- $\quad$ Regarding the requirement to break down financial operations of the foreign branches of Mexican banks according to a residency criterion, this change will be incorporated in this year's official balance of payments statistics.

Banco de México fully agrees with the mission's recommendation on the need to disseminate complete metadata related to balance of payments statistics. Banco de México plans to publish this year on its website metadata related to balance of payments statistics. Banco de México will, first, include summaries of the methodology, which can be found on the IMF's Dissemination Standards Bulletin Board, and, later in the year, will incorporate more detailed methodology on the balance of payments statistics.

Banco de México also concurs with the mission's recommendation regarding the need to inform in advance of any change in methodology, information coverage, concepts, and classification and statistical techniques employed in the elaboration of balance of payments statistics. Banco de México plans to comply with these practices in 2003.

With respect to the mission's recommendation of introducing a formal process of consultation with regard to users' needs, Banco de México agrees with the usefulness of such a tool and plans to evaluate its establishment. 


\section{Monetary Statistics}

In the area of monetary statistics, the IMF mission concluded that Banco de México has achieved a high degree of compliance with agreed international standards. The data module also helped to identify areas for improvement, mainly in the metadata of analytical releases, and the need to enhance the reported statistics. In particular the new surveys (central bank, ODC, and depository corporations) will be a useful tool for monetary analysis. The excellent coordination and cooperation between Banco de México and the IMF contributed to the release of the above-mentioned surveys and to the improvement in the timeliness of the data.

Regarding the mission's comments on the delays in the submission of the reports of some ODCs, which according to the IMF mission prevents more timely dissemination of detailed monetary statistics, the delay has been further reduced by nine days. Moreover, Banco de México expects that by the end of the second quarter of 2003 the data file will be transmitted to the IMF at the end of each month.

With respect to the mission's comment that Banco de México does not make available to the public extensive documentation of the methodology currently employed in compiling monetary statistics, Banco de México has already posted an extensive methodological note on its website.

On the mission's comments that the information on the IMF's website for the Dissemination Standards Bulletin Board should reflect recent changes in the ODCs source data or monetary aggregates and financial methodologies, Banco de México has already updated the metadata.

\section{Government Finance Statistics}

In general, the mission reports that government finance statistics observe the dimensions associated with prerequisites and integrity, as well as those related to relevance, consistency, metadata accessibility, and assistance to users.

The mission's evaluation of methodological soundness is based on the conceptual framework embedded in the Government Finance Statistics Manual (GFSM 1986) and not on the conceptual framework of public finances in Mexico, which is designed to facilitate the analysis of budgetary entries in accordance with Mexican regulations. In this context, the following elements should be highlighted:

- $\quad$ The balance definition, revenues minus expenditures, is the same in both conceptual frameworks. However, the classification of revenues and expenditures follows different criteria.

- $\quad$ The GFSM 1986 focuses its analysis on the Central and General Government classifications, while the Mexican budget focuses on the non-financial public sector classification. This result is attributable to the fact that fiscal policy in Mexico is not centered on governmental units but on the overall public sector. For instance, public 
entities absorb an important part of public debt, there is a significant dependency of Federal Government revenues on revenues of public entities such as PEMEX, and the implementation of investment projects in public entities is subject to Congress approval and not only to profitability criteria.

- Most importantly, Mexico provides monthly and annual information with the institutional coverage of the GFSM 1986 for the preparation of the publications International Financial Statistics and the Government Finance Statistics Yearbook, respectively. Thus, Mexican government finance statistics, consistent with international standards, are publicly available on a regular basis. The fact that the Mexican authorities follow national criteria in their official reports does not imply that internationally comparable statistics are not regularly disclosed. 


\section{Government Finance Statistics Follow-Up of Staff's Recommendations}

1. Ensure that the statistical agencies are required, as well as authorized, to disseminate to the public macroeconomic statistics for which they are responsible.

2. Introduce a mechanism in the information system to facilitate derivation of government finance statistics directly and automatically from budgetary accounts.

3. Routinely compile and disseminate statistics for the various levels of government (including consolidated central government and general government) following classification and presentation formats recommended in the GFSM 1986.
A proposal modifying the SHCP By-laws to make the Government Finance Statistics Department and the Press Office responsible for the dissemination of government finance statistics has been submitted to the appropriate authorities.

Since February 2002, with the implementation of the Sistema Integral de Administración de Fondos Federales (SIAFF), most of the expenditure statistics of the Federal Government are automatically generated.

In April 2002, the SHCP added to its website the document Balance Fiscal en México: Definición y Metodologia, which presents a detailed and integral definition of the different precepts related to the financial obligations of the public sector.

Mexico provides monthly and annual information with the institutional coverage of the GFSM 1986 for the preparation of the publications International Financial Statistics and the Government Finance Statistics Yearbook, respectively. Nonetheless, starting June 2003, the SHCP's website will include a section with public finance information following the classification and presentation formats recommended by the IMF.

Similarly, the information based on the traditional methodology will be complemented with additional tables to facilitate its analysis.

4. Consider adoption of the GFSM 2001 and develop a migration path for compiling and disseminating statistics in accordance with its guidelines.

5. Establish procedures for informing users about data revision studies.

The Ministry of Finance is currently evaluating the adoption of the GSFM 2001 and analyzing the appropriate strategy for gradually migrating to this new conceptual framework.

The Ministry of Finance's web page will report data revisions, as well as the main methodological modifications, when considered appropriate.

6. Compile and disseminate more timely statistics on state and local governments.

Starting 2003, INEGI implemented the Monthly Statistics of State Public Finances, which will allow the Ministry of Finance to compile revenue, expenditure, and financing information for state governments in a timelier manner.

An effort will be made to reduce the existing lag in the availability of data on general government operations.

Monthly data on central government operations will continue to be released 30-35 days after the end of the reference month (as opposed to the 30 days established in the SDDS). This policy allows the Ministry of Finance to comply with its different information disclosure obligations on only one dissemination date.

${ }^{1 /}$ Mexico currently avails itself of a flexibility option under the SDDS in this regard. 
INTERNATIONAL MONETARY FUND

MEXICO

\section{Detailed Assessments Using the Data Quality Assessment Framework (DQAF)}

Prepared by the Statistics Department and the Western Hemisphere Department

Approved by Carol S. Carson and Anoop Singh

May 23, 2003

This document contains a detailed assessment by dataset of the elements and indicators that underlie the data quality dimensions discussed in Section III of the Report on the Observance of Standards and Codes (ROSC) - Data Module and described in the general framework used for assessing Mexico's macroeconomic statistics (Appendix III) 


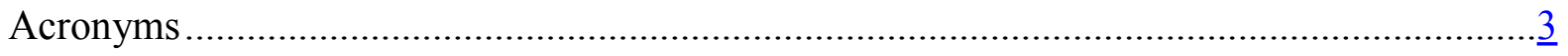

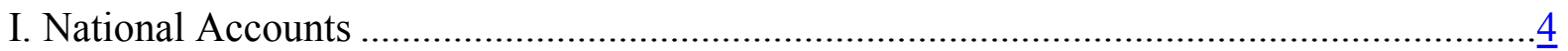

II. Consumer Price Index (CPI) ………………………..................................................

III. Producer Price Index ................................................................................................54

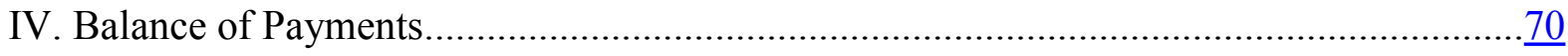

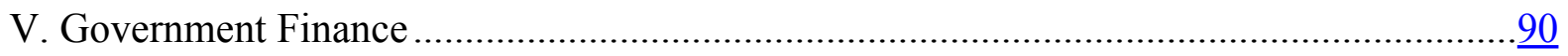

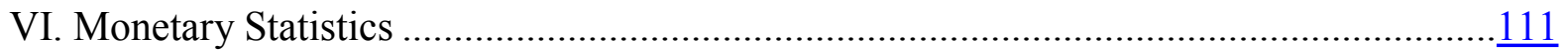

Appendices

I. Dimensions and Elements of the Special Data Dissemination Standard (SDDS)...............137

II. General Overview of Data Dissemination Practices in Comparison with the SDDS …….....139

III. The Data Quality Assessment Framework .............................................................141

IV. Data Quality Assessment Framework: Generic Framework …………........................143

V. Tables: Data Quality Assessment Framework ....................................................... $\frac{148}{158}$

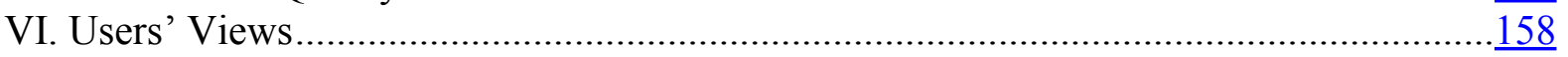

Appendix Tables

1. DQAF - Summary for National Accounts................................................................

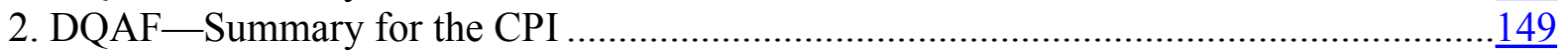

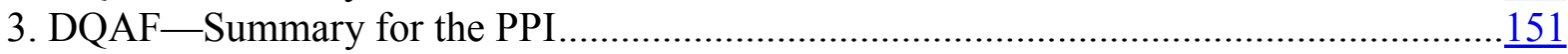

4. DQAF - Summary for Balance of Payments Statistics .................................................152

5. DQAF - Summary for Government Finance Statistics .................................................

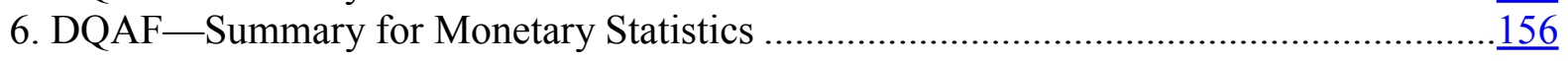




\section{ACronyms}

1993 SNA

AGA

$\mathrm{BM}$

BPM4

BPM5

CEMLA

CGT

CMAP

CNBV

COFOG

COICOP

$\mathrm{CPC}$

DCN

DED

DEH

DGCNESyP

DOF

DPSP

DSBB

ENIGH

FDI

GAM

GFSM 1986

IMSS

INEGI

ISIC

LIEG

MFSM

NCPI

NFPS

NPPI

ODC

PSBR

ROSC

SDDS

SCNM

SHCP

SBIB

SII

SIF
System of National Accounts, 1993

Customs General Administration

Bank of Mexico

Balance of Payments Manual, fourth edition

Balance of Payments Manual, fifth edition

Center for Latin American Monetary Studies

General Conditions of Employment of the Bank of Mexico

Mexican Classification of Activities and Products

Banking and Securities National Commission

Classification of the Functions of Government

Classification of Individual Consumption by Purpose

Central Product Classification

National Accounts Directorate

Debt Statistics Department

Government Finance Statistics Department

Directorate General of National Accounts, Socioeconomic Studies and Prices

Official Gazette of the Federation

Directorate of Prices, Wages, and Productivity

Dissemination Standards Bulletin Board

National Survey of Household Income and Expenditure

Foreign Direct Investment

Office of the Manager of Macrofinancial Analysis

Government Finance Statistics Manual, 1986

Mexican Social Security Institute

National Institute of Statistics, Geography, and Information

Technology

International Standard Industrial Classification of All Economic

Activities

Law on Statistics and Geographic Information

Monetary and Financial Statistics Manual

National Consumer Price Index

Nonfinancial public sector

National Producer Price Index

Other depository corporations

Public sector borrowing requirements

Report on Observance of Standards and Codes

Special Data Dissemination Standard

Mexican System of National Accounts

Secretariat of Finance and Public Credit

Basic Banking Information System

Integrated Government Revenue and Expenditure Information System

Financial Information System 


\section{DetAILED ASSESSMENT USING THE DATA QuAlity Assessment Framework (DQAF)}

The following information on indicators of statistical practices in the areas of national accounts, consumer prices, producer prices, balance of payments, government finance, and monetary statistics were derived from publicly available documents and information provided by Mexican officials. The mission used this information, organized according to the guidelines of the generic DQAF, to prepare the summary assessment of the data quality elements contained in Section III of Part I.

\section{National Accounts}

\section{Prerequisites of Quality}

\section{$0.1 \quad$ Legal and institutional environment}

\subsubsection{The responsibility for collecting, compiling and disseminating statistics is clearly assigned}

Mexico's national accounts are compiled and published by the National Institute of Statistics, Geography and Information Technology (INEGI). INEGI's activity is governed by the Law on Statistics and Geographic Information (LIEG), ${ }^{1}$ published in the Official Gazette of the Federation (DOF), and subsequent amendments to that Law. Art. 33 of the Law indicates INEGI is a deconcentrated agency of the Secretariat of Programming and Budget (which subsequently became the Secretariat of Finance and Public Credit (SHCP)) through which the provisions of the LIEG are to be enforced.

Art. 7 of the regulations to the Law provides that "the statistics to which the Law refers are those derived from censuses or administrative records, as well as those produced by integration of the national accounts, indices and indicators."

In terms of the national accounts, the powers of INEGI are also spelled out in the Rules of Procedure of the Secretariat of Finance and Public Credit (SHCP), Art. 100 (V) of which attributes to INEGI the following powers with respect to national accounting: "planning, promoting and implementing the organization and development of an integrated national,

\footnotetext{
${ }^{1}$ The Law has subsequently been amended by regulations and agreements authorized by Congress and published in the DOF. The DOF can be consulted by Internet at http://www.dof.infosel.com. The Law is also available at the Institute's website (http://www.inegi.gob.mx/estadistica/espanol/economia/feconomia.html).
} 
social, and economic accounts system; promoting the organization and development of sectoral and state accounts of an economic and social nature."

Operational responsibility for collecting, compiling and disseminating the information in the national accounts lies with the Directorate General of National Accounts, Socioeconomic Studies and Prices (DGCNESyP); the work is performed by the National Accounts Directorate (DCN), through four divisions: Goods and Services Accounts, Short-term Economic Accounts, Institutional Accounts and Regional Accounts, in addition to an information processing unit. Each of the substantive units is responsible for developing products for the Mexican System of National Accounts (SCNM), which are compiled from the following five macro processes:

1. Annual national accounts by economic activity

2. Annual national accounts by institutional sector

3. Annual regional national accounts by economic activity

4. Short-term national accounts by economic activity

5. Short-term regional national accounts by economic activity

Compiling and publishing Mexico's national accounts is the exclusive responsibility of the INEGI.

\subsubsection{Data sharing and coordination among data producing agencies are adequate}

Generally speaking, the flow of information needed to compile the national accounts is efficient and timely. To a large extent, the source data for compiling the national accounts, such as censuses and surveys, are prepared by other units within the same institution (Directorate General of Statistics). The data are supplied to the Directorate General of National Accounts in accordance with a strict schedule. In the case of external data sources, INEGI has no difficulty in obtaining them on a timely basis through official requests to public and private sector bodies. There is in fact an established practice of exchanging information between INEGI and various public sector institutions, which facilitates the provision of timely and detailed information for compiling the national accounts. These arrangements include agreements with the Bank of Mexico (BM) for balance of payments data, and a quadripartite committee for obtaining and coordinating data on foreign trade.

Coordination between INEGI and the various information-producing agencies is assured through working meetings designed to ensure greater efficiency in the compilation and provision of source data for the national accounts: the meetings discuss information needs in terms of conceptual characteristics, coverage and periodicity of the data requested and the availability of respondents, taking into account the effort and economic cost involved. To avoid duplication of information requests, "single windows" have been created to organize information requirements of the various INEGI areas in terms of their different breakdowns and periodicity (cyclical, annual, national, and regional), all of which are rolled into a single request for information. 


\subsubsection{Respondents' data are to be kept confidential and used for statistical purposes only}

Chapter V of the LIEG guarantees the confidentiality of statistical data supplied to INEGI, stipulating that such data may be used only for statistical purposes. Art. 38 of the Law declares that "data and reports provided by private parties for statistical purposes or derived from administrative or civil records shall be handled, for purposes of this law, with due regard to the principles of confidentiality and may not under any circumstances be disclosed in an individualized manner, nor may they be used as evidence before an administrative or fiscal authority, in judicial or other proceedings."

As a deconcentrated agency of the federal government, INEGI is also governed by the Federal Law on the Administrative Responsibilities of Civil Servants, Art. 47 (IV) of which obliges public officials to "safeguard documentation and information that, by reason of their employment, post, or commission, they may have in their safekeeping or to which they may have access, and to prevent the unauthorized use, removal, destruction, concealment or disregard of such information." As well, paragraph XV prohibits public officials from requesting, accepting or receiving money or gifts from individuals or companies whose activities are under their care and supervision and where a conflict of interest might arise.

All questionnaires used for censuses, surveys and special investigations by INEGI make clear reference to the confidentiality requirements regarding the information, in a section placed on the first page which reads: "Pursuant to the provisions of Art. 38 of the LIEG: data and reports provided by private parties for statistical purposes or derived from administrative or civil records shall be handled, for purposes of this law, with due regard to the principles of confidentiality and may not under any circumstances be disclosed individually or by name, nor may they be used as evidence before an administrative or fiscal authority, in judicial or other proceedings."

Art. 42 (1) of that Law states that "respondents are obliged to provide accurate and timely data and reports as and when requested by the competent authorities for statistical, census or geographic purposes, and to provide the required assistance and cooperation."

Art. 49 of the LIEG defines the violations imputable to public officials, such as "the revelation of confidential statistical data; violations of industrial or commercial secrets, or provision of data that is individualized or identified by name" (paragraphs I and II). Consequently, Art. 51 of the Law provides administrative sanctions for anyone who discloses confidential data: "a fine of up to 750 times the minimum wage valid for the federal district at the time the infraction was committed."

Art. 53 of the Federal Law on the Administrative Responsibilities of Civil Servants establishes penalties for administrative misconduct involving breaches of confidentiality. These consist of "private or public warning; private or public reprimand; suspension; dismissal; economic sanction; and temporary ineligibility for position or office in the public service", paragraphs I to IV. 
Moreover, the rules governing professional conduct in INEGI (the Sistema Integral de Profesionalización, SIP) specify disciplinary measures against staff who violate legal provisions: in particular, Art. 87 (III) includes among the grounds for dismissal "failure to observe the obligations established in the LIEG, especially as they refer to confidentiality."

Art. 38 of the LIEG provides that "when statistical information must be disclosed, the data in question may in no case refer to fewer than three observation units and must be compiled so as to preserve the anonymity of respondents."

Staff assigned to the national accounts regularly check and ensure the non-disclosure of confidential data. Success in this regard is due largely to the fact that the maximum disaggregation for disclosure is at the four-digit level of the SCNM Activities Code, which has already passed through several filters to avoid the release of confidential data. Specifically, compilation and review programs have been implemented to prevent the disclosure of confidential data.

The data provided by respondents are kept in the safekeeping of the officials responsible for their handling and are not shown to the public or, generally, to INEGI staff. The only persons who have access to the information are those authorized to perform calculations with the data, and those people are reminded in writing of the confidential nature of the data. In general, staff are fully aware of the penalties for disclosing confidential data.

Security measures for protecting installations are under the responsibility of security personnel who inspect all persons and things entering and leaving the premises.

In terms of information processing systems, the DCN's computer infrastructure is based on two local networks using the Novell NetWare 5.0 operating system, and 70 microcomputers. Local and network equipment alike have an access key that bars their use by third persons. This system guarantees the security of information for each user.

Users of both the local and network microcomputers maintain the security of information by storing it on hard disks or in the corresponding space on the server. Weekly recyclable backups of this information are made on rewritable disks, while quarterly fixed backups are made on non-rewritable disks.

The network servers and their backups are kept in areas of restricted access, in the offices of the network administrator, in the Quarterly Economic Accounts Coordinator's Office, and in the National Accounts Director's Office. A backup is also kept away from premises, in case of disaster, under the responsibility of the Area Director.

Confidential information is destroyed in accordance with the following process: once the information has been used, it is kept for five years in a storage facility belonging to INEGI, 
located away from headquarters, and is then sent to the national archives where it is kept for further five years. At the end of 10 years, the documents are destroyed.

\subsubsection{Statistical reporting is ensured through legal mandate and/or measures implemented to encourage voluntary response}

The legal powers of INEGI to compile information are clearly set out in chapter $\mathrm{V}$ of the LIEG, referring to the rights and obligations of users and respondents of "National Statistics and Geographic Information Systems." Art. 36 defines respondents, while Art. 42 requires respondents to provide the information requested in a truthful and timely manner.

There is no record of conflicts between legal provisions for the supply of information and those that protect respondents. Despite some discrepancies in the legislation, they do not affect the quality of national accounts estimates. For example, the banking secrecy law protects individuals and corporations, while the information provided is aggregated. A similar situation has occurred with the change in mining legislation, which formerly required mining companies to provide monthly and yearly information to the Secretariat of Economy (SE): the new mining law exempts them from that obligation. The Institute resolved the situation, under the powers granted to it by the LIEG, by conducting a monthly survey to gather the required information. A similar example relates to the privatization of public enterprises: when they belonged to the government their data were obtained from administrative records, whereas cooperation agreements have now had to be negotiated with their new private owners to supply information on their activity.

Chapter VI of the LIEG spells out procedures for the inspection of respondents, as well as infractions and sanctions to which they are subject. Art. 45 of Chapter VI states: "For statistical purposes, the information provided by respondents will be treated as confidential. Nevertheless, the Secretariat (SHCP-INEGI), exercising its powers under this Law, may conduct inspections to verify statistical and geographic information when the data provided are inconsistent or incomplete." The same article provides that this verification must be done under a written order from the competent authority: Art. 46 Paragraph III states that "the order must specify the statistical or geographic information to be verified, as well as the documentation that must be exhibited for inspection."

The Law also provides penalties for refusing or falsifying information. Art. 51 imposes a fine of "up to 750 times the minimum daily wage valid for the federal district at the time the infraction was committed."

Despite the existence of legal provisions for obtaining information, and penalties for noncompliance, they have rarely been enforced: the intent is to encourage voluntary reporting, by explaining to respondents in detail the use that will be made of their information, its confidential nature, and its importance for the country in terms of quantifying and characterizing economic activity. 
The information burden imposed on respondents is a constant concern of the DGCNESyP, which has taken several steps to minimize that burden: in preparing the questionnaires, for example, care is taken to request only the most significant information. INEGI staff are available at all times to help in reporting the data. Instructions are provided for recording the requested data, with a glossary of terms, and survey responses may be submitted electronically. In the case of public and private bodies providing administrative records to several national accounts areas, cooperation agreements have been established through the "single window" to avoid duplication of efforts and to include all information requirements in a single request.

INEGI encourages cooperation by respondents in its everyday work, stressing the importance of reliable and timely information and highlighting the link between the quality of basic statistics and that of derived statistics.

INEGI also provides information on the basic and derived statistics that it produces and on procedures for consulting data. It responds to respondents' requests for information.

\section{$0.2 \quad$ Resources}

\subsubsection{Staff, financial and computing resources are commensurate with institutional programs}

The human and financial resources devoted to the national accounts are consistent with the INEGI's mission, which is to provide a public service of statistical and geographic information and to promote computerization, as a contribution to Mexico's social welfare, economic growth and democratic development.

In fulfilling its mission, INEGI works through six Directorate Generals and an Administrative Coordination Office; the Directorate Generals are those for Statistics, Geography, IT Policy, Dissemination, Cadastral Cartography, and National Accounts, Socioeconomic Studies and Prices.

The Institute has units at both the central and decentralized (regional) levels for generating, compiling and processing census and survey data, and a central unit for calculating derived macroeconomic statistics. In terms of the number of statisticians with national accounts experience available to meet the needs of the general public, however, the ratio is one statistician per million inhabitants.

The staffing level in the DCN is considered sufficient in light of the annual work program. This directorate reports to the DGCNESyP and receives invaluable support from the Economic Statistics General Coordination office, in terms of planning, developing, reviewing and disseminating SCNM products. 
The directorate has 167 positions of which 35 are vacant or trust positions. The 132 active positions are distributed as follows: one Director, four coordinators, 11 deputy directors, 39 department heads, 59 technical staff, and 18 support staff.

The academic training of staff is considered adequate: the directorate has 77 economists (70 percent of the total), seven mathematicians and actuaries (6.4 percent), five administrators and accountants (4.5 percent), 12 from miscellaneous professions such as sociologists, agronomists, veterinarians, persons with degrees in tourism and biology (11 percent), four with technical diplomas (3.6 percent) and five without professional qualifications ( 4.5 percent), making up the team of 110 people who work on the national accounts.

All INEGI staff are enrolled in a continuous training program that keeps them up to date on various issues, from statistics and computers to national accounts questions. This training is covered in the SIP, Art. 68 of which states that "the Institute will encourage and take steps to ensure the professional development and skills upgrading for staff of the subsystem, in accordance with needs in each of its areas of specialization." The training program is divided into short-term courses, training cycles and diploma courses, support for the preparation of exams for bachelor's and postgraduate degrees, as well as facilities (leave, special working hours, fellowships, tuition payments, etc.) for the pursuit of specialized and postgraduate studies.

During 2001, 55 national accounts officers took courses in economics, statistics, quality control and computers; 42 took English courses at different levels. As well, staff took part in quantitative economics and econometrics courses organized by INEGI, given by professors from prestigious universities such as Colegio de Mexico, the National University, and the National Polytechnic Institute.

A degree course in national accounts was recently instituted: the first course was attended by 14 DCN officers, and will be repeated annually. It was conducted with the assistance of the Center for Latin American Monetary Studies (CEMLA) and the National Polytechnic Institute.

In addition, national accounts officers frequently attend courses, seminars and international conferences for training purposes. Visits are arranged every year to various international organizations for these purposes, including the Organisation for Economic Co-operation and Development (OECD), United Nations Economic Commission for Latin American and the Caribbean (ECLAC), and CSED-España (statistical training center for developing countries in Spain).

There is also a noteworthy effort at on-the-job training in national accounts methodology: this is accomplished by making all areas and all working groups aware of the overall national accounts process and holding group sessions to discuss methodology and propose improvements, while looking for ways to streamline and simplify procedures. The $1993 \mathrm{SNA}$ is available to all staff via the DCN net. 
The accumulated experience of DCN staff extends over many years, during which officers have specialized in specific areas, applying the concepts and practices suggested in the 1993 SNA and adapting them to local needs and information availability. The stability of national accounts personnel in the institution can be appreciated from the following table:

\begin{tabular}{cc}
\hline Time in service & Percentage of staff \\
\hline 1 to 7 years & 34.7 \\
7 to 14 years & 40.5 \\
14 to 21 years & 19.8 \\
21 to 28 years & 5.0 \\
\hline
\end{tabular}

This stability in DCN staffing can be explained, among other factors, by the SIP, which guarantees employment security and serves to retain trained personnel within the Institute. The SIP also includes a system of staff incentives: at the middle and senior levels, salary bonuses are awarded in accordance with productivity over the last six months, while technical staff compete for the award of "employee of the month," and are eligible for an annual cash bonus and/or an addition 10 days of vacation if they meet previously established goals.

The DCN's computer resources are considered adequate, in light of the directorate's staff numbers: it has 70 microcomputers and 31 printers. This amounts to one computer for every two employees, while the average for the institution as a whole is one computer for every five or six employees. This has meant that the DCN produces efficient, recurrent and timely output, taking advantage of information technology resources for generating and disseminating the SCNM, using internally developed applications (database managers, compilers, programming languages) as well as commercially available products (office software, operating environments and systems).

The Institute seeks to take advantage of all the possibilities offered by modern information technology, through links to the Internet, e-mail, and intensive use of computer programs such as Excel, Word, PowerPoint and Acrobat that are part of the basic platform of institutional software. As well, national accounts personnel have developed and introduced computer programs for automating, simplifying and streamlining work procedures. Installation of a second network server within the DCN recognizes the importance of the work of the Quarterly Economic Accounts office in developing macroeconomic data, and the confidentiality that it requires.

Distribution of the 70 microcomputers and 31 printers within the national accounts area takes into account staff numbers assigned to the different coordination offices, as well as their work programs, in the following manner: 


\begin{tabular}{lcc}
\hline Substantive Area & Computers & Printers \\
\hline Goods and Services Accounts & 28 & 15 \\
Quarterly Economic Accounts & 15 & 6 \\
Institutional Accounts & 10 & 4 \\
Regional Studies & 6 & 2 \\
Systems and Procedures & 9 & 3 \\
Office of the Director & 2 & 1 \\
Total & 70 & 31 \\
\hline
\end{tabular}

The budget of the national accounts area is deemed adequate, considering the authorized work programs and the overall funding available to the institution. Moreover, the entire Mexican federal public service is currently operating under an austerity program, despite which the resources allocated to the national accounts have been maintained intact because of their priority status.

In return, the DCN has adopted its own program of budgetary austerity, designed primarily to reduce current expenses (telephones, travel, per diems, paperwork) without jeopardizing the primary objective of completing its mandated work programs.

The DCN budget for 2001 was 29.9 million pesos (US\$3.2 million), and the DCN has managed to save almost five percent of its budget.

There is a medium-term plan to develop an input-output matrix, for which the required budget has already been estimated and approved. It should be noted that the national accounts area confines itself to the strictly technical aspects of present and future information needs, and has no substantive influence in determining financing for data collection programs. Nevertheless, it participates actively in considering new needs relating to the national accounts, in light of user demands for information.

\subsubsection{Measures to ensure efficient use of resources are implemented}

Work programs and the strategies for implementing them are subject to consultation among the different managerial levels of the directorate, during which output deadlines are worked out. This implementation strategy involves the entire staff and includes three presentations by the Director: one at the beginning of the year, and two at six-month intervals for assessing results to date. Bimonthly progress reports are prepared for the Internal Comptroller's Office. Working groups meet every two weeks in a session (known as "Quality Time") to review the work program and propose improvements in working procedures for the directorate.

INEGI is attempting to make more efficient use of resources by applying consistent and standardized concepts both in the statistics-generating areas as well as in the DCN. Within the DCN, working meetings are held to discuss concepts and international recommendations relating to the national accounts. The national accounts area makes suggestions to the survey 
and census areas for improving basic statistics, consistent with the requirements of the 1993 SNA.

Working procedures are designed to minimize coding, editing, and tabulation errors. The process of producing and coding data has been systematized and simplified, and the results are reviewed more quickly and efficiently by identifying activities that can be pursued at the same time as, or immediately after, recurrent calculations, such as statistical cross-checks, calculation of consistency ratios and variables, preparation of graphs and summary tables, correlation analysis, etc. The areas producing the calculations are also responsible for printing.

The INEGI Internal Control Organ is responsible for evaluating, measuring, and comparing resources used in national accounting and other areas. It presents a bimonthly status report as outlined in the 2002 Strategic Plan, tracking progress with the work program against available funding.

For several years, programs and working procedures have been reviewed as part of the Institute's quality program, under a module called Management of Working Procedures, the main purpose of which is to detect areas for improvement. Any staff member can propose improvements, through two procedures: individual and group proposals. Proposals that lead to a generalized improvement in working procedures earn a bonus for the staff who propose them. In addition, the area organization manuals are continuously updated, consistent with the general rule of the Federal Public Administration.

In light of the federal government's austerity program, the national accounts area attaches importance to the efficient administration of financial resources, allocating them to priority activities such as maintaining the work program and preparing new products within the limits of current personnel and budgetary constraints.

Innovations have been introduced to reduce time and costs throughout the chain of statistics production, editing and dissemination, making full use of the available information technology.

For data production, steps have been taken to systematize processing and calculation, using database managers instead of the previous worksheets, an approach that saves time and resources, such as paper, printing ink, and machinery and printer time.

Each of the coordinating offices and/or the information processing area of the DCN prepares documents for publication using the PageMaker editor, applying criteria that have been widely disseminated by the Directorate General of Dissemination in the Manual and Standards for Publication and Design, which contains institutional standards for publications. In addition, existing publications are converted to PDF format using Acrobat. Thanks to this process, the work of compiling, processing, analyzing and publishing economic statistics can be done in the DCN: in this way, the time that elapses between 
completion of calculations and the posting of the information on the INEGI webpage and in user service centers has been reduced to a few hours.

Outside experts have not yet been brought in to evaluate statistical methodology and data compilation systems: nevertheless, the DCN participates in the evaluation meetings of international agencies such as the UN, OECD, World Bank and ECLAC, and it responds to specific questionnaires on national accounting practices.

\subsection{Quality awareness}

\subsubsection{Procedures have been put in place for quality awareness}

Managers are aware of the importance of quality in its substantive aspects: they stress procedures associated with timeliness, frequency, production time, consistency, comparability over space and time, presentation, documentation, dissemination formats, the availability and clarity of the macroeconomic statistics that are published on a regular basis.

Managers have instituted the INEGI Quality Program, governed by an activities plan that seeks to foster teamwork, a user-oriented service ethic, efficient work administration, the use of quality techniques and tools, personnel training and improved dissemination for the Institute's products. To this end it has implemented quality-control training programs covering definition of the strategic plan, promoting integration of work teams and encouraging a new and more efficient approach to working procedures: all of this is intended to lay the basis for achieving ISO 9000-2000 certification for INEGI. Within the Federal Public Administration the "criteria for evaluation and compensation by results" include among their "Innovation and Quality" indicators a medium-term goal for the number of processes to be ISO 9002 certified.

INEGI has a comprehensive infrastructure for fostering quality, including facilitators, quality development committees, and a senior executive for managing and implementing the institutional quality process. The functions of the Institute are supplemented by the 32 State Coordination Offices and the 10 Regional Directorates responsible for compiling information, where statistical comparison is encouraged at both temporally and geographically detailed levels among the entities and agencies that provide information.

\subsubsection{Procedures have been established for monitoring the quality of data collection, compilation, and dissemination}

Within the institution, "Collegial Groups" have been created to bring together national accounts experts with the staff responsible for the economic censuses and the various surveys that INEGI conducts. Working meetings discuss specific information needs and ways of incorporating them into surveys and censuses, recognizing that those tools are intended to meet the needs of a broad range of researchers and users. 
The INEGI currently has only internal areas working on aspects related to statistical quality and improved data processing, and they hold working meetings with the major respondents and information users. The United Nations Development Programme (UNDP) provided continuous advisory services during the first 12 years of implementation of the national accounts system.

To date there have been no surveys among users of the economic statistics produced by INEGI: comments are compiled through the user service centers, via Internet, and through direct consultations with national accounting staff.

\subsubsection{Procedures are in place to assess the quality of statistics, to acknowledge and deal with tradeoffs within quality, and to guide planning for existing and emerging needs}

Managers are aware of the implicit and explicit trade-offs among quality dimensions, and decisions on data publication seek to strike a balance between the growing demand for timely, disaggregated and reliable information, and the availability of resources for meetings such demands.

Users are advised of the tentative nature of preliminary estimates. Comparisons are also made with other national accounts institutions around the world in order to improve efforts to meet user needs. Users' opinions are also taken into account: direct consultations are now underway to identify user needs in the course of preparing the Input-Output Matrix.

Identified needs for data quality improvement are included in the work programs. Emerging needs are evaluated at various levels and with different users.

At the different levels of government there are legal provisions for establishing Advisory Councils, as collegial bodies of consultation for identifying new needs. INEGI has senior representatives on these advisory councils, including the 32 State Coordinators (one for each state in the Republic) and the 10 Regional Directors.

Within the Federal Government, bilateral cooperation agreements have been established among the major secretariats of state for the flow of information between INEGI and those secretariats in recognition of mutual needs. These cooperation agreements operate through the Directors General and the President of the Institute. There are also agreements with the Legislative Branch.

INEGI works with the state governments, conducting courses, seminars and conferences for disseminating SCNM products and for detecting specific needs of the governors and the state finance secretariats, which it also consults and assists in preparing the annual current and accumulation accounts.

INEGI also holds conferences with the private sector for disseminating its products and identifying new needs, in coordination with the Chambers of Industry and business 
associations. Courses, workshops, seminars and conferences are organized with public and private universities.

The Dissemination Area is at the service of the general public, and undertakes to respond immediately to direct inquiries, and within three days to e-mail consultations.

In response to the demand for new information, INEGI has developed several products: the SCNM now provides the Global Indicator of Economic Activity on a monthly basis, as well as the System of Composite Indicators, Coincident and Leading, both of which were published during the year 2000. In the geographic areas, INEGI has developed the publication State Governments. Current and Accumulation Accounts. Production by End Use, as well as Regional Indicators of Manufacturing Production, Electricity Generation and Distribution for 17 Federative Entities (published monthly); these publications were also developed towards the end of 2000.

Whatever the form of dissemination (publications, the Institute's website or on tape), users are encouraged to express their opinions on the statistical series, and are provided with e-mail addresses, telephone numbers and the area responsible for the publication.

\section{Integrity}

\subsection{Professionalism}

\subsubsection{Statistics are compiled on an impartial basis}

Mexico recognizes the importance of professional independence for statistics personnel, as reflected in the SIP of INEGI which declares that "the National Institute of Statistics, Geography and Information Technology requires a highly specialized technical staff in order to carry out its various functions," and that "to achieve this objective, the professional development of human resources must be encouraged through adoption and implementation of a comprehensive professional development system," the SIP. In effect, the SIP creates a career civil service that encourages both independence and stability among the Institute's specialized personnel, and provides for examinations and competitions as the basis for recruitment and promotion within the Institute.

The SIP prohibits any undue external influence on the contents of statistical information or its release. Chapter VIII, on the obligations and prohibitions applicable to public servants, obliges them to "respect the confidentiality of matters that come to their knowledge as a result of their work, and to ensure the proper handling of documents, correspondence, money, valuables or goods entrusted to their administration or safekeeping" (Art. 79, paragraphs $\mathrm{V}$ and VI).

Consequently, staff are forbidden "to alter, conceal, modify, unlawfully destroy or falsify correspondence, documents, evidence and control records of the Institute; to provide in any way, without authorization, documents, data or reports on the affairs of the Institute; to 
solicit, insinuate or accept gifts or remuneration from the public for preference shown in the performance of their duties, for not obstructing the processing or resolution of requests, or for similar reasons" (Art. 80, paragraphs VI, VII and VIII).

The President of INEGI is appointed by the Secretary of Finance and Public Credit. Traditionally, however, the head of the statistics authority has remained in office for periods that exceed the mandate of a given government.

Professional competence is the basic criterion for recruitment and promotion within the INEGI. Determination of professional competence is governed by the SIP, which requires examinations and competitions for recruitment and promotion. There are seven salary levels for each position, and staff are allowed to advance by one level each year, subject to ongoing appraisal by their superiors. The institution also makes a practice of applying a semi-annual performance appraisal form to its staff: this covers objectives achieved with respect to the quality, quantity, timeliness and reliability of their work.

Meetings, conferences and presentations are frequently arranged with academics from the major public and private universities in the country, consultants, specialized journalists, central government officials and representatives of other levels of government in order to publicize calculation methodologies and the principal results of the national accounts.

Methodological documents are published together with the statistical tables on macroeconomic variables. A Collegial Group has been established within the national accounts area to prepare scientifically rigorous methodological documents for specialized users, in which the advantages and the limitations of the various SCNM products are described.

Publications containing national accounts data are carefully reviewed and validated at all levels of the hierarchy, in terms of their technical aspects and the Institute's publication standards, in order to protect the professional reputation of the INEGI.

\subsubsection{Choices of sources and statistical methods are informed solely by statistical considerations}

The choice of sources and methods is governed solely by statistical considerations and by the provisions of the LIEG, which for example declares that "census reports shall contain all the information needed to understand the circumstances under which the censuses were conducted, from preparation to presentation of results, for purposes of making subsequent censuses more efficient and economical and assessing the achievement of objectives and goals" (Art. 20).

The Law also indicates that "sample-based surveys may be used to gather statistical information by enumerating the set of members or strata considered as representative of the particular universe under review" (Art. 21). 
The Directorate General of Statistics is responsible for guaranteeing the quality and timeliness of all census and survey information and for considering the compliance costs to respondents. It therefore requests only the information that it considers necessary.

When it comes to information from other sources such as secretariats of state and public and private enterprises, which are not surveyed by the Directorate General of Statistics, cooperative agreements on reporting are negotiated, with provisions to ensure that statistics are of the quality, homogeneity, comparability and timeliness that are indispensable for meeting preset publication dates. These characteristics, as well as the cost that they represent for respondents, are evaluated by the collegial groups and at the "single windows," in an effort to compile high-quality statistics at low cost and to avoid duplication of requests for information.

INEGI has a practice of providing a technical justification for its use of calculation methodologies, thereby underlining the professional independence of its staff, while observing international guidelines at all times. The presentation of work plans and programs is governed by Chapter VII of the SIP: "Mid-level managers of the Institute are responsible for submitting work plans and programs to senior management, on an annual basis, indicating their goals clearly and objectively in sufficient detail to measure them and delimit responsibilities." (Art. 77).

\subsubsection{The appropriate statistical entity is entitled to comment on errors of interpretation and misuse of statistics}

In accordance with the Law, the Institute has on various occasions provided comments to the media in the case of errors of interpretation or misuse of statistics produced by INEGI. It also issues press releases explaining the Institute's position on errors of interpretation and these are posted on the Institute's webpage for public information.

The principal sources of information and methods of calculation for SCNM products are made public. In the case of short-term statistics reports, there is simultaneous mass distribution of the results in advance in the major media and are posted on the Institute's webpage. Annual publications are distributed to the major media and posted on the webpage on their publication day which, in general terms, comes at the end of the calendar year or the beginning of the following year.

As well, the Office of the President of INEGI closely monitors the specialized press and other media, preparing executive summaries that are stored electronically for consultation by sector of activity and by date of publication. 


\subsection{Transparency}

\subsubsection{The terms and conditions under which statistics are collected, compiled, and disseminated are available to the public}

The Institute's webpage provides the text of the LIEG and the metadata associated with its publications.

\subsubsection{Internal governmental access to statistics prior to their release is made known to the public}

The technical independence that the Institute enjoys guarantees that no government authority has access to its statistics before they are released publicly: thus, no government unit or public official has access to the data before they are published. In particular, in the case of short-term statistics reports, on the day they are published a note is sent the Presidency of the Republic and to the SHCP, at the same time as the reports are released to the press and posted on the INEGI website. The press releases indicate that the data have been prepared under the responsibility of INEGI, although it is not explicitly stated that approval of the results lies exclusively with the Institute.

\subsubsection{Products of statistical agencies/units are clearly identified as such}

Because INEGI is a decentralized agency of the federal government, under the SHCP, SCNM products are published with the SHCP logo as well as that of INEGI; it is clearly stated, however, that the entity producing the data is INEGI.

Data are published in a press bulletin bearing the SHCP logo and indicating clearly that the information was prepared by INEGI. At the same time, the press bulletin is posted on INEGI website, with SCNM insignia.

The Institute has a policy of releasing its annual publications in a standard format, in which presentation, titles, colors, typography, etc., are consistent.

In the case of joint publications with other institutions, the contribution of each is clearly identified, indicating that data associated with the national accounts are the exclusive responsibility of INEGI. Such publications bear the logos of the participating institutions, consistent with the Institute's editorial standards.

Moreover, the Federal Copyright Law requires that sources be cited when information is published. 


\subsubsection{Advance notice is given of major changes in methodology, source data and statistical techniques}

Any major change in source data and/or methodology is announced in advance through publications that contain notes specifying the methodology used, noting whether the data are preliminary or revised, and indicating that the results may be amended as the basic statistics are updated. Press releases specify any changes made in the publications.

In particular, when the base year was changed from 1980 to 1993 and the methodological recommendations of the 1993 SNA were incorporated, this move was preceded by an intensive publicity campaign, via the press and radio, and conferences at universities, secretariats of state and public and private institutions, dealing with the characteristics of the SCNM data and the differences between the two series.

\subsection{Ethical standards}

\subsubsection{Guidelines for staff behavior are made known to staff}

INEGI employees are subject to the rules of conduct and penalties for noncompliance established in the Federal Law on the Administrative Responsibilities of Civil Servants, as well as the rules contained in the LIEG. Detailed specifications of staff obligations and rights are established in the General Conditions of Employment deposited with the Federal Conciliation and Arbitration Tribunal on February 1, 1994.

Moreover, INEGI is currently preparing a code of institutional values characterizing workers in the institution. Development of the code has involved a series of stages with full staff participation. The work started with a "comparative evaluation" of the codes of other national and international institutions; this was followed by in-house consultations in order to identify a set of basic values that characterize employees of INEGI; that set of values was the subject of national consultations during the last days of November 2001, during which employees were invited to propose additional values. The results of this consultation, and the employee values code, will be presented in the first quarter of 2002 and will be widely disseminated to INEGI employees and the general public.

Within the "Quality Time" group on the national accounts, work is underway to develop a code of values for the preparation and publication of statistics produced in that area. As a first step, the Declaration on Professional Ethics of the International Statistics Institute is being reviewed.

All levels of management are aware of the pressing need to ensure irreproachable conduct within and beyond the institution, and for officials and workers of INEGI to fulfill their obligations to maintain the public credibility of the information they process.

During the induction of new workers, INEGI informs them of their rights and obligations as employees and ensures that they are familiar with the Quality Program. 
Daily practice, and the quality process within INEGI, provide constant reminders of the obligation to meet existing standards.

\section{Methodological Soundness}

\subsection{Concepts and definitions}

2.1.1 The overall structure in terms of concepts and definitions follows internationally accepted standards, guidelines, or good practices

Mexico's national accounts are based on the conceptual framework of the System of National Accounts 1993 (1993 SNA).

\subsection{Scope}

\subsubsection{The scope is broadly consistent with internationally accepted standards, guidelines, or good practices}

Mexico's system of national accounts includes annual, quarterly and monthly estimates. The published series of national accounts have 1993 as the base year; annual accounts are available from 1988, and quarterly data from 1993. Supply-and-use tables are compiled annually at current and constant 1993 prices, from which Gross Domestic Product (GDP) estimates are derived at current and constant prices, from both the production side and the expenditure side. These tables present in the rows the origin of the products by economic activity. Series of integrated economic accounts for the entire economy and for each institutional sector, from the production account to the financial account, are also compiled each year.

The quarterly accounts include GDP estimates at current and constant 1993 prices derived from the supply-and-use tables, in a manner similar to the annual calculation. A volume index, the Global Indicator of Economic Activity, is calculated each month as a weighted average index, with a 1993 base, of growth indicators for the branches of economic activity.

The national accounts are consistent with 1993 SNA in terms of the definition of units that make up the economy; Mexican government offices abroad, free zones, and workers residing abroad for less than one year are included in the accounts. The production boundaries are also consistent with $1993 S N A$ definitions, with a few exceptions reflecting data limitations. One such exception concerns household production of manufactured goods for ownconsumption, which are only partially included. Due to the lack of information sources also the production of original literary or artistic works is excluded from the accounts. On the other hand, original entertainment products such as movies are included. The production of computer programs is captured only when they are for sale to third parties, while the production of programs for internal use within the business is not separately identified. Inhouse research and development work is not identified separately, and expenditures on this activity are reflected in intermediate consumption for the principal activities. Oil and gas 
prospecting is explicitly included in mining production. Generally speaking, production arising from illegal activities is not included. Consistent with the $1993 \mathrm{SNA}$, production of capital goods for own account is included.

The definitional scope of assets is generally consistent with the 1993 SNA. Thus, national defense spending on construction and equipment of potential civilian use is included in assets. Work-in-progress on main agricultural products is included in assets. Due to lack of adequate information assets in the form of historical monuments and valuables are only partially covered. Because of the paucity of information, which is generally based on reports from establishments, investment in patented entities is excluded. The limitations of production records also mean that computer programs developed for own use, and literary and artistic works, are excluded. Although financial leasing is not a common way of financing capital goods acquisition in Mexico, significant transactions with the public sector, specifically in the energy sector (Investment Projects with Deferred Impact on Expenditure) have been identified and included in the accounts, recording the corresponding items in the capital and financial accounts.

\subsection{Classification/sectorization}

\subsubsection{Classification/sectorization systems used are broadly consistent with internationally accepted standards, guidelines, or good practices}

The classification of institutional units, transactions and other flows in Mexico's national accounts is consistent with the recommendations of the 1993 SNA. The classification of economic activities is based on the Mexico National Accounts Coding System, which is an adaptation for domestic purposes of the United Nations International Standard Industrial Classification of All Economic Activities (ISIC rev. 3). The product classification corresponds to that for economic activities. Mexico has not adopted the Central Product Classification (CPC). Consistent with international recommendations, household consumption expenditures are classified in accordance with the Classification of Individual Consumption by Purpose (COICOP), while government consumption is classified in accordance with the Classification of the Functions of Government (COFOG).

\subsection{Basis for recording}

\subsubsection{Market prices are used to value flows and stocks}

The Mexican national accounts record all transactions at market prices prevailing at the time the transactions take place, in accordance with the valuation principles of the $1993 \mathrm{SNA}$. Production is valued at basic prices, while intermediate consumption is valued at purchase prices, excluding the deductible portion of the VAT. The components of expenditure on final goods are valued at purchase prices, i.e., including trade margins and taxes on the corresponding products. Households' production for own-consumption is valued at basic prices for equivalent market production in the case of services of owner-occupied dwellings, and at cost in the case of other products. Market prices are adjusted when transfer pricing is 
detected between a parent company and its affiliates, particularly in the automotive industry and the oil industry. Consistent with the 1993 SNA guidelines, total exports and imports are valued at f.o.b. prices.

\subsubsection{Recording is done on accrual basis}

All transactions are recorded on an accrual basis. Construction works in progress, industrial goods involving a long production process, and a portion of agricultural output are recorded in the period in which they are produced. Government institution accounting is generally done on an accrual basis, which means that annual data on government revenues and expenditures used in the national accounts are on an accrual basis.

\subsubsection{Grossing/netting procedures are broadly consistent with internationally accepted} standards, guidelines, or good practices

Consistent with the 1993 SNA guidelines, transactions between establishments of the same firm are recorded at gross values.

\section{Accuracy and reliability}

\subsection{Source data}

\subsubsection{Source data are collected from comprehensive data collection programs that take into account country-specific conditions}

INEGI has a regular program of five-year economic censuses and monthly and annual surveys covering most economic activities. The directories of establishments that serve as the sampling framework are based on the economic censuses and are therefore thoroughly updated every five years.

Between censuses, partial updates are conducted as only large establishments are monitored through the Large Establishments Monitoring program, which uses data obtained from chambers of industry and producers' associations and public agencies, as well as daily monitoring of the media.

INEGI also has an area sampling framework that it uses for planning fieldwork for economic censuses and surveys. The sample for these surveys is based on the framework list derived from the economic censuses.

As noted earlier, INEGI has a regular program for surveying establishments on a monthly and annual basis. The economic census for 1993 was one of the main data sources of estimates for the base year 1993. That census collected information for calendar year 1993 for all economic activities except agriculture, for which data were taken from the 1991 Agriculture, Livestock and Communal Farming Census. 
The economic census collected detailed information at the six-digit level of the national economic activity code. Information of relevance to the national accounts included data on output per product (finished goods) in quantities and values, and sales, data on major inputs consumed, also in quantities and values, other detailed production expenses, monthly compensation of workers, separated into wages and salaries, number of persons employed, capital formation and stock of capital by type of good, own-account fixed capital formation and inventory stocks at the beginning and end of the period, broken down by type of inventory (finished products, work-in-progress and raw materials).

The annual surveys gather information on the value of output and sales at aggregated levels, not by product (this detail is available in the monthly survey). Information on intermediate consumption is also, since 1997, disaggregated by product, but this information has not been made available for national accounts compilation. Other data from the annual economic surveys are similar in coverage and detail to those of the economic censuses. The annual data are representative at the four-digit level of the national classification of economic activity for the activities covered. The annual survey covers manufacturing, trade and construction. For the latter two, only the formal sector is covered.

Monthly surveys provide data at the four-digit level of the national classification of economic activity, although they do not cover all activities, which means that they must be supplemented with special research by the DCN. There are monthly surveys available for manufacturing, mining, the export processing industry, trade, construction and services. Monthly manufacturing surveys provide information on output and sales by product, in values and quantities, as well as data on compensation of employees, persons employed, and hours worked. The monthly surveys do not provide information on intermediate consumption.

Manufacturing and trade surveys are based on a deterministic representative sample. In the case of manufacturing, 205 classes of activity were identified, from which establishments accounting for 80 percent of output were selected. Construction and services surveys are probabilistic. The methods used for imputing data in the case of non-response are adequate: the expansion factor is corrected in the case of probabilistic surveys and appropriate methods are used for imputing values in the case of non-random surveys.

INEGI has introduced a regular program of household surveys, with varying periodicity: the National Urban Employment Survey, which is monthly; the National Employment Survey, which is annual; the National Survey of Demographic Dynamics, every two years; the National Microbusiness Survey, also every two years; and the Household Income and Expenditure Survey, which again is conducted every two years.

The ENIGH is nationally representative, covering all geographic zones and the entire population, both urban and rural. The survey is based on a multi-stage random sample design. It provides estimates of household expenditure to a disaggregation of 700 groups of goods and services. Its results, however, are of little use for the national accounts, in part 
because these surveys collect information only over a three-month period, from August 15 to November 15, of the reference year.

INEGI receives complete annual data on government finance, including the execution of budgetary and non-budgetary expenditures of the federal government, the Social Security system, and state and local governments. Budgetary execution data for the federal government, including non-budgetary items, are obtained in detailed form from SHCP.

INEGI compiles its own statistics for State and Municipal Government Finance, based on information obtained directly from the 31 state finance secretariats and the government of the federal district, and this allows it to compile estimates for this institutional subsector in the national accounts. Quarterly data on a cash basis are available for the federal government only.

The available quarterly data are considered adequate for compiling reliable estimates of GDP by industrial activity. As noted above, monthly surveys are conducted for manufacturing, construction, trade and some services. For the agriculture, forestry and fishing sector, monthly information is obtained from administrative records. For services not covered by the surveys, special research projects are conducted periodically. In short, there are adequate indicators available for each economic activity at the four-digit level.

Quarterly estimates of GDP from the expenditure side are adapted to the availability of periodic information from economic surveys, foreign trade and balance of payments statistics, price indices and administrative records. Reflecting the sources available, household consumption and gross fixed capital formation are estimated based on the commodity flow method.

As a supplement to available information, DCN staff survey establishments in 55 subgroups of the national classification, on a monthly and annual basis (special research).

\subsubsection{Source data reasonably approximate the definitions, scope, classifications, valuation and time of recording required}

Source data reasonably approximate the concepts, definitions and scope of data required for compiling the national accounts. The high level of disaggregation in the source data allows for corrections to the classifications like for example, to the export processing zone survey which includes intermediate consumption of domestic goods and services as part of value added. Valuation adjustments must be made to data from the manufacturing survey, since output values are reported at producer prices and not at basic prices.

Total imports of goods are measured at f.o.b. prices, consistent with national accounts requirements. The breakdown of the statistics by tariff item, however, is also valued f.o.b., rather than c.i.f., as must be done for compiling the supply and use tables. The method of adjusting to c.i.f. value per product, by prorating total freight and insurance costs of imports as a proportion of f.o.b. values, is inadequate. 


\subsubsection{Source data are timely}

In practice, the data for compiling the national accounts are received on time for use in monthly, quarterly, and annual estimates. These data are supplied by other units of INEGI in accordance with a strict delivery schedule that reflects the production cycle for the national accounts. Likewise, there is no problem of timeliness with the data produced by other entities. The consumer and producer price indices compiled by the BM are received on time, as are the farm price indices supplied by the Secretariat of Agriculture, Livestock, Rural Development, Fisheries and Food (SAGARPA), the detailed foreign trade and balance of payments statistics (also from the BM), monetary statistics and government finance data.

\subsection{Statistical techniques}

\subsubsection{Data compilation employs sound statistical techniques}

\section{Production approach procedures}

Production estimates are compiled separately for 364 activities at the four-digit level (known as subgroups in the Mexican classification) of the SCNM classification. These are grouped into 198 groups, 73 branches and nine broad divisions of economic activity corresponding to the classes, subgroups, groups and divisions of the ISIC.

Intermediate consumption data are compiled at the same level of detail as that used for production, i.e., complete production accounts are prepared at the four-digit level of the SCNM.

In general, the use of fixed coefficients for estimating current prices is limited to activities such as cottage industry and certain personal and business services, where continuous information on cost structures is lacking. The use of fixed input coefficients is more common when it comes to estimating value added at constant prices, and applies to about 35 percent of GDP. Fixed input coefficients at 1993 prices are used in estimates for manufacturing industry and for a portion of agricultural production.

The estimates of imputed rents for owner-occupied dwellings are based on market rental prices for similar dwellings. The base-year estimate for the housing stock was obtained from the 1990 population census, updated to 1993 with data on capital formation in housing, and rental data were obtained from the household income and expenditure survey. Periodic estimates are made by extrapolating from base-year estimates with the housing stock index and the rent indices compiled by the BM.

The Mexican national accounts record production of construction work in progress, tree plantations, livestock and the construction of durable equipment. 
Goods production is estimated on the basis of output and price data, obviating the need to adjust for gains or losses from holding inventories of finished products. Nevertheless, output estimates for manufacturing in the 1993 base year included unadjusted book values for the change in work-in-progress. Periodic estimates for the manufacturing industry are based on extrapolation with volume and value indices.

Intermediate consumption was estimated for the base year from quantities and prices of inputs consumed in the production process, so that an adjustment for gains from holding inventories of materials and supplies was not necessary. In the periodic estimates, however, intermediate consumption at current prices is generally derived by extrapolation from base year data with nominal value indices reported in the economic surveys. These data could imply a valuation distinct from market replacement prices, as required in the national accounts.

It should also be noted that the method of estimating intermediate consumption at current prices is not consistent with the method used for its compilation at constant prices. The latter is derived assuming fixed input-output ratios of the base year while at current prices intermediate consumption is obtained by extrapolation of the base year values using the nominal value index obtained from the surveys. The inconsistency of the methods is therefore reflected in the implicit deflators of intermediate consumption which show not only changes in price but also changes in the cost structure of production between the base year and the current period. A consistent estimate of intermediate consumption with the assumption of fixed input-output ratios would require reflation of constant price estimates of this aggregate at constant prices with appropriate price indices.

Consumption of fixed capital is estimated by the perpetual inventory method. These estimates exclude fixed capital consumption by general government, except for the Social Security subsector. As a result, estimates of government production may be understated by the value of fixed capital consumption not included in the estimates.

Estimates at constant prices are generally obtained by extrapolation from the base-year estimates of production value, using a Laspeyres-type volume index with a 1993 base. These indices are constructed from detailed monthly output information derived from economic surveys and average product prices in the base year. The estimates are subject to a possible bias because of the lack of specifications of the products used in constructing these volume indices.

Intermediate consumption at constant prices for goods-producing industries is obtained by assuming fixed input ratios from the base year. In the case of services, a double indicator method is used, deflating intermediate consumption at current prices with a Laspeyres price index, although at a sufficiently detailed level by branch of activity.

The volume index of net taxes on production is assumed to be identical to the volume index of value added for the entire economy and this is inconsistent with internationally accepted practice, where tax rates for the base year are applied only to transactions subject to 
taxes/subsidies. On the other hand, the procedure for calculating trade margins at constant prices is adequate, applying rates for the respective base year to the volumes of trade transactions in detail.

GDP estimates at constant prices have a fixed 1993 base, from which Laspeyres-type GDP volume indices are derived. INEGI intends to change the base year every five years: the next base year will be 1998 .

It should be mentioned that the annual supply and use tables are not presented with a breakdown of intermediate consumption by industrial origin for each economic activity but only for the total economy. Detailed estimates of intermediate consumption have only been made available for the base year 1993.

Quarterly GDP estimates by production are compiled at the same disaggregated level of the industrial classification as in the annual estimates, that is, for 364 activities. However, quarterly value added by industry at current prices is calculated, in general, by extrapolation of the base year estimates by value indices of output, thus assuming fixed input output ratios at current prices. This unrealistic assumption is somehow corrected when the annual figures become available and the quarterly accounts are consequently revised to incorporate the information of the annual accounts through the benchmarking adjustment.

\section{Expenditure approach procedures}

There are no independent estimates available for household consumption, gross fixed capital formation, and inventories. The first two are estimated using the commodity flow method. The change in inventories is estimated on a residual basis by reconciling the supply and use tables at the one-digit level of the activity classification for the national accounts.

Estimates of household consumption are produced at detailed levels, according to the origin of the goods, at the four-digit level of the activity classification for the domestic component, and at the two-digit level for imports. Household consumption expenditure is classified by the COICOP categories, and also between durable and nondurable goods. Government consumption expenditure is classified in accordance with the COFOG. Gross fixed capital formation is not compiled by economic activity, but only by type of good and by institutional sector. Changes in inventories are not calculated by type, but as a residual by industrial branch of origin.

The use of fixed coefficients in estimates of household consumption and capital formation is very limited, and is restricted to those goods of domestic or imported origin that have multiple uses.

Government final expenditure excludes incidental sales. Household consumption expenditure includes household expenditures abroad and excludes expenditures in the country by nonresidents. Household expenditures on valuables are only partially included in the estimates. 
Estimates of household consumption at constant prices are obtained by extrapolation of the domestic component, using the detailed volume indices and deflating the imported component of expenditure by unit value indices for the respective imports. Exports of goods are measured at constant prices by extrapolation with volume indices, and exports of services are deflated with appropriate indices. Imports of goods are deflated with the detailed Laspeyres-type unit value indices. Government final consumption is obtained by the sum of production costs at constant prices, where compensation of employees is calculated by extrapolation with an employment index, and intermediate purchases are deflated.

\section{Specific techniques for quarterly compilation}

The benchmarking techniques used for aligning quarterly data with annual results are inadequate since differences are prorated. This method could cause step problems between estimates for successive years (by distorting the rate of growth between the fourth quarter of one year and the first quarter of the following year). Sound practice would suggest using a more appropriate benchmarking approach, such as the Denton method.

The compilation system generates original data, i.e., not seasonally adjusted. Seasonally adjusted data for quarterly GDP are calculated with the X11-ARIMA model. The series are also adjusted for calendar and public holiday effects (Holy Week).

\subsubsection{Other statistical procedures (e.g., data adjustments and transformations and statistical analysis) are also based on sound statistical techniques}

The Mexican national accounts employ procedures for adjusting and improving coverage, definitions, classifications and valuation to meet requirements.

To improve coverage, special studies are conducted for activities for which there are no surveys or administrative records, and activities that have only recently appeared in the economy, such as computer services, cellular telephones, privatization of activities, etc.

When it comes to definitions, there are procedures in place for making source-data definitions compatible with national accounts needs. For example, the statistic for EPZ exports reports raw materials consumed and other domestic expenditures as part of value added and these concepts are therefore reclassified so that intermediate consumption and value added are properly delimited.

With respect to classifications, there is a procedure for harmonizing the available classifiers (ISIC, CMAP - Mexican Classification of Activities and Products - COFOG, COICOP, HS) and the SCNM in order to ensure international comparability.

The SCNM calculations use procedures for measuring unrecorded activities, such as those related to farming, sand quarrying, cottage industry and services such as street vendors, miscellaneous repairs, or domestic service. 
The identification of production accounts for the informal household subsector is consistent with the 1993 SNA guidelines. Calculations are based on information provided by the ENAMIN, supplemented with the results of special research by SCNM.

SCNM data do not include illegal activities such as the manufacture and distribution of narcotics and psychotropic substances; usury; ticket scalping; unauthorized surgery; trade and transportation of contraband, etc., because of the difficulty inherent in estimating such activities without consistent and constant data. Estimates are included for sex services.

\subsection{Assessment and validation of source data}

3.3.1 Source data - including censuses, sample surveys and administrative records-are routinely assessed, e.g., for coverage, sample error, response error and non-sampling error; the results of the assessments are monitored and made available to guide planning

Information is available on sampling errors for probabilistic surveys, as well as on failure to respond and imputation methods. Survey results are monitored and atypical values are confirmed with the respondents.

Administrative records and other secondary sources are continuously evaluated by the national account compilers, who review them for consistency and accuracy and consult the sources on any inconsistencies. For international trade, there is a process for verifying consistency between foreign trade statistics, the balance of payments and customs records before they are included in the SCNM. Tariff item records are also reviewed so that temporary and definitive exports and imports can be determined and classified properly.

\subsection{Assessment and validation of intermediate and final output data}

\subsubsection{Main intermediate results are validated against other information where applicable}

The source data used in compilation are compared with alternative data, whenever possible. For example, farm prices supplied by SAGARPA are checked against PPI prices compiled by the BM, and foreign trade records.

In terms of consistency with related data sources, data are compared with alternative information sources that bear a correlation either as to levels or to the trend of observed variables. For example, in the manufacturing industry, survey information is compared against data provided by producers' associations and chambers of industry; foreign trade statistics are compared against EPZ export surveys and the balance of payments; financial information from businesses and public agencies is compared with the Federal Public Finance Account. 


\subsubsection{Statistical discrepancies in the intermediate data are assessed and investigated}

When they are detected, discrepancies are investigated and measures are taken to eliminate them.

\subsubsection{Statistical discrepancies and other indicators of potential problems with other output data are investigated}

There are no discrepancies in the Mexican national accounts between estimates of GDP by activity and GDP by expenditure component, since there is no independent estimate of changes in inventories, which are calculated as the residual between the value of GDP by activity and the sum of other expenditure components.

GDP estimates are comprehensive and are not compared with any unofficial estimates prepared by other organizations.

\subsection{Revision studies}

\subsubsection{Studies and analyses of revisions are carried out routinely and used to improve statistical processes}

The national accounts office maintains a constant watch for differences in the trend and magnitude of preliminary and definitive data, resulting from updates in information sources or calculation methods used. Studies of revisions identify the sources of any discrepancy and appropriate adjustment mechanisms are used. The studies, however, are not published in detail, and only the most significant differences are disclosed.

The results of research on revisions in data compilation have made national accounts compilers aware of the need to work more closely with respondents and the sources of basic statistics, in order to improve the content, quality, timeliness, disaggregation, coverage and concepts of basic statistics in subsequent periods, and thereby enhance the calculations.

\section{Serviceability}

\subsection{Relevance}

\subsubsection{The relevance and practical utility of the statistics in meeting users' needs are regularly assessed}

There is no established process for consulting statistics users, but meetings are frequently held with the principal users to hear their concerns. These meetings involve users in government agencies, consulting firms, universities and research institutes, among others. In practice, the National Accounts Program has from the outset attempted to satisfy users' needs, as evident in the introduction of changes to the base year, the adoption of international 
recommendations, and the expanded scope and level of detail of the accounts, in particular the economic accounts (compiled by institutional sector), the quarterly accounts, monthly estimates of economic activity, regional accounts and satellite accounts. In addition, INEGI tracks user needs as reflected in the information requests received through the Sales and User Service Centers and by e-mail.

INEGI keeps abreast of progress and developments in the national accounts field through its participation in international forums such as those of the United Nations, OECD and ECLAC, where the information needs of those international institutions are also identified.

\subsection{Timeliness and periodicity}

\subsubsection{Timeliness follows dissemination standards}

Having subscribed to the Special Data Dissemination Standards (SDDS), Mexico meets the requirements of timeliness for the quarterly accounts, and in fact exceeds those requirements. Quarterly GDP estimates by economic activity are published 45 days after the end of the period of reference, and the corresponding estimates at current prices are published within 52 days.

\subsubsection{Periodicity follows dissemination standards}

The periodicity of data is consistent with the requirements of the SDDS.

\subsection{Consistency}

\subsubsection{Statistics are internally consistent within the dataset (e.g., accounting identities are observed)}

GDP estimates are derived from the balances in the supply-and-use tables, from which consistent estimates of GDP by economic activity and by final expenditure component are derived. Although these latter estimates are not calculated independently, since household consumption and fixed capital formation are based on the flow of goods and inventories are residuals (total supply less the sum of other final expenditure components), the estimates are logically and numerically consistent.

Quarterly GDP estimates are consistent with the annual estimates, since both use the same concepts, definitions, and classifications. The source data and compilation methods are also similar, except when it comes to measuring agricultural activity (the agricultural year is used for annual estimates while the calendar year. The quarterly data are adjusted to annual values so that the sum of the quarters coincides with the annual figure. Any discrepancies between annual rates of change in GDP and the corresponding rate of change in the four-quarter totals are insignificant, and no more than a tenth of a percentage point. 


\subsubsection{Statistics are consistent or reconcilable over a reasonable period of time}

Mexico's national accounts series are consistent over long periods of time. The current series, with base year 1993, includes estimates from 1988 to the most recent period. When the base year is changed, historical revisions are made to the series to keep them consistent over sufficiently long periods. For example, for the base year 1980 the series were recalculated back to 1960 . Historical revisions of the series are also done when new data become available from the economic and population censuses, and when revisions are made to the source data or to other statistics systems that provide input for the national accounts. The revisions and their rationale are explained in the publications.

\subsubsection{Statistics are consistent or reconcilable with those obtained from other data sources or statistical frameworks}

The national accounts statistics are compatible with statistics on the balance of payments, and the net lending/borrowing figure in the national accounts coincides with the current account balance in the balance of payments, plus capital transfers. The discrepancies between data on general government savings in the national accounts and those in the government finance statistics are due to the fact that the sector is covered more broadly in the national accounts.

\subsection{Revision policy and practice}

\subsubsection{Revisions follow a regular, well-established and transparent schedule}

Mexico follows an established and stable cycle for producing and revising the national accounts and this is of public knowledge. A release calendar is prepared each December for the following year and is publicized through the media and at on the INEGI website. When the annual data-based estimates are published at the end of the year following the reference period, estimates for the preceding two years are generally corrected, as are quarterly estimates for those years and for the current period. Quarterly estimates for the current year are also revised when data for a new quarter are published.

\subsubsection{Preliminary data are clearly identified}

Preliminary data are clearly identified in the publications, and the level of detail for the revised data is exactly the same as for the preliminary data. The introduction to each publication explains that the data for the last two years are preliminary and subject to revision. The preliminary nature of the results is also indicated in the tables, on the covers of the publications, and in the publicly accessible Economic Information Database of the INEGI. 


\subsubsection{Studies and analyses of revisions are made public}

Historical series revisions, as in the case of changes to the base year, are documented and the explanation of differences from previous series is widely publicized. Although annual revisions are quantified and evaluated, this analysis is not made public.

\section{Accessibility}

\subsection{Data accessibility}

\subsubsection{Statistics are presented in a way that facilitates proper interpretation and meaningful comparison (layout and clarity of text, tables and charts)}

The annual national accounts statistics are published in tables containing absolute values, together with supplementary tables that include structures and percentage variations, physical volume indices, productivity indices and implicit price indices. In addition to supplementary tables, the short-term statistics offer graphs and seasonally-adjusted or trend series to facilitate analysis.

The presentation, the disaggregation and the classifications of SCNM product series are maintained over time in order to facilitate identification, comparison and consultation by users. The degree of detail in the variables depends on the type of product offered and its periodicity. In general, estimates are published at a fairly high level of detail. The results of SCNM products are published with a press release describing the principal results for the period under study.

The timing and level of detail of publications of SCNM output vary. The results are presented in monthly, quarterly and annual series, and with national and regional geographic coverage and supplemented with satellite accounts.

Gross Domestic Product and Total Supply and Use tables are published quarterly; Industrial Activity, Gross Fixed Capital Formation (for the national level), Manufacturing Output and Power Generation and Supply for 17 federative entities and by economic activity are published monthly.

The following are published annually: Goods and Services Accounts; Output, Wages and Salaries, Employment and Productivity in the Export Processing Industry, nationally and by geographic and federal region; Institutional Sectors Accounts; Gross Domestic Product by Federative Entity; Macroeconomic Indicators for the Public Sector; Current and Accumulation Accounts; Production Accounts by Purpose for State Governments; Informal Household Sector; System of Economic and Ecological Accounts of Mexico; and Tourism in Mexico.

INEGI has prepared an inventory of all SCNM products, with details on titles, series, variables, contents, year of publication, etc. In addition, the annual publications have a final 
page containing a table with a list of all publications with the 1993 base year and their respective series.

The following seasonally-adjusted national accounts series are published: quarterly gross domestic product, industrial activity, global indicator of economic activity, quarterly supply and demand components, and gross fixed capital formation (as a monthly index).

\subsubsection{Dissemination media and formats are adequate}

Statistics are published simultaneously through a press release and at the INEGI website, in full text PDF format. Hardcopy is subsequently released for annual publications. Printed publications with annual series for the base years 1970, 1980, and 1993 are offered for sale at a nominal price. Electronic versions are available on diskettes and CDs, and the 1993 baseyears series are posted in PDF format on the webpage and in the Economic Data Bank (BIE). Users may also submit special requests. Short-term calculations are available in the Shortterm Statistics Information System and in the BIE, on the INEGI website.

\subsubsection{Statistics are released on a pre-announced schedule}

With respect to monthly and quarterly information, the Market Information Release Calendar is now published over the Internet, a month before the beginning of the quarter in question, and a calendar for the coming year is published each December. Both of these calendars are posted on the Internet and disseminated in the form of an information bulletin.

All annual products of the SCNM intended for recurrent publication are recorded in the INEGI publications program. There is no publication calendar for the annual series, but there is an internal schedule that is established as of October of the previous year.

\subsubsection{Statistics are made available to all users at the same time}

The data are disclosed at the same time to all users, on the date established in the Short-term Statistics Information Release Calendar, at 2:30 p.m.

On publication day, a note is sent at the same time to the Office of the President of the Republic and to the Secretariat of Finance and Public Credit. The data are published in a press bulletin bearing the logo of the Secretariat of Finance and Public Credit and indicating clearly that the information was prepared by INEGI.

Regular annual publications are also released at the same time to all interested users, at the dates stipulated in the internal release calendar.

\subsubsection{Non-published (but non-confidential) subaggregates are made available upon request}

The DCN has a general policy of providing only published information to which specific aggregations may be added; upon specific and formal request, data can be provided at greater levels of detail, as long as they do not violate the principle of confidentiality. All information 
is provided free of charge. All publications make mention of the fact that additional information is available.

\subsection{Metadata accessibility}

5.2.1 Documentation on concepts, scope, classifications, basis of recording, data sources and statistical techniques is available, and differences from internationally accepted standards, guidelines, or good practices are

The metadata are available at the INEGI website and in printed publications, where methodological details are shown. Methodological summaries for the SDDS and OECD metadata for certain economic indicators are prepared in accordance with each agency's specifications, and are updated as changes are introduced.

\subsubsection{The degree of detail is adapted to the needs of users, to ensure their satisfaction}

Brochures and trifolds have been prepared and published on the national accounts, and a summary table of statistical series is included at the end of the regular annual publications.

Most SCNM publications include a section with information on sources and methods, which is updated regularly. In addition, supporting materials have been prepared with brief and straight-forward descriptions of the principal concepts in the national accounts, known as the ABC of Accounts by Institutional Sector and the ABC of National Accounts, which have been published since 1981 in countless editions and been widely disseminated throughout Latin America and the Caribbean.

\subsection{Assistance to users}

\subsubsection{Contact person for each subject field is publicized}

All SCNM publications and the INEGI website provide the area, e-mail, telephone number and address of persons responsible for preparing the data presented, and those of the public service section of INEGI. Users receive personalized attention at the Institute's information centers (CIINEGI) and in the national accounts office.

Publications include a list of related or supplementary information on their back page.

The user service area records the opinions of users at the CIINEGI as well as those that arrive by e-mail (atencion.usuarios@inegi.gob.mx) and channels requests to the relevant area for response. 
5.3.2 Catalogs of publications, documents and other services, including information on their cost, are easily obtainable

INEGI publishes a catalog of products and services, and this is updated annually. It is organized by topic, and each title contains a brief description of its contents. Product catalogs are available in hardcopy and online, and the price of each item is indicated clearly. Products and specialized services are offered for sale at the CIINEGI and online. Order forms are easy to use and contain instructions for completing them. 


\section{Consumer Price Index (CPI)}

\section{Prerequisites of Quality}

\section{$0.1 \quad$ Legal and institutional environment}

\subsubsection{The responsibility for collecting, compiling and disseminating statistics is clearly assigned}

The Fiscal Code of the Federation, Art. 20, designates Bank of Mexico (BM) as the institution responsible for compiling and disseminating the National Consumer Price Index (NCPI). It requires that at least 30 urban areas in 20 states be represented in the index, and that they should include the 10 largest cities. It also specifies that only towns of 20,000 or more inhabitants should be considered in the index. Today the NCPI is composed of subindices for 46 urban areas in 32 states.

The Fiscal Code stipulates that the NCPI must be published in the official gazette of the Federation within the first 10 days of the month following the month to which the index refers.

Although the BM bears full responsibility for price quotations and for compiling the NCPI, the data source for consumption expenditures used to determine the household consumption expenditures basket for the NCPI is the National Survey of Household Income and Expenditure (ENIGH), conducted by the National Institute of Statistics, Geography, and Information Technology (INEGI). Data-sharing procedures have been established for that purpose.

\subsubsection{Data sharing and coordination among data producing agencies are adequate}

The BM is currently conducting a project designed to update the NCPI family shopping basket. A new, preliminary list of goods and services and their weights, based on ENIGH findings for 2000, has already been drawn up, which, given the very short time that has elapsed between the gathering of ENIGH data and the preparation of the new household consumption expenditures basket for the NCPI, points to extraordinarily smooth coordination between the BM and INEGI.

Through periodic meetings and workshops, the BM also keeps in touch with other statistics institutions in and outside the government in order to foster a clear understanding of the BM's work in relation to the NCPI.

\subsubsection{Respondents' data are to be kept confidential and used for statistical purposes only}

Art. 24, VIII of the BM Manual General Conditions of Employment explicitly underscores the importance of integrity in the Bank staff and the confidential nature of BM data. It also 
points out that breaches of the Bank's confidentiality rules may lead to dismissal of the officer concerned.

For price surveys, respondents are given a note explaining the BM policy regarding confidentiality and that the data they provide are used only for statistical purposes. Moreover, the BM does not publish data in such a way that its respondents can be identified.

The BM has taken steps to ensure that its installations are secure and its computerized data protected from unauthorized access. In addition to institutional security measures, each computer has its own security.

\subsubsection{Statistical reporting is ensured through legal mandate and/or measures implemented to encourage voluntary response}

The BM has sought and encouraged voluntary participation by NCPI respondents by explaining the purpose of the indicator and underscoring the confidential nature of data inputs. Historically, the BM has not had any difficulty gathering NCPI data on a voluntary basis.

Price surveyors always try to find the least invasive and most efficient way to collect data. Where possible, price data are collected independently. If that is not possible, an effort is made to designate an employee as a contact who can help provide the data.

\section{$0.2 \quad$ Resources}

\subsubsection{Staff, financial, and computing resources are commensurate with institution programs}

The staff assigned to preparation of the NCPI are both qualitatively and quantitatively sufficient to produce an index that meets national needs and international standards. The team responsible for this task consists of 100 field surveyors (60 of whom are shared with the National Producer Price Index-NPPI), two field supervisors, 15 regional supervisors at head office (three of whom act as chief supervisors), three analysts and one chief analyst (shared with NPPI), three researchers and one chief researcher (shared with NPPI), five data processors and two supervisors (shared with NPPI), and three secretaries (shared with NPPI).

Every year, formal in-house training in CPI methodology is provided for all price surveyors, while head office staff receive more frequent courses. Some staff members have also attended training courses abroad. In addition, the BM is in the process of organizing a conference with specialists from other countries to exchange ideas on the change in the NCPI base, which is scheduled to take place in $2002 .^{2}$

\footnotetext{
${ }^{2}$ After the visit of the mission, the BM updated the base period for the NCPI. The index is now compiled with the second half of June 2002 as the price reference period. It uses new
} 
Sufficient incentives are in place to retain trained personnel, especially core staff.

The BM's computer unit has provided institutional support and in-house experts to ensure efficient calculation of the NCPI. The data processing and index calculation system is sophisticated and automated. Price data collected in the field are transmitted via e-mail to the head office of the Bank and the index is published instantaneously on the BM's website.

\subsubsection{Measures to ensure efficient use of resources are implemented}

The staff in charge of the NCPI establish guidelines, based on the ISO 9001 certification, for compiling the index and they keep close tabs on the activities involved.

Although no formal accounting system has been set up in the BM that would allow the exact costs of the NCPI program to be measured, the program's directors are able to gauge them indirectly through budget management in the Directorate of Prices, Wages, and Productivity. Thus, most of the data needed to carry out precise, separate estimates of the costs of each of the various price index programs are already available. Shared resources are identifiable and not very significant.

As regards the NCPI, the BM has attempted to take advantage of state-of-the-art computer technology to process and disseminate data. Extensive use is made of the BM website to disseminate information on the NCPI, and the index itself is published every two weeks.

\subsection{Quality awareness}

\subsubsection{Procedures have been put in place for quality awareness}

The NCPI program is totally focused on the quality standards set as a result of the ISO 9001 certification of the index. A quality awareness manual has been produced, which informs both the BM team and users of the goals and structure of the quality plan adopted. This plan includes installation of a quality awareness committee composed of all the staff members responsible for managing the NCPI program. This committee meets once a month to review progress in compiling the NCPI.

\subsubsection{Procedures have been established for monitoring the quality of data collection, compilation, and dissemination}

For the NCPI a record is kept of processing errors, such as mistaken coding. Moreover, the analysis and procedures group conducts ongoing studies of ways to improve the quality of the data and process them more efficiently.

expenditure weights from the year 2000, aligned to the second half of June 2002 for relative price changes. 
A quality assurance system has been established (under the ISO 9001 international standard), which includes an audit program for the NCPI, in which personnel from the Directorate of Prices, Wages, and Productivity (DPSP) conduct field audits in accordance with a preestablished schedule. During these visits, the team verifies that the objectives of the NCPI have been understood, the instructions on how to perform the work are followed, that the work is properly organized, the prices collected are valid, and that any problems in the field are identified. As part of its mission, the team prepares a report indicating what corrective and preventive measures should be implemented.

The BM is not currently conducting user surveys to elicit comments on quality-related issues.

\subsubsection{Procedures are in place to assess the quality of statistics, to acknowledge and deal with tradeoffs within quality, and to guide planning for existing and emerging needs}

The BM periodically convenes meetings with policy-makers and other users of the data to examine existing series and establish any new data requirements. The $\mathrm{BM}$ also tries to encourage user comments on the NCPI, especially when the index is being revised.

The BM is in the process of updating the list of goods and weights used for the NCPI. For this project, comments have been invited from persons inside and outside Mexico with a view to implementing every possible improvement. Tradeoffs between quality and the resources available for drawing up the new NCPI are taken into consideration.

\section{Integrity}

\subsection{Professionalism}

\subsubsection{Statistics are compiled on an impartial basis}

Art. 8 of the Federal Law on the Administrative Responsibilities of Civil Servants specifies in considerable detail the ethical norms that civil servants are expected to abide by. Specific rules apply to professional behavior, courtesy towards those reporting and using the data, integrity, and impartiality in the hiring of personnel and in performance of assigned tasks. No influence of any kind may be exerted by third parties.

For its part, the BM has a long tradition of independence, professionalism, and impartiality in producing and disseminating official statistical series. The General Conditions of Employment manual is very explicit regarding the importance of integrity in the Bank's officers and states on page nine that a staff member in breach of the conditions of employment may be dismissed. In the BM, professional competence is a key consideration in hiring and promotion practices.

The methodology and analysis group of the Directorate of Prices, Wages, and Productivity regularly conducts scientific studies of the price indices and those studies are examined both internally and externally. In addition, staff in the Directorate keep up to date with studies on 
price indices and methodologies used in other countries. These activities help to maintain the Bank's reputation and to enhance the quality of the NCPI.

\subsubsection{Choices of sources and statistical methods are informed solely by statistical considerations}

Those responsible for compiling the NCPI are completely independent in their choice of sources and statistical methods. Only statistical and budgetary considerations are taken into account.

\subsubsection{The appropriate statistical entity is entitled to comment on errors of interpretation and misuse of statistics}

The BM considers that it would be untoward of a statistics-producing entity to comment on improper interpretations and misuse of statistics, although it is entitled to do so. However, the $\mathrm{BM}$ does make every effort to provide in-depth explanations of the statistics it publishes.

\subsection{Transparency}

\subsubsection{The terms and conditions under which statistics are collected, compiled, and disseminated are available to the public}

The terms and conditions under which the NCPI is compiled and disseminated are established in Articles 20 and 20bis of the Fiscal Code of the Federation. The bimonthly publication of NCPI findings in the official gazette (Diario Oficial) of the Federation refers to these two Articles.

\subsubsection{Internal governmental access to statistics prior to their release is made known to the public}

For the monthly publication of NCPI findings, a press release is prepared and submitted to the Governing Board of the BM at noon on the day the index is disseminated, two hours prior to the press conference and publication of the NCPI on the BM website at $2 \mathrm{p} . \mathrm{m}$. The government does not have access to the data prior to their dissemination to the public.

\subsubsection{Products of statistical agencies/units are clearly identified as such}

All the BM publications bear the Bank's logo. In the case of joint publications, each agency's contribution is clearly labeled. Although there is no explicit requirement to acknowledge the $\mathrm{BM}$ as the source of the cited BM data, users normally do so, given the BM's reputation for statistics. 


\subsubsection{Advance notice is given of major changes in methodology, source data and statistical techniques}

The BM gives advance notice of any major change of the methodology used to prepare the NCPI. It does so at least 15-30 days prior to the change, and in the case of really important changes, such as revision of the index and change of base, much earlier announcements are made through meetings with principal users and analysts in a position to comment on the proposed changes of base data and methodology.

\subsection{Ethical standards}

\subsubsection{Guidelines for staff behavior are made known to staff}

Newly hired personnel of the Bank receive an explanation of the ethical standards to govern their personal behavior, professional independence, conflicts of interests, maintenance of the BM's reputation, and the compilation of statistics. These standards are clearly set out in the General Conditions of Employment manual. Moreover, the BM has a long tradition of integrity, professional independence, and impartiality in respect of the statistical series it produces. An effort is made to maintain this tradition at every phase in the preparation of the NCPI.

\section{Methodological Soundness}

\subsection{Concepts and definitions}

2.1.1 The overall structure in terms of concepts and definitions follows internationally accepted standards, guidelines, or good practices

Mexico's NCPI bases its weights on the National Survey of Household Income and Expenditure (ENIGH) of 1989. These new weights were introduced in 1994, the base year used for the index.

Although the current NCPI's design and methodology were implemented before 1993, the concepts and definitions of household consumption expenditure are very similar to those used in 1993 SNA/SEC95 and to ILO Guidelines.

In compiling the NCPI, concepts and definitions similar to those in the Consumer Price Index Manual (which is being prepared for press, but has already been published on the Internet) are used in respect of individual goods and services for which periodic price measurements are required. Whenever possible, specific goods and services are selected by scientific random methods within the point of sale at the start of the price collection process. 


\section{$2.2 \quad$ Scope}

2.2.1 The scope is broadly consistent with internationally accepted standards, guidelines, or good practices

Mexico's NCPI has a geographical and demographic coverage of all households located in towns of 20,000 or more inhabitants. The 20,000 floor is established by law. It includes household consumption expenditure of families of all different sizes and all head-ofhousehold occupations.

The concept of household consumption expenditure used in the household income and expenditure survey on which the weights in the current index are based corresponds to acquired consumption, i.e., it includes goods and services purchased on the market by households; consumption of goods produced for one's own consumption; payments of wages and salaries in kind; and an imputed rent for owner-occupied housing.

\subsection{Classification/sectorization}

\subsubsection{Classification/sectorization systems used are broadly consistent with internationally accepted standards, guidelines, or good practices}

The NCPI uses a Mexican classification system for consumption items, which at the 313 generic headings level is compatible with the Classification of Individual Consumption by Purpose (COICOP). That is to say that it would be feasible to reclassify most of the 313 generic headings within the COICOP framework at the four- or five-digit level. Nevertheless, the BM has not developed a national individual consumption classification system based on the COICOP in the sense that the first five digits of the system coincide with the five-digit level COICOP. Nor has the Central Product Classification (CPC) been taken into account for specific products.

\section{$2.4 \quad$ Basis for recording}

\subsubsection{Market prices are used to value flows and stocks}

The CPI weights are based on household expenditure on goods and services valued at the market prices in effect at the time of purchase. These are purchase prices, i.e., they include both taxes and distribution margins for the products included in the price paid by the consumer. Apart from prices, information is also gathered and recorded in the database on detailed characteristics of the specific goods and services for which prices are collected.

\subsubsection{Recording is done on an accrual basis}

For both the ENIGH, which serves as the basis for the weights, and the bimonthly price survey, the recorded prices (total values) of the goods and services are those in effect at the time of purchase. 


\subsubsection{Grossing/netting procedures are broadly consistent with internationally accepted standards, guidelines, or good practices}

In the 1989 ENIGH, expenditures on durable goods, such as vehicles, are valued at the total purchase price of the durable good. However, the sales price of a vehicle is recorded as household income. This same methodology was used for the NCPI weights.

\section{Accuracy and reliability}

\subsection{Source data}

\subsubsection{Source data are collected from comprehensive data collection programs that take into account country-specific conditions}

The 1989 ENIGH conducted by the INEGI is based on a sample of 11,531 households considered representative of the Mexican population as a whole. A two-stage random sampling system was used to ensure representation of all households in the country. In the first stage, both urban and rural geographical areas were selected. The homes/households to be interviewed were selected in the second stage. Expenditures on goods and services reported by these households were multiplied by the inverse of the sampling fractions to obtain estimates of consumption expenditure corresponding to expenditure of the total population.

Since 1994, the ENIGH has been conducted every two years, during a three-month period beginning in mid-August of the year of the survey. The survey consists of a questionnaire on daily expenditures, such as expenditure on food, public transport, etc., which is filled in by the respondents, and a section on less frequent expenditures, such as expenditure on furniture, vehicles, etc., which is based on personal interviews with respondents. Data collection periods vary according to the type of expenditure.

The fact that the ENIGH is only conducted over a three-month period in the fall is problematic. This can bias the findings due to the seasonal nature of expenditure on food and other expenditures associated with holidays, such as Christmas and New Year.

For the ENIGH, expenditures on goods and services were valued at market prices. Also recorded were the values of goods produced for a home consumption and an imputed rental value of owner-occupied dwellings.

For the monthly price survey, approximately 170,000 prices are collected from 14,000 commercial establishments and 5,000 households. These establishments were selected using deterministic and random samples, based on lists of establishments in the 46 urban areas in which price data are collected. These lists were generated by the BM's Directorate of Prices, Wages, and Productivity and are kept up to date as a source for choosing substitute establishments, if the need arises. 
The NCPI towns and cities were selected by using a scientific random sampling system. The index excludes the rural sector and towns of fewer than 20,000 inhabitants.

The 313 generic goods and services in the household expenditures basket were selected by using cut-off samples and scientific random sampling procedures. The different types (variety) of products were selected at the criterion of the researcher and by using scientific random sampling within the point of sale. Sufficient data are collected on the characteristics of the specific varieties selected to ensure that the price of the same variety is recorded in each period.

For the NCPI, prices are recorded twice a month. The index is also published on a bimonthly basis.

Periodically, a survey of brand names and presentations is conducted in order to keep an upto-date list of the specific varieties under each generic heading, to be used for substitution purposes and to introduce new products. Market penetration studies of new products are also undertaken to determine when they should be included in the index.

3.1.2 Source data reasonably approximate the definitions, scope, classifications, valuation, and time of recording required

Except in the case of the medical sector, the expenditure headings used for ENIGH tables are compatible with NCPI requirements. The breakdown is sufficient to allow a list of goods and services to be drawn up and to calculate the corresponding weights.

\subsubsection{Source data are timely}

ENIGH findings are now being processed in a more timely fashion. Previously, there were long lags between the data collection period and preparation of the survey results.

Other sources of timely price data for comparative purposes are Producer Price Index (NPPI) data and agricultural prices.

\subsection{Statistical techniques}

\subsubsection{Data compilation employs sound statistical techniques}

In general, the level of breakdown of the 313 generic goods and services of the NCPI is sufficient to permit reclassification to a five-digit COICOP and also to the CPC, though not as easily. This makes it possible to analyze price variations in the context of these international classification systems.

There is no breakdown of capital formation expenditure on housing, since the NCPI uses the imputed rent concept. 
The NCPI employs an unbiased, modified Laspeyres, calculation formula. Price relatives are estimated for 313 generic goods and services. Splicing is used when there are noncomparable substitutions and to introduce new goods and services. The reference period of the weights is 1989 and it has been used for over seven years. So far the splicing of indices corresponding to revisions has been effected by superimposing a one-year period. In future, the idea is to use a one-month overlap period.

The current NCPI weights were updated to reflect changes in prices between 1989, the year of the ENIGH, and 1993, the base year for calculating the index. After compiling the index every two weeks, a conversion factor is applied to change the base to $1994=100$.

Whenever a price is not available, owing to seasonality or for some other reason, the most recently reported price is kept constant. However, this procedure is only rarely applied.

If necessary, quality adjustments are made or splicing is used to introduce new specific, noncomparable varieties.

\subsubsection{Other statistical procedures (e.g., data adjustments and transformations and statistical analysis) are also based on sound statistical techniques}

The INEGI produces implicit deflators to account for areas of the economy that are not covered in the NCPI is compilation. The proportion of final consumption expenditure not covered by the index is estimated at less than 20 percent.

\subsection{Assessment and validation of source data}

3.3.1 Source data-including censuses, sample surveys and administrative records-are routinely assessed, e.g., for coverage, sample error, response error and non-sampling error; the results of the assessments are monitored and made available to guide planning

The 1989 ENIGH is the data source for the estimation of the NCPI weights. For this survey, there are data on sample and non-sampling errors. These findings were taken into account in estimating the grossed-up values for the current NCPI weights. Atypical values and their impact on the weights were also analyzed and the appropriate adjustments made. Moreover, as part of the NCPI weights estimation process, steps were taken to validate all the ENIGH data with respect to temporal consistency, consistency of related data taken from different sources, definitions, valuation, recording times, and classification.

The way the 1989 ENIGH was designed creates two serious problems. First, the survey was conducted in only one quarter of the year. That means that weights based on typically seasonal expenditures may be biased. In addition, the reference periods for expenditures on goods and services not covered by the daily expenditures survey are not long enough to yield 
a sufficient number of transactions with which to estimate weights for the 46 urban areas in the NCPI. For instance, the reference period for the purchase of vehicles is only six months. The other reference periods are also too short.

\subsection{Assessment and validation of intermediate and final output data}

\subsubsection{Main intermediate results are validated against other information where applicable}

Every month NCPI prices and indices are compared with NPPI prices and also with farm prices.

\subsubsection{Statistical discrepancies in the intermediate data are assessed and investigated}

The BM has implemented a quality-control program to analyze significant discrepancies in different components of the index. Atypical changes in prices are checked before the index is published.

\subsubsection{Statistical discrepancies and other indicators of potential problems with other output} data are investigated

The methodology and analysis group conducts studies of the price gathering and NCPI tabulation processes. A record is also kept of all errors detected during data processing for the monthly NCPI. Based on those studies, adjustments are made to the price gathering and data processing procedures.

\subsection{Studies of revisions}

3.5.1 Studies and analyses of revisions are carried out routinely and used to improve statistical processes

No preliminary indices are published and no revisions of the NCPI are carried out, except for the infrequent changes of the base period.

\section{Serviceability}

\subsection{Relevance}

4.1.1 The relevance and practical utility of the statistics in meeting users' needs are regularly assessed

There is a quarterly meeting with analysts from the press, government, and academic circles that use the NCPI. This meeting coincides with publication of the quarterly report on inflation. There are also periodic consultations with policy departments and user advisory groups, which include representatives of the private sector and academics. These meetings are held more frequently during periods, such as the present one, of a change in the base of 
the index. ${ }^{3}$ The BM does not currently conduct surveys to ascertain whether the program meets users' needs.

Officers in the Directorate of Prices, Wages, and Productivity occasionally participate in international statistical meetings and seminars on price indices.

\subsection{Timeliness and periodicity}

\subsubsection{Timeliness follows dissemination standards}

The NCPI is published within 10 calendar days of the end of the month it refers to, in accordance with SDDS dissemination requirements.

\subsubsection{Periodicity follows dissemination standards}

The periodicity of the NCPI is bimonthly and monthly, which is in line with SDDS dissemination requirements.

\subsection{Consistency}

4.3.1 Statistics are internally consistent within the dataset (e.g., accounting identities are observed)

NCPI index totals are the same, regardless of whether the aggregation is by category of expenditure or by geographical area.

\subsubsection{Statistics are consistent or reconcilable over a reasonable period of time}

NCPI historical series, in more or less their current format, are available with data from 1978, although the series have only been published on the website with data since 1980, when the geographical coverage of the index was expanded.

The BM's policy is not to publish NCPI series with retrospective adjustments reflecting updates in the list of goods and services and their weights and methodological changes based on revisions of the index. During revision of the NCPI, links are established between major series to ensure that they remain historically comparable. Since 1980, there are no interruptions or significant discontinuities in the historical series.

\footnotetext{
${ }^{3}$ After the visit of the mission, the BM updated the base period for the NCPI. The index is now compiled with the second half of June 2002 as the price reference period. It uses new expenditure weights from the year 2000, aligned to the second half of June 2002 for relative price changes.
} 
Whenever erratic changes in the monthly time series occur, they are explained by the incidence of the components of the index on the change in the index.

\subsubsection{Statistics are consistent or reconcilable with those obtained from other data sources or statistical frameworks}

The monthly NCPI indices are routinely compared with the corresponding NPPI indices to detect any possible errors.

\subsection{Revision policy and practice}

\subsubsection{Revisions follow a regular, well-established and transparent schedule}

There has been no fixed timetable for updating NCPI weights and methodology. New weights were introduced in 1980 based on the results of the $1977 \mathrm{ENIGH}$, and again in 1994, based on the results of the 1989 ENIGH. Although new surveys were conducted in 1994, 1996, 1998, and 2000, the NCPI has not been revised since 1994. A revision scheduled for 1998, based on the findings of the 1994 ENIGH, never materialized. The idea now is to revise the index on the basis of the 2000 ENIGH findings. The BM officers say that the new list of goods and services and the new weights have already been drawn up and estimated and that the new index will be published this year (2002). In future, revisions are to be carried out every two years, using the findings of the most recent ENIGH. Thanks to improvements in ENIGH processing procedures, this schedule is considered feasible. ${ }^{4}$

A draft manual on the methodology to be used for the new index is currently being prepared.

\subsubsection{Preliminary data are clearly identified}

Preliminary NCPI data are not published.

\subsubsection{Studies and analyses of revisions are made public (see section 3.5.1)}

No revisions of published NCPI series are carried out unless there is a serious mistake that was not detected prior to publication of the index. In such a case, the BM would publish an explanation of the correction.

\footnotetext{
${ }^{4}$ After the visit of the mission, the BM updated the base period for the NCPI. The index is now compiled with the second half of June 2002 as the price reference period. It uses new expenditure weights from the year 2000, aligned to the second half of June 2002 for relative price changes.
} 


\section{Accessibility}

\subsection{Data accessibility}

\subsubsection{Statistics are presented in a way that facilitates proper interpretation and meaningful comparison (layout and clarity of text, tables and charts)}

The NCPI is published twice a month. For the first two weeks of the month, the index is compiled on the basis of prices collected during those first two weeks, and for the last two weeks of the month all the prices gathered that month are included. Every two weeks, a brief note is published in the official gazette (Diario Oficial de la Federación), indicating the level of the NCPI and the percentage change in the index over the two-week period. For the second two weeks of the month, a monthly percentage change in the index is included, along with a brief analysis of the components for which there were significant price changes during that month.

The monthly press release provides further details, a few tables and charts, and more analysis. This release is also published on the Internet. In addition to its bimonthly/monthly publications, the BM also produces quarterly and annual reports with more breakdown and analysis. In terms of layout, all the BM publications on the NCPI are professionally presented with tables and charts alongside the data to facilitate analysis.

\subsubsection{Dissemination media and formats are adequate}

While the bimonthly/monthly press releases are very short, much more extensive information on the NCPI can be found in other, quarterly and annual, publications and on the Bank's website. This information includes a list of all the monthly prices used to calculate the index and indices for 46 urban areas and seven geographical regions, broken down into eight large consumption expenditure categories. The Bank's web page also has links to detailed historical series since 1980 .

\subsubsection{Statistics are released on a pre-announced schedule}

The BM's statistical series are released in accordance with a precise pre-announced schedule, which is published each quarter. Moreover, by law the NCPI has to be published within the first 10 days of the month following the month to which the data refer.

\subsubsection{Statistics are made available to all users at the same time}

On the official publication date, the NCPI is disseminated simultaneously to all users via a press release and on the Internet. The press is not given a preview of the NCPI. 


\subsubsection{Non-published (but non-confidential) sub-aggregates are made available upon request}

In the case of the NCPI, nonconfidential compilation data are published in the official gazette and on the Internet.

\subsection{Metadata accessibility}

\subsubsection{Documentation on concepts, scope, classifications, basis of recording, data sources and statistical techniques is available, and differences from internationally accepted standards, guidelines, or good practices are noted}

A leaflet entitled 25 Preguntas Sobre el Indice de Precios al Consumidor [25 Questions about the Consumer Price Index] describes the methodology used to construct the NCPI and facilitates ample debate on key methodological aspects. This leaflet is also published on the Internet. A methodology manual has also been prepared for the revision of the NCPI based on the findings of the $2000 \mathrm{ENIGH}$, which is expected to be completed this year. ${ }^{5}$

As regards the methodology employed to calculate the NCPI, data sources, and statistical techniques, the BM basically conforms to internationally accepted standards, guidelines, or good practices. However, the last revision of the NCPI was carried out in 1994, before dissemination of some of the current internationally accepted standards. That is why no reference is made in the official documentation of the NCPI to discrepancies vis-à-vis these standards, such as the fact that the COICOP is not used to classify goods and services.

SDDS statistical methodologies and other related metadata are routinely updated and revised.

\subsubsection{The degree of detail is adapted to the needs of users, to ensure their satisfaction}

The leaflet 25 Preguntas Sobre el Indice de Precios al Consumidor published in August 1995 contains information written for the general public. The BM has not yet published any official document with more detailed information on the methodology employed for the index. Nor has the leaflet been updated.

\footnotetext{
${ }^{5}$ After the visit of the mission, the BM updated the base period for the NCPI. The index is now compiled with the second half of June 2002 as the price reference period. It uses new expenditure weights from the year 2000, aligned to the second half of June 2002 for relative price changes. The BM also published, on the web page http://www.banxico.org.mx/inpc/, a new Guía sobre el Indice Nacional de Precios al Consumidor [National Consumer Price Index Guide].
} 


\subsection{Assistance to users}

\subsubsection{Contact person for each subject field is publicized}

The press release published in the official gazette mentions the name of the Director of the DPSP and the BM's Office of the Assistant Manager of Prices as a source of information on the index. The BM also has a special office responsible for providing quick and reliable service to index users who have questions regarding it or who need leaflets or further information. Staff of the Directorate of Prices, Wages, and Productivity report that telephone inquiries have become much less frequent now that the information is available on the Internet.

Periodic surveys of NCPI users' needs have not been conducted.

5.3.2 Catalogs of publications, documents and other services, including information on their cost, are easily obtainable

No catalog of publications, documents, and leaflets on the NCPI has been prepared. 


\section{Producer Price Index}

\section{Prerequisites of Quality}

\section{$0.1 \quad$ Legal and institutional environment}

\subsubsection{The responsibility for collecting, compiling and disseminating statistics is clearly assigned}

For the National Producer Price Index (NPPI) there is no legal framework under which the tasks of collecting, compiling, and disseminating the index are assigned to an institution. However, Bank of Mexico's by-laws, published in the official gazette (DOF), indicate that the Bank's Directorate of Prices, Wages, and Productivity (DPSP), shall be empowered to gather, process, and disseminate statistics on price indices, wages, labor market trends, and productivity. There are also provisions, such as Art. 58, Part II, of the Law on Public Works and Related Services, published in the DOF, indicating that percentage increases or decreases in the prices of construction materials applicable to cost adjustments shall be calculated pursuant to the producer price indices with services published by Bank of Mexico (BM).

The laws do not establish guidelines on the minimum characteristics that the DPSP should observe in compiling the NPPI, as they do for the National Consumer Price Index (NCPI). Nevertheless, there has always been a constant effort to improve the quality of the components used in the calculation.

The BM conducts the whole process of compiling and disseminating the NPPI calculations, thereby guaranteeing consistency in methods and outcomes.

\subsubsection{Data sharing and coordination among data producing agencies are adequate}

The only data that are not price data collected directly by personnel working for Bank of Mexico are those referring to weights, which are obtained from the National Institute of Statistics, Geography, and Information Technology (INEGI) and correspond to published statistics. Staff at the Institute are contacted to clear up any doubts about definitions and/or coverage.

The BM also holds periodic meetings and workshops with other statistics-producing entities both in and outside the government in order to foster a clear understanding of the BM's work in respect of the NCPI.

\subsubsection{Respondents' data are to be kept confidential and used for statistical purposes only}

Art. 24, VIII of the BM Manual General Conditions of Employment explicitly underscores the importance of integrity in the Bank's officers and the confidential nature of the BM data. It also points out that breaches of the Bank's confidentiality rules may lead to dismissal of the officer concerned. In addition to the BM's internal rules and sanctions with regard to the 
confidential nature of the data gathered by the Bank, other rules are established by the Federal Law on the Administrative Responsibilities of Civil Servants.

For price surveys, respondents are given a note explaining the BM policy regarding confidentiality and that the data they provide are used only for statistical purposes. Moreover, the BM does not publish data in such a way that its respondents can be identified indirectly. However, government enterprises or sole producers of a good or services are requested in writing for permission to publish average changes in their prices, whereby the Bank undertakes not to disseminate actual prices.

The BM has taken steps to ensure that its installations are secure and its computerized data protected from unauthorized access. In addition to institutional security measures, each computer has its own security.

\subsubsection{Statistical reporting is ensured through legal mandate and/or measures to encourage response}

Since the BM is an autonomous agency of the government, the Law on Statistical and Geographical Information, which provides the legal underpinning for provision of data to the government for statistical purposes, does not apply to the Bank. That means that there have been cases of major enterprises not cooperating in providing important data for preparation of the NPPI. Nevertheless, in most cases the BM has been able to elicit the required data because it has sought and encouraged voluntary participation by NCPI respondents by explaining the purpose of the indicator and underscoring the confidential nature of data inputs.

Price surveyors always try to find the least invasive and most efficient way to collect data. Normally, an effort is made to designate an employee as a contact who can help provide the data. In any case, the surveyors are trained during regular meetings on ways in which to encourage respondents to collaborate by attempting to convey a sense of good faith.

\section{$0.2 \quad$ Resources}

\subsubsection{Staff, financial and computing resources are commensurate with institutional programs}

The staff assigned to preparation of the NPPI is both qualitatively and quantitatively sufficient to produce an index that meets national needs and international standards. The team responsible for this task consists of 15 persons at the head office, including directors (some of whom are shared with the NCPI), five data processors (shared with the NCPI), and approximately 83 price surveyors (23 of whom work only on the NPPI and 60 shared with the NCPI in the smaller urban areas), who help gather information on the agricultural and livestock sector, forestry, fisheries, and construction. 
Every year, formal in-house training in NPPI methodology is provided for all price surveyors, while head office staff receive more frequent courses. Some staff members have also attended training courses abroad.

Sufficient incentives are in place to retain trained personnel, especially core staff. Rotation of staff is most frequent among those compiling the statistics, given the nature of the post. This job is assigned to professional services staff, who are generally undergraduates when they enter the bank and, when they finish studying, have various options open to them as NPPI or NCPI supervisors, or else in other areas of the Bank, unless, as happens in some cases, they resign.

The BM's computer unit has provided institutional support and in-house experts to ensure efficient preparation of the NPPI. The data processing and index calculation system is sophisticated and computerized. Wherever possible, price data culled in the field are transmitted via e-mail to the head office of the Bank and the index is published instantaneously on the BM's website.

\subsubsection{Measures to ensure efficient use of resources are implemented}

The staff in charge of the NCPI establish guidelines, based on the ISO 9001 certification for the NPPI that the BM is currently seeking, for compiling the index and they keep abreast of the activities involved.

Although no formal accounting system has been set up in the BM that would allow the exact costs of the NPPI program to be measured, the program's directors are able to gauge them indirectly through budget management in the Directorate of Prices, Wages, and Productivity. Thus, most of the data needed to carry out precise, separate estimates of the costs of each of the various price index programs are already available. Shared resources are identifiable and not very significant.

As regards the NPPI, the BM has attempted to take advantage of state-of-the-art computer technology to process and disseminate data. Extensive use is made of the BM website to disseminate information on the NPPI, including monthly publication of the index in the press release.

\subsection{Quality awareness}

\subsubsection{Procedures have been put in place for quality awareness}

The NPPI program is totally focused on the quality standards set in view of the application for the ISO 9001 certification of the index. A quality awareness manual has been produced, which informs both the BM team and users of the goals and structure of the quality plan adopted. This plan includes installation of a quality awareness committee composed of all the staff members responsible for administering the NPPI program. This committee meets once a month to review progress in compiling the NPPI. 


\subsubsection{Procedures have been established for monitoring the quality of data collection, compilation, and dissemination}

For the NPPI a record is kept of processing errors, such as mistaken coding. Moreover, the analysis and procedures group conducts ongoing studies on how to improve the quality of the data and process them more efficiently.

An audit program has been established for the NPPI, in which personnel from the Directorate of Prices, Wages, and Productivity (DPSP) conduct field audits in accordance with a preestablished schedule. During these visits, the team verifies that the objectives of the NPPI have been understood, the instructions on how to perform the work are followed, that the work is properly organized, the prices collected are valid, and that any problems in the field are identified. As part of its mission, the team prepares a report indicating what corrective and preventive measures should be implemented.

The BM is not currently conducting user surveys to elicit comments on quality-related issues.

\subsubsection{Procedures are in place to assess the quality of statistics, to acknowledge and deal with tradeoffs within quality, and to guide planning for existing and emerging needs}

The BM periodically convenes meetings with policy-makers and other users of the data to examine existing series and establish any new data requirements. The $\mathrm{BM}$ also tries to encourage user comments on the NPPI, especially when the index is being revised.

The BM is in the process of updating the list of goods and weights used for the NPPI. For this project, comments have been invited from persons inside and outside Mexico with a view to implementing every possible improvement. Tradeoffs between quality and the resources available for drawing up the new NPPI are taken into consideration.

\section{Integrity}

\subsection{Professionalism}

\subsubsection{Statistics are compiled on an impartial basis}

Art. 8 of the Federal Law on the Administrative Responsibilities of Civil Servants specifies in considerable detail the ethical norms that civil servants are expected to abide by. Specific rules apply to professional behavior, courtesy towards those reporting and using the data, integrity, and impartiality in the hiring of personnel and in performance of assigned tasks. No influence of any kind may be exerted by third parties.

For its part, the BM has a long tradition of independence, professionalism, and impartiality in producing and disseminating official statistical series. The General Conditions of Employment manual is very explicit regarding the importance of integrity in the Bank's 
officers and states in Art. 24, VIII that a staff member in breach of the conditions of employment may be dismissed. In the BM, professional competence is a key consideration in hiring and promotion practices.

The methodology and analysis group of the Directorate of Prices, Wages, and Productivity regularly conducts scientific studies of the price indices and those studies are examined both internally and externally. In addition, staff in the Directorate keep up to date with studies on price indices and methodologies used in other countries. These activities help to maintain the Bank's reputation and to enhance the quality of the NPPI.

\subsubsection{Choices of sources and statistical techniques are informed solely by statistical considerations}

Those responsible for compiling the NPPI are completely independent in their choice of sources and statistical methods. Only statistical and budgetary considerations are taken into account.

\subsubsection{The appropriate statistical entity is entitled to comment on erroneous interpretation and misuse of statistics}

The BM considers that it would be untoward of a statistics-producing agency to comment on improper interpretations and misuse of statistics, although it is entitled to do so. However, the BM does make every effort to provide in-depth explanations of the statistics it publishes, within the restrictions imposed by the principle of confidentiality.

\subsection{Transparency}

\subsubsection{The terms and conditions under which statistics are collected, compiled, and disseminated are available to the public}

The NPPI data are published on the ninth day of each month or on the immediately preceding business day on the Internet site, which also contains the note on methodology. Although the laws stipulating ethical standards and confidentiality requirements with respect to compilation and dissemination of the index are available to the public, no reference is made to them on the BM website.

\subsubsection{Internal governmental access to statistics prior to their release is made known to the public}

For the monthly publication of NPPI findings, a press release is prepared and submitted to the Governing Board of the BM at noon on the day the index is disseminated, two hours prior to the press conference and dissemination of the NPPI on the BM website at 2 p.m. Apart from that the Government does not have access to the data prior to their dissemination to the public. 


\subsubsection{Products of statistical agencies/units are clearly identified as such}

All the BM publications bear the Bank's logo. In the case of joint publications, each agency's contribution is clearly labeled. Although there is no explicit requirement to acknowledge the $\mathrm{BM}$ as the source of the cited BM data, users normally do so, given the BM's reputation for statistics.

\subsubsection{Advance notice is given of major changes in methodology, source data and statistical techniques}

The BM gives advance notice of any major change of the methodology used to prepare the NPPI. It does so at least 15-30 days prior to the change and, in the case of really important changes such as revision of the index and change of base, much earlier than that via meetings with principal users and analysts in a position to comment on the proposed changes of base data and methodology.

\subsection{Ethical standards}

\subsubsection{Guidelines for staff behavior are made known to staff}

Newly hired personnel of the Bank receive an explanation of the ethical standards to govern their personal behavior, professional independence, conflicts of interests, maintenance of the BM's reputation, and the compilation of statistics. These standards are clearly set out in the General Conditions of Employment manual. Moreover, the BM has a long tradition of integrity, professional independence, and impartiality in respect of the statistical series it produces. An effort is made to maintain this tradition at every phase in the preparation of the NPPI.

\section{Methodological Soundness}

\subsection{Concepts and definitions}

2.1.1 The overall structure in terms of concepts and definitions follows international standards, guidelines or agreed practices

The overall structure of the NPPI is based on the internationally recommended concepts and definitions contained in the System of National Accounts 1993 (1993 SNA) and in the Producer Price Index Manual (currently being prepared). The index covers all economic activities, except financial services and the export processing industry. The concepts and

definitions used to determine the specific goods and services for the producer price survey follow international standards and recommendations. 


\section{$2.2 \quad$ Scope}

\subsubsection{The scope is broadly consistent with international standards, guidelines or agreed} practices

The NPPI is broad in scope, encompassing economic activities in mining, manufacturing (except the export processing industry), electricity and energy, and water resource exploitation; farming, forestry, and fishing; transport, communications, and commerce (except financial services). Also included are private final consumption services not included in the aforementioned fields. These include personal services such as hairdressing, rent paid, and imputed rentals for owner-occupied dwellings. Households' production for ownconsumption is not included. Nor are illegal goods and services, or own-account fixed capital formation, such as production of equipment and buildings or other structures. Conceptually, the value of construction of dwellings for own-use, using a construction company, is included in the construction industry weights.

No explanation is provided to the general public regarding the differences between the global coverage concepts of the national accounts and the NPPI coverage, except as regards exclusion of the financial sector.

It should be mentioned that Mexico's NPPI coverage is relatively broad, compared to the coverage typical of other countries.

\subsection{Classification/sectorization}

\subsubsection{Classification/sectorization systems used are broadly consistent with international standards, guidelines or agreed practices}

Classification of establishments and enterprises by branch of economic activity is based on the Catálogo Mexicano de Actividades Económicas-1980-CMAE-80 (Mexican Chart of Economic Activities, 1980) while products are classified according to the Catálogo Mexicano de Actividades y Productos 1994-CMAP-94 (Mexican Chart of Activities and Products, 1994). The CMAP classifies the various products within the branches specified in the CMAE-80. Although these systems are consistent within the Mexican framework, they are not compatible with internationally accepted classification systems, such as the International Standard Industrial Classification, Rev. 3-ISIC or the North American Industry Classification System (NAICS) for classifying establishments and enterprises by branch of economic activity, and the Central Product Classification (CPC) for products. The DPSP reports that it envisages adopting the NAICS as soon as it is adopted for use in the national accounts. No formal study has been carried out of the differences between the Mexican classification systems and the internationally recommended systems. A new CMAP-1999 exists. 


\subsection{Basis for recording}

\subsubsection{Market prices are used to value flows and stocks}

The NPPI is really a set of indices, rather than a single index. The weights were constructed in several stages. During the first stage, data were obtained on the production value of goods and services by category of economic activity, at the four-digit level of the CMAE-80, from 1993 national accounts publications.

In the second stage, these values were distributed to final goods (by source and use) and to intermediate goods (by use), by using the input-output table based on the 1993 national accounts. Apart from this breakdown of the value of overall output, another set of weights was constructed corresponding to net output by source. These indices are composed of final goods and intermediate goods, excluding those used as inputs (self-consumption) by the industries that produced them (this is done by sector, major divisions, divisions, branches, classes, and generic concepts of economic activities).

In the third stage, weights were estimated at the generic concepts (product) level, which is more disaggregated than the CMAP-93 four-digit breakdown. This breakdown was based, in most cases, on the findings of the economic censuses and/or industry surveys conducted by the INEGI.

Given that the economic activity level weights are based directly on published national accounts data, by definition the weights are consistent with the national accounts, except that they are expressed as percentages and not as absolute values. Moreover, all the other data are used only to disaggregate these data. This means that the weights are valued at producer market prices and that all the adjustments, imputed values, and concepts are the same as those used in the national accounts.

For the NPPI, product specifications include transaction characteristics.

\subsubsection{Recording is done on an accrual basis}

Valuation of the output of goods and services is based on accrued values.

\subsubsection{Grossing/netting procedures are broadly consistent with internationally accepted standards, guidelines, or good practices}

The weights conform to internationally accepted standards, guidelines, and practices, given the conceptual framework of the indices making up the NPPI. Conceptually, the weights are very sound. 


\section{Accuracy and reliability}

\subsection{Source data}

\subsubsection{Source data are collected from comprehensive data collection programs that take into account country-specific conditions}

The BM maintains an up-to-date register of enterprises in order to keep the sample of enterprises and establishments used in the monthly producer prices survey up to date. The register is updated using information on large and medium-sized enterprises contained in specialized private sector publications.

As explained under 2.4.1, the weights reflect full coverage and the findings of the censuses and industrial surveys are only used to disaggregate the weights. Nevertheless, economic censuses are conducted regularly, approximately every five years, while economic surveys are, in most cases, conducted on a monthly and an annual basis. The censuses are practically global in terms of coverage, and the surveys using deterministic and random sampling cover approximately 75-85 percent of the enterprises selected. In both cases the weights of enterprises that are not selected (but identified in the sampling framework) are included by imputation to the selected enterprises, which means that, in technical statistical terms, coverage is comprehensive except in respect of the enterprises that do not appear in the sample framework.

The source data obtained from the INEGI, plus the data culled from private sector sources, are appropriate for calculating sufficiently itemized NPPI weights. The most complicated part of the work required for the last change of base in 1994 was updating the input-output table for 1980 to 1993, the base year of the current index. This work was done by the BM, using data from the INEGI and other sources. ${ }^{6}$

For the NPPI prices are collected by means of monthly surveys of enterprises producing goods and services. The enterprises to be surveyed were selected by means of a combination of cut-off and random samples of products. In most cases the sample covers 85 percent or more of the value of output. At any rate, the value of total output is included in the weights.

\footnotetext{
${ }^{6}$ The 1993 input-output table used to prepare the weights of the current NPPI was obtained by Bank of Mexico by updating the 1980 input-output table. This updating was based on the data available for 1993: (1) System of National Accounts, 1993; (2) Industrial Censuses of 1993; (3) the 1989 National Survey of Household Income and Expenditure updated to 1993 ; (4) external sector statistics; (5) annual industrial surveys; and (6) various yearbooks of public and private industrial chambers and institutions.
} 
The prices of products for which prices could not be obtained are kept constant. At the product level, the enterprise samples are continuously updated by regular revision based on private sector lists of enterprises involved in production. As part of its regular monitoring of the procedures used to calculate the NPPI, the DPSP conducts ad hoc studies to identify new products and include them in the index.

\subsubsection{Source data reasonably approximate the definitions, scope, classifications, valuation and time of recording required}

Both the source data for calculating the weights and the source data collected in the monthly prices survey are consistent with and conform to the definitions, scope, classifications, valuation, and time of recording required by the NPPI conceptual framework.

\subsubsection{Source data are timely}

All the NPPI source data are timely, except for oil product prices, which, generally speaking, are only available two or three months after the month they refer to.

\subsection{Statistical techniques}

\subsubsection{Data compilation employs sound statistical techniques}

The NPPI is published every month for 71 branches of economic activity (two digits), 275 classes (four digits), and 626 generic or basic products (six digits). The weights were estimated for 626 generic products. Nevertheless, prices are collected for specific products, which have no separate weights.

For weights at the four-digit economic activity level, the data employed were those published in the national accounts for 1993. This means that accrual values were used and that product inventories were taken into account. For rents, the value used was either the rent paid by tenants or the imputed rent for owner-occupied dwellings.

The Laspeyres formula is used to calculate the index. Long-term price relatives are calculated between the current period and the base period, for each individual product. Then, long-term price relatives are calculated for generic products, based on the arithmetic mean of the longterm relatives for specific products. Links for new specific products are made at the specific product level.

The last change in the NPPI base was made in 1994, using 1993 data. The new series were spliced with the historical series of the previous index.

Prices for temporarily missing products are handled by maintaining the last available price. New specific products are used to substitute those that are, permanently, no longer available on the market. New products are included in the NPPI, based on regular studies of their market shares. 


\subsubsection{Other statistical procedures (e.g., data adjustments and transformations, and statistical analysis) employ sound statistical techniques}

The NPPI covers an extensive portion of the Mexican economy. It covers all final demand, except for financial services, the export processing industry, and the informal and/or illegal sector.

The NCPI and the implicit national accounts deflator are available to facilitate comparisons between the different measures of inflation. The BM conducts studies on a regular basis to explain discrepancies between these indicators.

\subsection{Assessment and validation of source data}

3.3.1 Source data-including censuses, sample surveys and administrative records-are routinely assessed, e.g., for coverage, sample error, response error and non-sampling error; the results of the assessments are monitored and made available to guide planning

Most of the source data for the current NPPI weights were obtained from the national accounts and censuses and industry surveys for 1993 conducted by the INEGI. By definition, the industry surveys cover all identifiable enterprises. Most industry surveys employ deterministic (cut-off) samples. Some surveys use systematic random sampling methods. In those cases, no extensive studies of sampling errors are conducted. However, for all censuses and all surveys assessments are made of non-sampling errors, especially failure to respond, and samples are adjusted accordingly. Moreover, all censuses and all surveys are checked for atypical values and an effort is made to either correct or validate such values.

Most of the NPPI weights are based on four-digit economic activity output figures published in the System of National Accounts, 1993. To disaggregate these weights, data were taken from the industry surveys and censuses carried out by the INEGI, 1989 ENIGH findings updated to 1993, external sector statistics, and various yearbooks of public and private sector industrial chambers and institutions. The process of calculating NPPI weights included validation of all these data for consistency over time, consistency of related data taken from different sources, definitions, valuation, recording times, and classification.

\subsection{Assessment and validation of intermediate and final output data}

\subsubsection{Main intermediate data are validated against other data where applicable}

Each component of the NPPI is regularly compared with the corresponding NCPI data and other data, such as farm prices published by the Ministry of Agriculture. 


\subsubsection{Statistical discrepancies in the intermediate data are assessed and investigated}

Every month all the prices collected for the NPPI are checked. Atypical variations are investigated, and corrected or validated. The causes and effects of such atypical variations are analyzed in the monthly bulletin.

\subsubsection{Statistical discrepancies and other indicators of potential problems with other output data are investigated}

The causes of errors detected in collection or processing of data for the NPPI are investigated on a regular basis. An independent internal audit of price data collection has also been instituted on a regular basis. As a result of it, changes have been made in the methods used for collecting and processing data for the index.

\subsection{Revision studies}

\subsubsection{Studies and analyses of revisions are carried out routinely and used to inform statistical processes}

The NPPI is published with and without the petroleum sector. Since definitive oil price data are available with a two-to-three month time lag, preliminary indices are published for the NPPI, with a note to the effect that the series are preliminary. The series with the definitive prices included are published every month as soon as the prices are available. However, there is no indication of which monthly indices are definitive and which preliminary. As a result, the series without petroleum are final and those including it are preliminary.

\section{Serviceability}

\subsection{Relevance}

\subsubsection{The relevance and practical utility of the statistics in meeting users' needs are regularly assessed}

There is a quarterly meeting with analysts from the press, government, and academic circles that use the NPPI. This meeting coincides with publication of the quarterly report on inflation. There are also periodic consultations with policy departments and user advisory groups, which include representatives of the private sector and academics. These meetings are held more frequently during periods, such as the present one, of a change in the base of the index.

The BM does not currently conduct surveys to ascertain whether the program meets users' needs.

Officers in the Directorate of Prices, Wages, and Productivity occasionally participate in international statistical meetings and seminars on price indices. 


\subsection{Timeliness and periodicity}

\subsubsection{Timeliness follows dissemination standards}

The NPPI is published within nine calendar days of the end of the month it refers to, in accordance with SDDS dissemination standards.

\subsubsection{Periodicity follows dissemination standards}

The periodicity of the NPPI is monthly, in line with SDDS dissemination standards.

\subsection{Consistency}

4.3.1 Statistics are internally consistent within the dataset (e.g., accounting identities are observed)

NPPI index totals are the same, regardless of the type of aggregation used.

\subsubsection{Statistics are consistent or reconcilable over a reasonable period of time}

NPPI historical series, in more or less their current format, are available on the website with data from 1981, in the case of goods, and from 1994 for services.

The indices that make up the NPPI are constructed using several different definitions. For example, for final demand indices, weights corresponding to final demand are employed, while net output weights are used for the indices by economic activity. Given the different definitions employed, the indices do not coincide. Nevertheless, tests have been carried out to validate the results, using final demand weights for all levels of aggregation and the results are the same.

The BM's policy is not to publish NPPI series with retrospective adjustments reflecting updates in the list of goods and services and their weights and methodological changes based on revisions of the index. During revision of the NPPI, links are established between major series to ensure that they remain historically comparable.

Whenever erratic changes in the monthly time series occur, they are explained by the effect of the components of the index on the change in the index.

\subsubsection{Statistics are consistent or reconcilable with those obtained from other data sources or statistical frameworks}

The monthly NPPI indices are routinely compared with the corresponding NCPI indices to detect any possible errors. 


\subsection{Revision policy and practice}

\subsubsection{Revisions follow a regular, well-established and transparent schedule}

Revisions of the NPPI are only carried out in respect of petroleum prices that are initially preliminary. They are known to come with a time lag of several months, but, historically, that lag has not been fixed. Normally, it is two-to-three months. The BM's policy is to include the definitive prices as soon as they become available in the monthly dissemination of the index.

\subsubsection{Preliminary data are clearly identified}

Since definitive oil price data are routinely available with a certain lag, preliminary indices are published for the NPPI, with a note in the monthly bulletin to the effect that the series are preliminary. However, there is no indication of which monthly indices are final and which preliminary. This means that it is impossible to tell up to what month the indices are final without comparing the series published in the current month with the series disseminated in preceding months.

\subsubsection{Studies and analyses of revisions are made public (see section 3.5.1)}

Apart from the series including petroleum prices, there are no revisions of the NPPI.

\section{Accessibility}

\subsection{Data accessibility}

\subsubsection{Statistics are presented in a way that facilitates proper interpretation and meaningful comparison (layout and clarity of text, tables and charts)}

The set of indices making up the NPPI is published every month. The monthly press release contains a summary of the NPPI indices by use and by source (economic activity), a few tables and charts, and a brief analysis of the components for which there were significant price changes during that month. This release is also published on the website, along with the historical disaggregated series of the NPPI system. The BM also produces quarterly and annual reports with more breakdown and analysis. In terms of layout, all the BM publications on the NPPI are professionally presented with tables and charts alongside the data to facilitate analysis.

\subsubsection{Dissemination media and formats are adequate}

While the bimonthly/monthly press releases are very short, much more extensive information on the NPPI can be found in other, quarterly and annual, publications and on the Bank's website. The BM's policy is to place all the information on the website, while printed publications are being phased out. However, the formats of the earlier printed publications are being preserved on the Internet, to facilitate access for users needing them. 


\subsubsection{Statistics are released on a pre-announced schedule}

The price indices are released in accordance with a precise pre-announced schedule, which is published each quarter. The NPPI is published within the first nine calendar days of the month following the month to which the data refer.

\subsubsection{Statistics are made available to all users at the same time}

On the official publication date, the NPPI is disseminated simultaneously to all users via a press release and on the Internet. The press is not given a preview of the NPPI.

\subsubsection{Non-published (but non-confidential) sub aggregates are made available upon request}

In the case of the NPPI, non-confidential itemized data are published on the website. In addition, compilation level data can be obtained if an interested party requests them, provided that the data refer to average prices or scope of the samples and the confidentiality of the information is respected.

\subsection{Metadata accessibility}

5.2.1 Documentation on concepts, scope, classifications, basis of recording, data sources and statistical techniques is available, and differences from internationally accepted standards, guidelines, or good practices are noted

Published on the BM's website is a document entitled Metodología de Cálculo del Índice Nacional de Precios Productor-INPP [Methodology used to calculate the National Producer Price Index-NPPI], which describes the structure of the NPPI indices system, its scope, the weight calculation concepts, the methodology employed to collect producer prices, the estimation formulae employed, the composition of the weights, and the classification system used.

The SDDS statistical methodologies and other related metadata are routinely updated and revised.

\subsubsection{The degree of detail is adapted to the needs of users, to ensure their satisfaction}

The document on NPPI methodology and calculation published on the website provides users with explanations of the concepts and composition of the index. The same site also contains itemized NPPI data. 


\subsection{Assistance to users}

\subsubsection{Contact person for each subject field is publicized}

The press release published in the official gazette mentions the name of the Director of the DPSP but does not indicate an address (telephone number, fax number, e-mail, postal address) where information on the index can be obtained. However, the BM has a special office responsible for providing quick and reliable service to index users who have questions regarding it or who need leaflets or further information. Staff of the Directorate of Prices, Wages, and Productivity report that telephone inquiries have become much less frequent now that the information is available on the Internet.

Periodic surveys of NPPI users' needs have not been conducted.

5.3.2 Catalogs of publications, documents and other services, including information on any changes, are widely available

No catalog of publications, documents, and leaflets on the NPPI has been prepared. 


\section{Balance of Payments}

\section{Prerequisites of Quality}

\section{$0.1 \quad$ Legal and institutional environment}

\subsubsection{The responsibility for collecting, compiling and disseminating statistics is clearly assigned}

The Bank of Mexico (BM) compiles, processes, and disseminates balance of payments statistics. The Bank of Mexico Law, which entered into force on April 1, 1994, does not specifically assign these functions to the BM. However, Art. 62.I of the Law indicates that the BM, in coordination with the other competent authorities, may prepare, compile, and publish economic and financial statistics, as well as operate information systems based on these statistics, and collect the necessary data for these purposes. In addition, Presidential Decree of December 31, 1952, amending Art. 12 of the text of Mexico's agreement to join the International Monetary Fund (IMF), establishes that agencies of the federal government, local governments, municipalities, private businesses and individuals are required to provide the BM with any data or information it may request in compliance with the above-referenced agreement. The Decree establishes sanctions for submitting incomplete or inaccurate data or reports, but the amounts of these sanctions have not been revised.

An institutional agreement in the area of foreign direct investment guarantees ongoing consultation and information sharing. External trade data is handled by a working group on external trade statistics comprising the BM, the National Institute of Statistics, Geography, and Information Technology (INEGI), the Secretariat of Economy, and the Customs General Administration (AGA). This working group discusses the methodological and operative aspects of the information, with the BM in charge of preparing the trade balance statistics on the basis of customs information provided by AGA. The statistics compiled and published by INEGI are regulated by the Law on Statistical and Geographic Information of December 30, 1980.

\subsubsection{Data sharing and coordination among data producing agencies are adequate}

The BM has established institutional procedures and frequent contact with other public sector agencies for performing the tasks of data compilation, validation, reconciliation, and dissemination.

The BM has established operational mechanisms to obtain information on components of the balance of payments from public and private sector entities. The AGA provides monthly information on imports and exports electronically; the Secretariat of the Interior provides monthly information on the number of international tourists; and the Directorate General of Public Credit of the Secretariat of Finance and Public Credit (SHCP) provides information on public external debt. In addition, the BM obtains information on services directly from 
surveys and specific questionnaires addressed to the private sector. Information on foreign direct investment in the country is obtained in coordination with the Secretariat of Economy.

Suitable mechanisms have also been put in place for obtaining data from other departments or areas of the BM, such as the Directorate of Market Analysis and Assessment, and Directorate of Macroeconomic Analysis.

The BM holds periodic meetings with various public sector agencies, such as the Secretariat of the Interior and Secretariat of Tourism, for the purpose of coordinating information requirements on travel and avoiding the duplication of efforts. There are also regular meetings with the SHCP to coordinate the information required on foreign public external debt and with the Secretariat of Economy to coordinate information under the Foreign Direct Investment (FDI) heading. BM staff consult in person and by telephone with the principal companies providing basic data for compiling the balance of payments in order to discuss problems and mechanisms for reporting data. In the case of statistics on international travel, the Bank of Mexico has its own system of surveys, which includes permanent survey staff in the country.

\subsubsection{Respondents' data are to be kept confidential and used for statistical purposes only}

The Bank of Mexico Law explicitly establishes that the BM is required to protect the confidentiality of the individual information provided to it by natural and legal persons. In addition, Art. 24, Section VIII of the General Conditions of Employment of the BM, establishes that "workers are required to act with discretion in discharging their duties, observing the strictest confidentiality with regard to the Bank's business. They shall refrain from disclosing in writing or orally to outsiders the events, dealings, data, analyses, studies, expert opinions, documents, and any other information known or made available to them in the course of their work at the Bank. Failure to comply with the provisions of this section shall be considered serious misconduct and shall result in termination of appointment, without the Bank incurring any liability."

The cover letter that accompanies surveys and other requests for statistical information informs companies or institutions that the information requested of them will be treated in a strictly confidential manner generally and for the purpose of compiling balance of payments statistics. The Law on Statistical and Geographical Information also establishes that data on private individuals or legal entities must not be provided or published individually, but rather as part of overall figures, except with prior authorization from the party that provided the data. For these purposes, overall figures shall be deemed to mean those that refer to three or more individuals or legal entities. Moreover, Art. 8 of the Federal Law on the Administrative Responsibilities of Civil Servants establishes in sections III and IV the duty to maintain the confidentiality of the information they handle.

In the BM, access to individual data is restricted to staff of the Office of the Deputy Manager for External Sector Analysis (SASE), who require such information for balance of payments 
compilation. Some steps have been taken in the BM, Secretariat of Economy, and SHCP to protect the information on individual companies.

\subsubsection{Statistical reporting is supported by legal mandate and/or measures implemented to encourage voluntary response}

The Presidential Decree of December 31, 1952, amending Art. 12 of the text of Mexico's agreement to join the International Monetary Fund (IMF), establishes that agencies of the federal government, local governments, municipalities, and individual businesses and persons are required to provide the BM with any data or information it may request in compliance with the above-referenced agreement. The Decree establishes economic sanctions for the submission of incomplete or inaccurate data or reports, but these sanctions have not been updated. The BM adheres to various nonformal agreements on data compilation with other public sector agencies.

The Bank of Mexico Law does not specifically assign the BM the role of compiling balance of payments statistics and the BM is not empowered by the Law to require the reporting of information by private sector companies and individuals for purposes of compiling the balance of payments statistics. Given that the BM does not have legal authority to request information from the private sector, it is likewise unable to impose sanctions on those who do not report. However, BM staff have established procedures to encourage voluntary reporting, e.g., in the letter that accompanies surveys the BM explains to respondents the importance of the information being requested of them for purposes of compiling the balance of payments and asks for their cooperation in providing the information sought in the surveys.

In some cases, the BM gathers direct information from public and private companies for purposes of compiling the balance of payments. In order to ensure adequate reporting, BM staff visit companies to provide support and give assistance over the telephone in filling out the form to those companies that request it. The survey forms include the telephone number and e-mail address of a contact person who can answer questions. The same is offered to respondents with whom there is verbal contact, in addition to providing them with the name of an expert who can guide them through the survey process.

To encourage respondents to cooperate, the BM participates, at the request of interested parties, in seminars with private sector organizations and sends statistical information to companies that provide data to the BM for balance of payments compilation purposes.

\section{$0.2 \quad$ Resources}

\subsubsection{Staff, financial and computing resources are commensurate with institutional programs}

Financial, computing, and staff resources are generally sufficient to compile the balance of payments statistics. However, greater coverage of some balance of payments components, such as the services account, will require additional staff and resources. The SASE has 
17 professionals who are responsible for compiling and preparing balance of payments statistics. This information is disseminated jointly with the media unit.

The SASE staff has adequate computing resources to compile and disseminate balance of payments statistics. Each staff member has an individual computer with Internet access and appropriate software. The information technology packages used include, in particular: the Economic Information System (SIE), developed in the BM, databases in Excel for quarterly surveys, programs that give access to foreign investment information from the Secretariat of Economy, and to the database used to generate the monetary statistics reports from the BM and the rest of the National Financial System, in addition to programming specifically designed for using the foreign trade data on CD-ROM from AGA, and monthly surveys of international travel. Information on private sector external liabilities is obtained from a survey processed in Fox Visual Basic.

The staff has sound knowledge of and familiarity with the concepts and methodology recommended in the Balance of Payments Manual, Fourth Edition (BPM4) and Fifth Edition (BPM5). Staff are properly trained in the concepts and methodologies applicable to their specialization in compiling the balance of payments. The more experienced, senior technical staff have a more comprehensive view of the balance of payments statistics. Most of the members in the SASE have many years of experience and/or have received in-country or overseas training in the balance of payments compilation methodology, particularly the IMF course on balance of payments methodology. New SASE staff members receive theoretical and practical training in data compilation methods from employees with extensive experience, and they are encouraged to participate in courses on balance of payments methodology in the BPM5. The BM promotes staff training through its participation in balance of payments courses and seminars organized by the IMF and the Center for Latin American Monetary Studies (CEMLA). SASE staff train foreigners attending seminars organized by CEMLA and/or visiting the BM in balance of payments issues.

As new staff are hired, they receive practical training in the area to which they are assigned. Technical training, which involves a broader view, is gradual, and considered a worker's right in Art. 23, Section XI, of the General Conditions of Employment of the BM. The training of new staff is geared toward data handling and processing procedures, and subsequently international statistical standards. However, the SASE retains a group of very experienced persons in balance of payments compilation.

\subsubsection{Measures to ensure efficient resource use are implemented}

Despite the fact that the SASE budget is prepared at the institutional level in the BM, the SASE is in charge of preparing the budget for the survey of tourists conducted at the border points, airports, and sea ports of entry into the country. The resources allocated to the travel survey make it possible to maintain a high level of quality in the data compiled by the survey personnel, who are continuously supervised. 
Every effort is made to use the most advanced information technology instruments available for data processing and dissemination. External experts are used only on an as-needed basis, but not to evaluate methodologies and systems.

\subsection{Quality awareness}

\subsubsection{Procedures have been put in place for quality awareness}

There are no formal quality assessment processes (external audits). However, internal procedures have been established to conduct ongoing quality assessment of surveys and verification of data collection and processing. Where feasible, information is cross checked and compared with other statistical series available in the BM on related areas. These procedures make it possible to verify the consistency of the data incorporated in the balance of payments statistics. In addition, the BM assesses on an ongoing basis the functionality of the systems for data entry, processing, and dissemination.

SASE employees participate in seminars and conferences on the balance of payments and seek to implement international standards in the country, for which they sometimes request assistance from international agencies. With a view to maintaining the quality of balance of payments data, the BM makes adjustments to the primary source data in some lines of the balance of payments.

The BM recognizes that timeliness is not consistent with accuracy and reliability. This disconnect is implicit in the dissemination of data subject to later revisions to improve its quality.

Regarding public opinion on the balance of payments statistics, it is not common practice to consult users to learn their views on the balance of payments statistics, however, any comments they may make are registered and considered. Requests and questions on BM information are handled electronically. There is an e-mail address on the BM's website to which requests or inquiries may be sent.

\section{Integrity}

\subsection{Professionalism}

\subsubsection{Statistics are compiled on an impartial basis}

Since April 1, 1994, the Constitution of the United Mexican States has granted autonomy to the BM, substantiated by the enactment of its Law on April 1, 1994.

The tradition and techniques of professionalism are encouraged, as indicated in the articles on the rights and duties of employees in Chapter IV on the General Conditions of Employment of the BM. The appointment and terms of staff in positions related to the production of balance of payments statistics obey technical criteria. SASE staff have a 
significant degree of autonomy in their work and are generally guided by international standards in compiling and processing balance of payments statistics. The assignment of tasks in the area of data compilation is based solely on technical and professional criteria.

The BM organizes conferences and seminars in the country individually and in cooperation with CEMLA and some chambers of commerce and industry. It also promotes staff training through attendance at courses organized by international institutions in the country or overseas, such as the IMF and CEMLA. In addition, the BM finances postgraduate courses for its employees (specialization, masters, doctorate), and pays the cost for its staff to attend training courses in the country or overseas. SASE selects the staff to work in the balance of payments area and the BM's personnel management office conducts the hiring process.

Fairly frequently, SASE staff attend national forums at the request of organizations interested in learning about preparing balance of payments statistics. SASE has also accepted invitations to international forums where experiences are shared with other countries. The documents produced by SASE refer to the clarification and explanation of concepts and methodologies for internal use by the BM.

\subsubsection{Choices of sources and statistical techniques are informed solely by statistical considerations}

SASE staff chooses the source data and statistical methodologies used in compiling the balance of payments based on statistical considerations only and on evaluation of the timeliness and quality of alternative sources. The surveys are selected and designed solely on the basis of statistical considerations, taking into account international methodological standards and sound quantitative methods. The criteria for introducing new surveys are based exclusively on improving the quality of information available and broadening of the coverage of Mexico's balance of payments.

Important methodological changes are disseminated in the quarterly press releases on the balance of payments. The BM is the only entity that publishes balance of payments statistics and the Data Template on International Reserves and Foreign Currency Liquidity. Once the $\mathrm{BM}$ has published these statistics, balance of payments information is also input into the database on economic variables that is accessible to the public at INEGI, citing the BM as the data source. The BM presents reports and analyses of balance of payments statistics with objectivity and independence. The SHCP disseminates balance of trade data on a monthly basis and public external debt statistics. For its part, the Secretariat of Economy is responsible for dissemination of foreign direct investment statistics.

\subsubsection{The appropriate statistical entity is entitled to comment on errors of interpretation and misuse of statistics}

If an incorrect interpretation is detected regarding the published balance of payments statistical statements in general, or in a particular item, efforts are made to contact the person or organization having interpreted the data to explain that interpretation. 
In addition to real time electronic media, the balance of payments is disseminated in the Annual Report of the BM and in quarterly and sufficiently extensive press releases, which provide guidelines to the user for interpreting the figures. The Economic Indicators section published on the BM website includes quarterly balance of payments data but not explanatory notes. However, the press releases that accompany the quarterly publication of the balance of payments include these explanatory notes. The BM holds press conferences to disseminate the reports on inflation, in which it analyzes general developments in the economy, including balance of payments data.

\subsection{Transparency}

\subsubsection{The terms and conditions under which statistics are collected, compiled, and disseminated are available to the public}

The terms and conditions under which statistics are compiled and disseminated are usually made available to reporting entities but not to the public. The metadata providing that information are found only on the Mexico pages of the SDDS website. The Bank of Mexico Law is published on the BM website. However, the name of the contact person for additional information on the balance of payments statistics published by the BM is only available on Mexico's SDDS webpage. The BM website gives the e-mail address of a person who can answer questions. This person refers requests for information to the relevant area. The Statistical and Geographic Information Law is published on the INEGI website.

\subsubsection{Internal governmental access to statistics prior to their release is made known to the public}

No one has access to the information before release. The Board of Governors of the BM (the highest level of authority of the institution) has knowledge of the information moments before its release. This prior access to the information by the Board is not publicly known.

The federal government and other public entities do not know the statistics until they are announced to the general public, except for the agencies working jointly with the BM, such as the SHCP and the Secretariat of Economy. However, these institutions are only privy to the data they help to compile.

\subsubsection{Products of statistical agencies/units are clearly identified as such}

The name and logo of the BM appear on press releases concerning balance of paymentsrelated issues. The statistical tables are only disseminated on the BM's website and in its annual report. The balance of payments is not disseminated jointly with any other institution. Any official government report that includes balance of payments information always cites the BM as the data source. The SHCP disseminates the balance of trade separately and the Secretariat of Economy disseminates foreign direct investment data. 


\subsubsection{Advance notice is given of major changes in methodology, source data and statistical techniques}

Users are notified of changes in methodology or sources used to calculate the balance of payments in the quarterly press releases disseminating the data. However, modifications or changes in methodology are only announced when the amended statistics are published, but not in advance.

\subsection{Ethical standards}

\subsubsection{Policies and practices are guided by ethical standards}

There are no written ethical standards applicable to the staff involved in producing balance of payments statistics. There are ethical standards that apply to the employees of the Bank of Mexico in general, and these are set out in Chapter IV of the General Conditions of Employment of the BM. In addition, all new employees sign a letter in which they commit to safeguarding the confidentiality of the information with which they work. The General Conditions of Employment of the BM are disseminated on its internal website and made known to all new employees when they assume their positions. In addition, the reputation of the employees of the Bank of Mexico and the Bank's long-standing independence from other public entities, protect the central bank from political interference. The ethical standards of governmental agencies compiling statistics are governed by Art. 8 of the Federal Law on the Administrative Responsibilities of Civil Servants.

\section{Methodological Soundness}

\subsection{Concepts and definitions}

2.1.1 The overall structure in terms of concepts and definitions follows internationally accepted standards, guidelines, or good practices: See corresponding dataset-specific framework

The structure and classification of the balance of payments statistics are consistent with the methodological standards established in the Balance of Payments Manual, Fourth Edition (BPM4). However, the transition to BPM5 methodology is considerably advanced and the balance of payments is also disseminated using the BPM5 classification in IMF statistical publications. Some BPM5 recommendations have been implemented, such as the incorporation of goods for processing in the goods account, grouping all the income account items in a single section, and including the liabilities of the BM to the IMF in Other investment. BPM5 recommendations still to be implemented include a more detailed breakdown of services in the current account, identification of capital transfers, and separate identification of the financial transactions of foreign branches of Mexican banks, using the appropriate criterion of residence. With the adoption of the $B P M 5$, the BM will include a methodological note explaining the main variations and changes made as a result of the introduction of the BPM5. 


\subsection{Scope}

2.2.1 The scope is broadly consistent with internationally accepted standards, guidelines, or good practices: See corresponding dataset-specific framework

The balance of payments statistics include the transactions of institutional units resident in Mexico with the rest of the world. The criterion of residence is generally determined on the basis of principles established in the BPM5. However, due to limitations in the compilation process, some transactions calculated using BPM5 criteria may not be included in the statistics. In the goods account, the statistics include transactions with nonresidents by companies that manufacture goods for processing (export processing enterprises). There are no estimates for contraband, undervaluation of imports, or overvaluation of exports. The coverage of some services is limited by comparison with the breakdown proposed by the BPM5. Mexico's financial account considers the branches of Mexican banks abroad to be resident entities. Some branches are classified as residents due to the mere fact that they operate as intermediaries between their head offices and the rest of the world and conduct very little business of their own. The BM recently finished the task of breaking down the monetary statistics using the residence criterion for the operations of Mexican banks and their foreign branches, a change that will be incorporated in the coming months in the official balance of payments statistics.

\subsection{Classification/sectorization}

\subsubsection{Classification/sectorization systems used are broadly consistent with internationally accepted standards, guidelines, or good practices: See corresponding dataset-specific framework}

The balance of payments statistics are organized according to the structure and classification recommended in the BPM4. The unit of account for the balance of payments is the U.S. dollar. Following BPM4 guidelines, the balance of payments is compiled in accordance with the main standard components, which are classified in two main groups of accounts: the current account, which includes goods, factor services, nonfactor services and transfers; the capital account; and international reserves. The BM reports the balance of payments to the Fund's Statistics Department using the BPM5 classification.

In the goods account, an explicit distinction is made between general merchandise and goods for processing. Exports and imports are recorded f.o.b., except for some imports via sea ports. Repairs on goods and nonmonetary gold are included but are not classified separately. Goods procured in ports by carriers are classified in services as suggested in the BPM4. Some financial services, such as commissions and royalties, are classified as income. Furthermore, as it is practically impossible to divide transfers into current and capital transfers, they have to be recorded as current.

The capital account records the financial transactions of the government, financial, and private sectors, as well as direct investment. The Economic Indicators section published on 
the BM website includes quarterly balance of payments data in which the capital account is classified by financial instruments and by institutional sectors. The capital account is broken down into loans and deposits, direct investment, portfolio operations, and assets held abroad. Reserve assets are presented as a below-the-line item. In the capital account, the data on direct investment in the country are obtained from the quarterly reports that companies submit to the Secretariat of Economy. The data on portfolio investment is obtained from information available in the BM, the SHCP, and the National Banking and Securities Commission. Data on the external transactions of the commercial banks are obtained from the monetary accounts. The data on international reserves are obtained directly from the balance sheet accounts of the BM, denominated in U.S. dollars.

It should be noted that quarterly FDI data are delivered in a timely manner and must therefore be supplemented with information from an annual questionnaire that companies are required to submit to the Secretariat of Economy. However, from 1998 to date, the Secretariat of Economy, has not given the Bank of Mexico access to these questionnaires owing to confidentiality issues with individual company information. The Bank of Mexico and the Secretariat of Economy have been looking for a way around this restriction without success to date. This means that there are no final figures for FDI flows, which would provide better coverage, in addition to being necessary for preparing the corresponding line item in the International Investment Position statistics, since the annual questionnaires under reference are the source of information on the foreign direct investment position (stocks).

\subsection{Basis for recording}

\subsubsection{Market prices are used to value flows and stocks}

Every effort is made to ensure valuation at market prices. However, there are exceptions to this rule, mostly related to the external debt. Both public and private debt are recorded at face value, as in some cases these liabilities are traded on the secondary markets, where they are listed at a discount. Only transactions in Brady bonds are identified and adjusted, because their market price is known.

The balance of payments of Mexico is recorded in U.S. dollars, which simplifies the conversion problem, since the majority of transactions are executed and recorded in that currency. When a transaction is not recorded in U.S. dollars and the precise transaction date is known, the exchange rate on the value date is used. However, if the transaction date is not known, the average exchange rate for the period in which the transaction is known to have occurred is used as a proxy.

\subsubsection{Recording is done on accrual basis}

An effort is made to follow this criterion, with the exception of the calculation of interest on the public external debt, which is recorded on a cash basis, in other words, as each payment is made. In the case of goods, the statistics are compiled on the basis of customs information, which do not rigorously adhere to the change-of-ownership criterion. For example, goods 
that for some reason must be deposited in a customs bonded warehouse before entering the country are recorded as imports when they leave the bonded warehouse and their customs and tax status in the country are defined.

\subsubsection{Grossing/netting procedures are broadly consistent with internationally accepted standards, guidelines, or good practices}

The balance of payments is compiled on the basis of the gross figures for each current account item. In the capital account, some concepts are known only in net terms.

\section{Accuracy and reliability}

\subsection{Source data}

\subsubsection{Source data are collected from comprehensive data collection programs that take into account country-specific conditions}

The balance of payments of Mexico is combined with information that the SASE obtains from a mix of primary and secondary sources. In many cases, secondary sources are used which, in combination with the primary sources, provide adequate balance of payments coverage. It is felt that the source data used by the SASE in compiling the balance of payments are adequate. The principal sources of information used in compiling the balance of payments are:

In the case of the trade balance, the AGA provides the BM with detailed monthly information on all transactions through customs in the country. For other items as well, there is a list of special respondents that are surveyed; this list includes companies that provide services, government entities, embassies, and international cooperation agencies. The SASE believes that the data gathered from the sources is sufficiently comprehensive to ensure adequate coverage of balance of payments transactions. Notwithstanding, coverage, it is felt, can always be improved. Regarding information on foreign direct investment companies, management and updating of the directory of these companies is the responsibility of the Secretariat of Economy. Statistics on international travel are obtained by surveying a sample of tourists defined by the SASE. The methodology applied uses scientific techniques and the sample is duly stratified.

The BM has a banking supervision area and possesses detailed information on international transactions. The data on bank transactions in the balance of payments are obtained from the monetary accounts area, whose purpose is not to supervise but to integrate the statistics.

The BM uses specialized information systems (Bloomberg, Infosel), which give the details of the largest external financial operations. These sources and the financial press are used to anticipate the amounts of financial transactions reported and to verify that country's largevalue external transactions are properly covered in the customary sources. However, press monitoring is not a source of primary data. Meetings are held with financial market 
participants and the business community, not on a regular basis but in response to events which, presumably, might be captured by the compilation system only partially or not at all.

\subsubsection{Source data reasonably approximate the definitions, scope, classifications, valuation and time of recording required}

Specific procedures have been created to adjust the data from the various sources in such a way as to improve coverage, classification, and valuation. For example:

In the case of some agricultural export products, their volumes are correctly reported at customs but not their value, since the price is only known once it is agreed upon at the point of sale. In such cases, the known volume is applied to the prices observed on the destination market.

In the travel item, the survey used is designed to obtain a measure of average expenditure per person under different compilation criteria, using different concepts for tourists, excursionists, border visitors, and cruise ship passengers. The number of tourists produced by the migration authorities is applied to these data. However, at the northern border of the country, the migration authorities have no record of the number of border crossings, thus the $\mathrm{BM}$ is obliged to estimate that number from partial head counts, so as to infer the total amount using scientific procedures.

The public external debt is recorded by the SHCP. But, in cases where a liability is traded on a secondary market at a price other than face value, the corresponding adjustment is made provided that the market value is known.

\subsubsection{Source data are timely}

Source data are timely, since both in the questionnaires used and in direct contacts with the sources, deadlines are given for submitting the information. When there are delays in the submission of information, the source is contacted to request the survey. SASE staff consistently follow up on those companies that have not reported data by the deadline through telephone calls.

\subsection{Statistical techniques}

\subsubsection{Data compilation employs sound statistical techniques}

The SASE has no procedural manuals that document management, processing, and quality control for balance of payments surveys. The surveys are designed for easy completion and electronic processing. A series of measures have been established to control quality and conduct appropriate and timely verification of the information provided in the surveys, before and after their electronic processing. 
In the case of the merchandise and travel accounts, diagnostic tests are scheduled for errors and/or figures that are outside the usual trend or expected seasonal changes. The surveys are designed to facilitate completion by the respondent and for easy processing. The surveys are normally not subject to pilot tests.

\subsubsection{Other statistical procedures (e.g., data adjustments and transformations and statistical analysis) are also based on sound statistical techniques}

The coefficient used to estimate freight and insurance is derived from periodic consultation with customs officials. Border trade transactions, which are large enough to warrant declaration at customs, are included in the goods account. If such transactions are small, declaration is not required and they are compiled under the item of travel, with the probability of selection determined by the existing sampling system at the SASE. If the transactions are not selected in this system, they will then be inferred.

The SASE does not require adjustments to correct underestimation of exports because all exports are captured given that they are declared at customs, even if they are nontaxable. Only in those cases in which the data are not available in a timely manner from some basic source of the balance of payments are estimates made, which are subsequently replaced with real values as soon as they can be obtained from the source.

\subsection{Assessment and validation of source data}

\subsubsection{Source data-including censuses, sample surveys and administrative records-are} routinely assessed, e.g., for coverage, sample error, response error and non-sampling error; the results of the assessments are monitored and made available to guide planning

In international travel surveys, all the quality indicators are frequently assessed. In the case of: (a) surveys; (b) reports of respondents, and; (c) administrative records, the data source is consulted and, where necessary, the economic agent. This makes it possible to validate the amount reported in cases where unusually high or low transaction amounts are observed. In the travel survey, atypical cases are excluded in order to maintain the quality of the information and given that it is impossible to double check with the respondent.

The financial information from banks is not compiled by the SASE, since the SASE is a user of this information. The customs figures used as the basis for external trade statistics are routinely assessed to determine any unusual transactions reported. When these are detected, the customs office is contacted and, where necessary, the company involved as well, to ensure that the data reported by the company and the customs office match.

The data sources that do not strictly meet balance of payments criteria are adjusted, as appropriate, to meet methodological criteria. For example, the public debt data source records Brady bond amortization at the time when the bonds are formally cancelled with the 
U.S. Treasury, but amortization is recorded in the balance of payments during the period in which the Mexican government acquires the bonds from foreign debt holders.

There are cases in which the data received from respondents differs considerably from the usual figures during a given period. In these cases, attempts are made to contact the source of the primary data for confirmation. In cases where it is impossible to contact the source in a timely manner, a statistical adjustment is made to adjust the trend to the historical behavior of the series. The series are later revised.

\subsection{Assessment and validation of intermediate and final output data}

\subsubsection{Main intermediate data are validated against other data where applicable}

Regarding the goods account, automobile exports registered by customs are cross checked with those reported by companies in the national bulletin of the Mexican Automobile Industry Association. In the capital account, information published in the media and in some specialized information systems (Bloomberg and Infosel) is used to corroborate and/or flag major FDI and external debt transactions.

Information on nonbank private sector external debt incorporated in the balance of payments comes from a survey of external creditors managed by another area of the BM. The balance of payments area also conducts a survey of indebted enterprises that has not been used in the balance of payments statistics because its coverage is less extensive, though it has been useful for cross checking data and assessing quality.

\subsubsection{Statistical discrepancies in the intermediate data are assessed and investigated}

Resources permitting, statistical discrepancies in the intermediate data are assessed and investigated. For example, in the case of public external debt, data on stocks, flows, and interest come from the same data source and checks are made to ensure that the implicit interest rate on the public external debt is consistent with the level and trend in the international reference rates. Regarding private debt, only balances are available, so interest amounts are estimated using a combination of interest rates and spreads taken from the survey of debtor enterprises. The data recorded by the immigration authorities are one of the inputs used in the production of statistics and do not require cross checking.

\subsubsection{Statistical discrepancies and other indicators of potential problems with other output data are investigated}

The size and sign of the errors and omissions heading is monitored and often used as an indicator of the type of deficiencies in the statistics. Trends in the major balance of payments accounts are monitored using statistical methods.

The trade balance is reconciled on a bilateral basis with the figures for merchandise trade with the United States and Canada. The sources of some discrepancies have been identified 
for the United States, caused by weaknesses in the systems of both countries. In the Mexican case, the main source of discrepancies in trade with the United States is being corrected. ${ }^{7}$

\subsection{Revision studies}

\subsubsection{Studies and analyses of revisions are carried out routinely and used to improve statistical processes (see Section 4.4.3)}

The direction and size of the revisions between the preliminary and final data are examined. The size and sign of the errors and omissions heading provide the frame of reference for investigations into the deficiencies in balance of payments statistics. In the case of major revisions by sources, the latter are consulted on the reason for the revision.

\section{Serviceability}

\subsection{Relevance}

\subsubsection{The relevance and practical utility of the statistics in meeting users' needs are regularly assessed}

There is no formal process of consultation regarding users' needs. In practice, many requests for information are received; these are handled primarily through e-mail and serve as an indicator of the users' information requirements. SASE staff members regularly participate in statistical meetings and seminars organized by the IMF, CEMLA, and business organizations in the country.

\subsection{Timeliness and periodicity}

\subsubsection{Timeliness follows dissemination standards}

The timeliness of the foreign trade, balance of payments, and international reserves statistics is consistent with the SDDS. The foreign trade statistics are disseminated 23 calendar days after the reference month. The quarterly balance of payments data are disseminated within two months after the reference quarter. The annual balance of payments data are disseminated within two months of the close of the reference period. Weekly international reserves are published two days after the reference week. The data template on international reserves and foreign currency liquidity is released 30 days after the reference month.

\footnotetext{
${ }^{7}$ This discrepancy is due to entering the wrong country on the customs declaration.
} 


\subsubsection{Periodicity follows dissemination standards}

The periodicity of the data is consistent with the Special Data Dissemination Standards (SDDS) and the data are published on the BM website. Foreign trade statistics are published monthly. Balance of payments data are released quarterly. International reserves are disseminated weekly and calculated daily. The data template on international reserves and foreign currency liquidity is prepared and distributed monthly exclusively via the BM website.

\subsection{Consistency}

4.3.1 Statistics are internally consistent within the dataset (e.g., accounting identities are observed)

Flows of errors and omissions are variable with a tendency toward a prevalence of positive flows in recent years.

The balance of payments time series from 1979-2001 have been reclassified in accordance with the structure of the BPM5, which is disseminated in Fund publications International Financial Statistics (IFS) and in Balance of Payments Statistics Yearbook (BOPSY).

\subsubsection{Statistics are consistent or reconcilable over a reasonable period of time}

Balance of payments dissemination formats were started in 1980 and, when changes are made in the source data, the time series are reconstructed if there is enough information to make the estimates. When major methodological changes are made, they are indicated in the external sector section of the Annual Report of the Bank of Mexico. No detailed methodological notes are made. In the quarterly press release incorporating an analytical text on the balance of payments, atypical fluctuations in the figures are noted and explained, where possible, and any methodological changes made over the period are also mentioned.

The annual balance of payments statistics are consistent with the quarterly statistics. The BM continuously revises methodology, procedures, and output in order to ensure the internal consistency of the statistics.

\subsubsection{Statistics are consistent or reconcilable with those obtained from other data sources or statistical frameworks}

The balance of payments statistics can be reconciled with the national accounts, monetary and government finance statistics. Differences are identified and explained. The BM works jointly in different working groups to reconcile balance of payments figures with those of other statistics-producing agencies, such as INEGI, SHCP, and the Secretariat of Economy, and with some internal areas of the BM. 
The balance of payments statistics are largely compatible with the national accounts statistics as the SNA external account is compiled on the basis of balance of payments current account data. The asset and liability items of commercial and development banks, as well as those of the Bank of Mexico, are compiled on the basis of money and banking statistics, hence their compatibility with the monetary and financial statistics. The public external debt data produced by the Secretariat of Finance and Public Credit contain beginning and ending balances, resource allocation, amortization, foreign exchange adjustments, and coverage adjustments. Therefore, this concept is fully compatible with the balances and flows recorded in the balance of payments. Data produced on private debt are only available as end-ofmonth balances (commercial banks) and end-of-quarter balances (nonbank sector), consequently the balance of payments flows are differences in stocks.

The international investment position is not currently calculated, therefore there is no reconciliation with balance of payments flows. Work on obtaining such statistics is in progress and the Bank of Mexico hopes to complete it during $2002 .^{8}$

\subsection{Revision policy and practice}

\subsubsection{Revisions follow a regular, well-established and transparent schedule}

There is no formal revisions policy, but revisions are carried out on predictable dates and are linked with the quarterly balance of payments dissemination dates. It should be noted that revisions are part of a normal statistical process of incorporating additional information, as it becomes available, which is reflected in the fact that so many corrections are made whenever necessary. Whenever a revision is made, it is reported in the press releases in which the information is published.

Timely monthly and revised figures on merchandise trade are produced and disseminated 23 and 40 calendar days, respectively, after the reference date. The release calendar is made public in INEGI's brochure and on its website. The balance of payments is disseminated quarterly and the corresponding press release publishes the revised figures for the previous periods.

\subsubsection{Preliminary data are clearly identified}

Preliminary data are clearly identified.

\footnotetext{
${ }^{8}$ After the visit of the mission, the BM compiled and disseminated the international investment position.
} 


\subsubsection{Studies and analyses of revisions are made public (see Section 3.5.1)}

The factors contributing to preliminary figure discrepancies are explained to the BM authorities. These changes are later published in press releases and in the Annual Report. However, they are not included in the databases. No formal procedure has been established for disseminating studies and analyses of revisions.

\section{Accessibility}

\subsection{Data accessibility}

\subsubsection{Statistics are presented in a way that facilitates proper interpretation and meaningful} comparison (layout and clarity of text, tables and charts)

The quarterly balance of payments statistics disseminated on the BM website follow the structure and classification recommended in the BPM4.

In the releases on merchandise trade and those corresponding to the balance of payments, graphs and tables are added as deemed useful. Furthermore, in the two balance of payments formats, additional details on the current account, merchandise trade, and international travel are presented. In the press releases a brief analysis is made of the trends and salient points of the main items. The BM reports the balance of payments to the Fund's Statistics Department in accordance with the standard components of the BPM5.

\subsubsection{Dissemination media and formats are adequate}

The formats used for disseminating the balance of payments statistics, like the rest of the BM's statistics, are suitable for electronic dissemination via the Internet. The only printed publication available to the public with balance of payments statistics is the Annual Report of the Bank of Mexico.

The data are disseminated in a press release, which highlights the most salient aspects of the statistics covering the most recent period. This release is sent to the principal media outlets in the country and, at the same time, is posted on the BM's website. The statistical tables are also posted on the BM's website when the press release is issued. Users can consult the publication on external sector indicators on the website. In this section, the balance of payments is published in greater detail, in particular the merchandise trade statistics. The balance of payments time series may be consulted on the BM's website. 


\subsubsection{Statistics are released on a pre-announced schedule}

In the case of the balance of payments, the dissemination date is announced over the Internet the week before. ${ }^{9}$

\subsubsection{Statistics are made available to all users at the same time}

The figures are made available to all interested parties at the same time via the Internet and the principal media in the country.

\subsubsection{Non-published (but non-confidential) subaggregates are made available upon request}

Additional details are provided upon request, respecting the confidentiality criteria laid down in the Statistics Law. The terms for requesting balance of payments data according to users' needs are not specified.

\subsection{Metadata accessibility}

5.2.1 Documentation on concepts, scope, classifications, basis of recording, data sources and statistical techniques is available, and differences from internationally accepted standards, guidelines, or good practices are noted

No additional metadata other than the SDDS are published.

\subsubsection{The degree of detail is adapted to the needs of users, to ensure their satisfaction}

The BM has not prepared general information sheets for users on balance of payments and other external sector statistics as such information is available on the BM's webpage.

\subsection{Assistance to users}

\subsubsection{Contact person for each subject field is publicized}

Support and advisory assistance is provided to users that so request by e-mail from the BM. However, such support is not advertised in any of the available media. Balance of payments contact information can be found on the Mexico balance of payments SDDS website. However, the Bank of Mexico website makes available to all users the e-mail address of a deputy governor who can be consulted and/or asked about the activities of the Bank or the

\footnotetext{
${ }^{9}$ After the visit of the mission, the BM included in the advance release calendar posted on the website the dissemination dates for the balance of payments statistics information and press releases for the current calendar year.
} 
statistics it produces. The BM follows up with users of its data until they are satisfied with its answers.

5.3.2 Catalogs of publications, documents and other services, including information on their cost, are easily obtainable

There is a catalog of publications, documents and other services to users, which is updated yearly and includes the prices of services. 


\section{Government Finance}

\section{$0 \quad$ Prerequisites of quality}

\subsection{Legal and institutional environment-The environment is supportive of statistics}

\subsubsection{The responsibility for collecting, processing, and disseminating statistics is clearly specified}

Government finance statistics (GFS) on the central government, general government, and other levels of public sector aggregation are compiled and disseminated by the Secretariat of Finance and Public Credit (SHCP), in accordance with the terms and conditions established in the following laws and regulations and their amendments: (a) the Organic Law of the Federal Public Administration, dated December 29, 1976; (b) the Statistical and Geographical Information Law dated December 30, 1980; (c) the General Law on Public Debt, dated December 31, 1976; and (d) the SHCP By-laws dated January 17, 1989.

Art. 31 of the Organic Law of the Federal Public Administration states that the SHCP is responsible for coordinating and developing national statistics and geographical information offices, establishing rules and procedures for the organization, functioning, and coordination of the national statistics and geographical information systems, as well as for regulating and coordinating the information technology units of the offices and agencies of the federal public administration. Art. 7 of the Statistical and Geographical Information Law assigns to the National Statistics Service the task of providing statistics for monitoring economic, demographic, and social developments of national interest, and Art. 30 of the same Law assigns to the SHCP the task of publishing statistics compiled by the units of the National Statistics Service. Art. 5 of the General Law on Public Debt empowers the SHCP to maintain a register of federal public sector debt, and Art. 27 of the same Law assigns to the SHCP the task of periodically disseminating public debt data.

Finally, Art. 16 of the SHCP By-laws states that the General Directorate of Fiscal Planning is responsible for designing and integrating the economic, financial, and fiscal information collected by the SHCP's information systems, incorporating information on the principal financial and fiscal variables of the federal government and the parastatal public administration, with a view to providing elements to support decision making by the fiscal authorities. The General Directorate of Fiscal Planning is also made responsible for designing and integrating fiscal information from states and municipalities and for coordinating the dissemination of fiscal information within the SHCP, in collaboration with the Media Unit. Art. 18 of the same By-laws assigns to the Office of the Deputy DirectorGeneral of Public Debt the task of centralizing public debt statistics, while Art. 38 of the Bylaws makes the Revenue Policy Unit responsible for maintaining a fiscal economic statistics system. Finally, Art. 100 of the By-laws assigns to the National Institute of Statistics, Geography, and Information Technology (INEGI) the task, inter alia, of providing the public service of disseminating statistical information. It is noteworthy that the SHCP has the power, but not the obligation, to disseminate GFS to the public. GFS are disseminated as a 
service to the public, except in the case of the public debt statistics, the publication of which is a legal obligation.

The task of compiling GFS on the central government, general government, and other levels of public sector aggregation is assigned to two SHCP departments: (a) the Government Finance Statistics Department (DEH) of the General Directorate of Fiscal Planning, and (b) the Debt Statistics Department of the General Directorate of Public Credit. The DEH compiles the GFS on operations of the central government and other levels of public sector aggregation (except general government), consolidates the GFS on general government operations, and disseminates all GFS (including public debt), while the Debt Statistics Department compiles statistics on central government and public sector debt. It should be noted that both the Bank of Mexico (BM) and the INEGI disseminate in their publications GFS compiled by the DEH. Lastly, the INEGI is responsible for compiling and disseminating GFS on the operations of state and local governments.

\subsubsection{Data sharing and coordination among data producing agencies are adequate}

The DEH maintains close communications and information flows with the SHCP departments responsible for compiling statistics related to government finance and with the departments that manage accounting or financial resources operation centers. In addition, collaboration and information sharing with the INEGI and the BM are adequate; in particular, there is close coordination with the BM on financing figures, which are reconciled monthly. Collaboration is close with the departments and units mentioned above, therefore, in addition to the pertinent laws and regulations, informal arrangements have been established to streamline coordination and information sharing.

The Law on Revenue and the Decree Approving the Expenditure Budget of the Federation for each financial year point out the obligation of the Executive Branch to submit to the Congress of the Union, through the SHCP, reports on the economy, government finance, and public debt, 35 days after the end of each quarter, together with revenue and public debt statistics, 35 days after the end of each month. The statistics included in such reports are compiled by the DEH and the Debt Statistics Department and are consistent with the monthly and quarterly GFS disseminated by the SHCP. A similar situation obtains with the GFS disseminated by the BM and the INEGI. Furthermore, INEGI uses the basic information in the subannual GFS to compile timely statistics for the national accounts.

In addition, the SHCP's Unit of Public Accounting and Management Reports compiles and forwards annually to the Congress of the Union, the Federal Government Finance Account (Public Account). The figures in the Public Account are consistent with the GFS and are used by the INEGI to prepare the final national accounts.

The SHCP's website provides users with an e-mail address and a telephone number for consultations or seeking further information. Also, two surveys have been carried out to ascertain users' opinions. For its part, the DEH maintains routine communications with the international and national agencies that use its statistics. 
There are three units that centralize public sector information, namely, the SHCP, the BM, and the Secretariat of the Office of the Controller and Administrative Development. These three units are represented on the Technical Information Committee, which operates an Integrated Government Revenue and Expenditure Information System (SII) at the SHCP. The purpose of this system is to prevent a duplication of efforts and unnecessary work on the compilation of information by respondents. Departments of the federal government and parastatal entities send the required information using forms that are forwarded electronically to the SII, which is responsible for distributing the information to the respective users.

\subsubsection{Respondents' data are to be kept confidential and used for statistical purposes only}

The confidentiality of data received from respondents is protected by the Statistical and Geographical Information Law, Art. 38 of which states that data and reports provided by individuals for statistical purposes or obtained from administrative or civil records must be handled in accordance with the principles of confidentiality and secrecy. In the particular case of decentralized public sector agencies (including government corporations), information is presented on individual entities, but care is always taken to maintain confidentiality on aspects necessary for the proper management of the entity in question. Decentralized agencies are aware of the rules and procedures regarding the confidentiality of information reported.

Art. 8 of the Federal Law on the Administrative Responsibilities of Civil Servants establishes the obligation of all civil servants to, inter alia, use the restricted information to which they have access through their functions exclusively for the assigned purposes and to safeguard and protect any documentation or information under their care or to which they have access because of their functions, responsibilities, or commissions, and to prevent the misuse of such data. Any failure to meet this obligation may incur sanctions, including dismissal. Copies of this law are distributed to all civil servants once a year, to remind them of their duties.

\subsubsection{Statistical reporting is ensured through legal mandate and/or measures to encourage voluntary response}

For the federal public sector, there are legal and administrative provisions for collecting the information necessary for the compilation of GFS. According to these provisions, it is mandatory to report any information requested, within the deadlines given and according to the pertinent established procedures.

Articles 42-44 of the Statistical and Geographical Information Law state that all federal public sector respondents are required to provide statistical information whenever so requested by the authority concerned. In addition, Art. 10 of the Federal Law on Parastatal Entities states that parastatal entities are required to provide to other entities in the sector in which they are grouped, as well as to the Secretariats of State and Administrative Departments, any information or data they may request. Lastly, the Decree Approving the 
Expenditure Budget of the Federation establishes that all entities are required to provide any information necessary for monitoring the budget within the deadlines stipulated.

Art. 32 of the Statistical and Geographical Information Law establishes the requirement for state and local governments to collaborate with the SHCP whenever the latter requests statistics, in accordance with the pertinent agreements. There are currently no administrative procedures for ensuring the timely hand-over of statistics.

Lastly, as indicated in section 0.1.2 above, the SII streamlines requests for information from respondents.

\subsection{Resources—Resources are commensurate with needs of statistical programs}

\subsubsection{Staff, financial, and computing resources are commensurate with statistical programs}

The human resources set aside for GFS compilation are adequate. Staff training in methodological aspects is mainly internal. Opportunities are limited for staff rotation. The necessary resources are available in computer hardware and other modern technologies that facilitate the timely compilation and dissemination of quality GFS.

\subsubsection{Measures to ensure efficient use of resources are implemented}

The costs associated with GFS compilation are not calculated and there is no confirmed information on whether the available resources are used as efficiently as possible. However, the increasing adoption of automated processes for GFS compilation has been leading to substantial savings in terms of the person-hours for such task.

\subsection{Quality awareness-Quality is a cornerstone of statistical work}

\subsubsection{Processes are in place to focus on quality}

The SHCP is fully aware that quality is key for maintaining public confidence in the statistics. To this end, a major effort has been under way for several years to compile and disseminate a larger amount of statistics with increasing coverage and timeliness and to adopt new ways of measuring public sector financial requirements. In addition, Mexico participates in and observes the Special Data Dissemination Standards (SDDS).

\subsubsection{Processes are in place to monitor the quality of the collection, processing, and dissemination of statistics}

Mechanisms are in place for assessing the quality of GFS compilation and dissemination. These mechanisms are geared primarily to ensuring the consistency of the primary information with the results. In particular, steps have been taken to encourage automation of the various processes for producing and cross-checking data. 
The Unit of Public Accounting and Management Reports approves the accounting rules applicable to all budgetary units. All central government units thus use the same chart of accounts. The parastatal entities use a different chart of accounts that follows criteria of private accounting, but this is also approved by the Unit of Public Accounting and Management Reports. Consequently, the GFS are compiled and cross-checked in accordance with prevailing accounting rules.

The SII has established procedures for controlling the quality of the information submitted. The information must be consistent with that provided in other forums, with indications of whether it is preliminary or final and explanations of any major changes compared with previous versions, and it must be accurate (it is not valid to omit data or make estimates).

Similarly, as stated above, the SHCP's website provides users with an e-mail address and a telephone number so that they can raise queries or request further information.

\subsubsection{Processes are in place to deal with quality considerations, including tradeoffs within quality, and to guide planning for existing and emerging needs}

Formal processes have not been established for assessing the quality of the statistics and the information disseminated. However, continuous efforts are made to ensure the internal consistency of the data and to improve their quality in general. For example, since May 2001 monthly information has been published 30-35 days after the end of each month; previously this lag had been 45-105 days. Also, the growing dissemination of government finance statistics, primarily through the SHCP's website, is an incentive for compilers to improve the quality of their products.

Work is under way to develop the Integrated Federal Financial Administration System, which will facilitate the availability of government finance data through fully automated, real-time processes. The launching of this system in 2003 will provide ample and timely information for the central government and, as a result, for GFS compilation.

\section{Integrity-The principle of objectivity in the collection, processing, and dissemination of statistics is firmly adhered to}

\subsection{Professionalism-Statistical policies and practices are guided by professional principles}

\subsubsection{Statistics are compiled on an impartial basis}

GFS compilation and dissemination are not supported by specific laws or formal safeguards affording professional independence to the departments responsible for the GFS. Nonetheless, Art. 8 of the Federal Law on the Administrative Responsibilities of Civil Servants points out that it is the duty of all civil servants to inform the head of the department or agency at which they work, in writing, of any reasonable doubts they may have regarding the legality of orders they receive. 
GFS are compiled on the basis of accounting records and administrative reports from the accounting centers, which follow charts of accounts and budgetary rules derived from the legal framework. Also, compilation practices are described in methodological notes posted on the SHCP's website.

\subsubsection{Choices of sources and statistical techniques are informed solely by statistical considerations}

Statisticians are free of political influence in the choice of the most appropriate data sources and methods for compiling the GFS and changes in the statistical procedures are made on the basis of technical rather than political criteria. Data sources are selected according to both the basis of recording and the availability of the information needed to compile and disseminate quality GFS. The choice of compilation methods to be used is dictated by the objective of measuring public sector borrowing requirements (PSBR) from a national budget tracking standpoint.

\subsubsection{The appropriate statistical entity is entitled to comment on erroneous interpretation and misuse of statistics}

GFS are disseminated through coordination between the DEH and the SHCP's Media Unit (Press Office). The latter's role is to issue any necessary clarifications for the proper interpretation of statistics. In addition, when GFS are disseminated, a press release is issued to announce the event. Press releases on monthly GFS highlight the principal results for the month, while those on quarterly GFS include an interpretation by the authorities' of the principal results. Finally, methodological notes are posted on the SHCP's website to facilitate understanding of the GFS.

GFS compilers are authorized to address reservations expressed about technical aspects and to respond to users' requests for further information. They are, however, not allowed to express opinions on government policies.

\subsection{Transparency-Statistical policies and practices are transparent}

\subsubsection{The terms and conditions under which statistics are collected, processed, and disseminated are available to the public}

The laws, regulations, methodologies, and manuals for classifying expenditure that govern GFS compilation and dissemination are available to the public on the SHCP's website. There are no explicit restrictions on the aggregate information produced by the $\mathrm{DEH}$ and users can be provided with any further information they may request, provided it is available and the rules of confidentiality of the information are observed. 


\subsubsection{Internal government access to statistics prior to their release is publicly identified}

No official or public agency outside of the SHCP has access to GFS prior to their dissemination. These statistics are released simultaneously to the entire public, through the SHCP's website. Also, as indicated in section 1.1.3 above, a press release is issued informing the public of the availability of the GFS.

The procedures authorizing the dissemination of GFS are deemed internal arrangements and are not published. GFS dissemination is authorized by the Director-General of the General Directorate of Fiscal Planning.

\subsubsection{Products of statistical agencies/units are clearly identified as such}

GFS compilation is the exclusive task of the DEH and the Debt Statistics Department of the SHCP. The tables disseminated by the SHCP identify the department responsible for their compilation. The tables distributed by the BM and the INEGI identify the General Directorate of Fiscal Planning as their source. The publications printed or posted on the INEGI's website identify the producer of the information in question.

\subsubsection{Advance notice is given of major changes in methodology, source data, and statistical techniques}

Methodological changes are usually described in the Draft Expenditure Budget of the Federation and in the General Economic Policy Criteria for the pertinent year. Such changes are normally indicated in footnotes to the GFS. Similar procedures apply to the recording of special operations and other methodological changes (e.g., in institutional coverage).

\subsection{Ethical standards-Policies and practices are guided by ethical standards}

\subsubsection{Guidelines for staff behavior are in place and are well known to staff}

Art. 8 of the Federal Law on the Administrative Responsibilities of Civil Servants spells out the duties of civil servants for ensuring legality, integrity, loyalty, impartiality, and efficiency in the exercise of their functions, tasks, and commissions. Failure to comply will lead to prosecution and appropriate sanctions. The sanctions envisaged in the Law are applied in practice, including dismissal in certain cases. 
2. Methodological soundness-The conceptual basis for the statistics follows international standards, guidelines, or good practices

2.1 Concepts and definitions-Concepts and definitions used are in accord with internationally accepted statistical frameworks

2.1.1 The overall structure in terms of concepts and definitions follows internationally accepted standards, guidelines, or good practices

The national concepts and definitions used are similar to those described in A Manual on Government Finance Statistics, 1986 (GFSM 1986). Overall, there is a direct, transparent relationship with international standards. The authorities will assess in due course the timing and possible method of migrating to the Government Finance Statistics Manual, 2001 (GFSM 2001).

2.2 Scope-The scope is in accord with internationally accepted standards, guidelines, or good practices

2.2.1 The scope is broadly consistent with internationally accepted standards, guidelines, or good practices

For improved comprehension of GFS coverage, the structure of the federal public sector is set out below.

\section{Federal Public Sector}

\section{Autonomous Authorities and Entities}

1. Legislature

2. Judiciary

3. Federal Electoral Institute

4. National Commission on Human Rights

\section{Federal Executive}

\section{A. Central government}

1. Secretariats of State

2. Deconcentrated agencies (without a legal personality or their own capital, attached to a secretariat)

3. Agricultural courts

4. Federal Court of Fiscal and Administrative Justice

5. Office of the Attorney-General of the Republic

6. Office of the Legal Adviser of the Federal Executive 


\section{B. Parastatal public administration}

1. Decentralized agencies (with a legal personality and their own capital)

2. Entities with majority state ownership

3. National credit corporations (development banks)

4. Trusts with an organic structure (financial and nonfinancial)

5. Bank of Mexico

The following definitions related to the institutional coverage of the GFS and used by the Mexican authorities are useful for better understanding the same:

- $\quad$ Federal government: Autonomous authorities and entities, plus the central government;

- $\quad$ Central government: Federal government, plus social security (IMSS, ISSSTE);

- $\quad$ General government: Central government, plus state governments (states and federal district), plus local (municipal) governments;

- $\quad$ Budgetary public sector: Federal government, plus 10 nonfinancial parastatal entities (Pemex, CFE, LFC, Ferronales, Capufe, ASA, Conasupo, Lotenal, IMSS, ISSSTE); ${ }^{10}$

- $\quad$ Entities under indirect budgetary control (135 entities): nonfinancial public sector (NFPS), minus budgetary coverage;

- $\quad$ NFPS: Federal government, plus parastatal (nonfinancial) public administration;

- $\quad$ Public sector borrowing requirements (PSBR): Government balance sheet (traditional balance sheet) of the NFPS, plus financing requirements for other NFPS transactions not covered in the government balance sheet, plus the financing requirements of development banks and financial trusts.

GFS are compiled and disseminated for the federal government (budgetary central government), consolidated central government, general government, budgetary public sector, nonfinancial public sector, and public sector borrowing requirements. The GFS for general government are not disseminated regularly and are provided only on request. The focus of the compiled and disseminated GFS is on the federal government, the budgetary public sector, the NFPS, and the PSBR; there is no focus on consolidated central government or general government as recommended in the GFSM 1986. GFS presentation formats differ

\footnotetext{
${ }^{10}$ In 2002, there were seven parastatal entities: Pemex, CFE, LFC, IMSS, ISSSTE, Capufe, and Lotenal. In the GFS 10 entities are shown, because coverage includes those in existence for the past three years.
} 
from the tables recommended in the GFSM 1986, but their content is similar. GFS are also compiled annually for consolidated central government, state governments, and local governments in accordance with the presentation formats in the GFSM 1986, but only for their publication in the IMF's Government Finance Statistics Yearbook (GFSY). Information is available for preparing the revenue, expenditure, financing, and debt tables for almost all levels of coverage.

The institutional coverage of the consolidated central government used differs from the international guidelines because it does not include the decentralized agencies engaging in noncommercial activities or the armed forces social security agency. This difference also has an impact on general government coverage. It is important to note that these agencies do not engage in financing and that most of their revenue consists of subsidies and transfers from the federal government, which are recorded as expenditure. As a result, the institutional coverage of the federal government includes virtually all the operations of the consolidated central government. GFS compilation on the central government and general government is based on information from all their component institutions; in other words, information coverage is comprehensive.

The DEH posts every month on the SHCP's website a set of 10 tables that provide monthly and cumulative figures on the financial position (revenue, expenditure, financing, overall balance) of the federal government, consolidated central government, budgetary public sector, and NFPS. Also included are tables on the domestic debt of the federal government and on the external debt of the NFPS. In addition, the DEH publishes every quarter a document entitled Estadísticas Oportunas de Finanzas Públicas y Deuda Pública [Timely Government Finance and Public Debt Statistics], which is also posted on the SHCP's website. This document provides ample pertinent quarterly information, including GFS, for the various levels of coverage (except general government). Lastly, the SHCP publishes every quarter a document entitled Informes sobre la Situación Económica, las Finanzas Públicas y la Deuda Pública [Reports on the Economy, Government Finance, and Public Debt], which is also posted on the SHCP's website. This document contains, among other information, GFS tables with formats similar to those referred to above.

Every month the BM publishes a document entitled Indicadores Económicos [Economic Indicators], which is also posted on its website. This document contains, among other information, GFS prepared by the DEH, for the federal government, budgetary public sector, and NFPS. Lastly, every year the INEGI publishes a document entitled Finanzas Públicas Estatales y Municipales de México [State and Local Government Finance of Mexico], which is also posted on the INEGI website. This document contains detailed information on government finance of the states and 300 municipalities, as well as general information on the 2,429 municipalities. 


\subsection{Classification/sectorization-Classification and sectorization systems are in accord with internationally accepted standards, guidelines, or good practices}

\subsubsection{Classification/sectorization systems used are broadly consistent with internationally accepted standards, guidelines, or good practices}

GFS are provided separately for the various levels of government. The classification of revenue, expenditure, financing, and debt is in accordance with national criteria, broadly similar to those recommended in the GFSM 1986, but with major presentation differences. In general, a link can be established between the national classifications and those recommended in the GFSM 1986.

The revenue of the federal (and central) government is classified as established in the Fiscal Code of the Federation, in: taxes, social security contributions, and nontax revenue, with subclassifications of tax revenue and nontax revenue. The revenue of the parastatal entities is classified in: sales of goods and services, social security contributions, and financial and other products. Various internal standards defining these concepts are not always in line with international guidelines. The principal differences are: (a) the tax revenue of the federal (and central) government represents the total collected in federal taxes, including the collected portion pertaining to other levels of government under fiscal coordination agreements in return for transferring their tax powers to the Federation (share of federal revenue to federative entities and municipalities); (b) the nontax revenue of the federal (and central) government is as established by law, including those in which the administrative fees and duties bear no relationship to the service provided (for hunting, fishing, and import permits); and (c) loan repayments are recorded as nontax revenue. Revenue is also classified by institution receiving the revenue, and by whether or not it is derived from petroleum. Expenditure is classified in accordance with the current Classifier by Purpose of Expenditure, which allows for the identification of expenditure by economic type, that is, as current expenditure and capital expenditure, and includes subclassifications (personnel services, materials and supplies; general services; subsidies and transfers; physical investment; etc.). A functional classification of expenditure is also used, grouping together expenditure items by public sector activity, into three major functions: (a) social development, (b) governance, and (c) productive activities. These groups are subdivided by specific function.

In addition, an institutional classification of expenditure is used in accordance with the Expenditure Policy Guidelines for the pertinent year, which, for budgetary purposes, group federal government expenditure into administrative branches and general branches. The former are associated with the activity of a department, and the latter relate to overall expenditure items that cannot be associated with the activity of a department. The expenditure of the parastatal entities is identified, for its part, by entity.

Finally, expenditure is also classified as programmable or nonprogrammable. The former group contains expenditure items directly associated with a public program for carrying out government functions and social or productive activities, while the latter group contains expenditure items that cannot be associated with any specific program, such as interest 
payments, state or municipal federal revenue shares, debit items from previous financial years, and items of expenditure incurred on behalf of third parties.

The main differences between the national concepts of expenditure and the international guidelines are: (a) the so-called third party operations [operaciones ajenas] are recorded as expenditure and include transactions on behalf of third parties by the federal government and operations pending budgetary regularization that cannot be classified in timely fashion; (b) the financial cost includes in addition to interest, commissions and expenditures associated to public debt, the fiscal cost derived from programs in support of bank debtors and financial soundness; and (c) loans granted are recorded as expenditure.

Financing is classified as domestic and external. In turn, domestic financing is divided into central bank, banks and other financial institutions, and private sector. Financing is also classified as federal government and agencies and enterprises. There is no domestic financing classification by instrument, nor any classification of external financing by instrument or by holder.

Federal government domestic debt is classified by instrument and by term, and not by holder. Social security and the decentralized agencies that conceptually form part of the central government have neither domestic nor external debt. No information is presented on the domestic debt of parastatal entities to prevent duplication in accounting, as the domestic debt of the parastatal entities originates in external debt contracted by the development banks, which is included in the external debt statistics. Debt guaranteed by the federal government is classified by beneficiary and is not broken down into domestic and external debt, although the bulk of it is domestic debt.

The external debt of the NFPS is classified by source of financing (instrument), by direct debtor to the rest of the world, by user of the resources, by country and currency, and by term; it is not classified by holder. No classification is shown by instrument or by holder for the external debt of the federal government (and consolidated central government).

The classification of financing and debt as domestic or external is determined by the residence criterion, applied on the basis of location rather than of nationality. Accordingly, financing or domestic debt is the debt contracted on the local market and payable within Mexico in domestic currency, while financing or external debt is that contracted abroad and payable abroad in foreign currency. Surveys are not carried out to determine the residence of debt holders. As a result, the classification of financing and debt is not based strictly on the residence criterion. It is worth noting, in this regard, that the BM releases information on the holding of government securities according to the residence criterion, based on periodic surveys.

The legislature of each state and local government approves its own revenue laws and expenditure budgets. Because state and local governments do not all have the same structures and conceptual aspects, the INEGI prepares tables showing homogeneous information, for statistical purposes. 
Lastly, a number of items in the PSBR are not treated in conformity with the guidelines of the GFSM 1986. In particular: (a) increases in the cash reserves of the IMSS and FOVISSSTE are treated as investment expenditure instead of as financial assets (actuarial reserves that must, by law, be retained and are unavailable for financing operational expenditure of the entity, unless the event for which they were constituted arises); and (b) all net loans to the private sector and operational losses of the development banking sector are treated as expenditure, whereas only the grant component of such lending operations and related operational losses should be included as expenditure.

\subsection{Basis of recording-Flows and stocks are valued and recorded according to internationally accepted standards, guidelines, or good practices}

\subsubsection{Market prices are used to value flows and stocks}

Revenue, expenditure, financing, and the overall balance are presented on a modified cash basis. For budget monitoring purposes these include: (a) cash transactions; (b) offset operations (not involving cash movements) between revenue and expenditure and between expenditure and financing; and (c) operations in kind, at commercial value.

Debt is shown on a cash basis. All transactions are recorded at the time of their placement and on the dates when the principal and the financial cost are paid. Domestic debt is recorded in domestic currency and external debt is recorded in the original currency. When reports are presented on external debt, other currencies are converted into U.S. dollars at the exchange rate prevailing at the end of the reference period, provided by the BM. Gross domestic debt is recorded at face value, except in the case of treasury bills [CETES], which are recorded at first issue placement value.

To reconcile the financing figures in the GFS with the public debt statistics and the monetary statistics, foreign currency flows are revalued to eliminate the effects of exchange rate changes. For this, the average exchange rate published by the BM is used.

\subsubsection{Recording is done on an accrual basis}

Transactions are recorded at a time close to payment, and more specifically when the Treasury of the Federation (Treasury) allocates its liquid resources in the banking system. This represents the penultimate or last phase in the expenditure process.

\subsubsection{Grossing/netting procedures are broadly consistent with internationally accepted standards, guidelines, or good practices}

All transactions are expressed in gross values, except for financing transactions, which are shown in net values. 


\section{Accuracy and reliability—Source data and statistical techniques are sound, and statistical outputs sufficiently portray reality}

\subsection{Source data-Source data available provide an adequate basis to compile statistics}

\subsubsection{Source data are collected from comprehensive data collection programs that take account of country-specific conditions}

The main sources of information for the compilation of GFS on the federal government are the administrative systems that monitor budget execution and cover all budgetary units. These sources provide information on the whole range of economic flows and stocks. The information comes mainly from the accounting centers administered by the SHCP (Collection, Public Debt, and Federal Funds). In particular, public expenditure figures are obtained from the accounts payable certified as paid by the Treasury (Federal Funds accounting center). This information is supplemented with information from other sources, primarily the BM (monetary accounts) and the General Directorate of Public Credit.

The main source of information for the parastatal entities is the SII, briefly described in section 0.1.2 above. Through this system, all the parastatal entities submit every month the bulk of the information necessary for compiling the GFS. In addition, the parastatal entities forward every month directly to the General Directorate of Public Credit, comprehensive information on flows and stocks of domestic and external debt.

Once the Congress approves the Public Account, usually in June of the following year, it becomes the source of information for compilation of the final GFS on the budgetary public sector. The Public Account shows only annual figures, but procedures are in place for collecting consistent monthly information.

The main source of information for the state and local governments is the INEGI's annual publication entitled Finanzas Públicas Estatales y Municipales de México [Mexico State and Municipal Government Finance]. The sources of information for this publication are: (a) for the state governments, the administrative accounting records on the public accounts of each federal unit; and (b) for the local governments, a questionnaire distributed by the INEGI and completed by each Municipal Treasury or, if this is unavailable, accounting information from local governments, available at the Congress of the pertinent state.

The information necessary for compiling consolidated GFS for the various levels of government is available. Moreover, the GFS are normally presented in consolidated form.

\subsubsection{Source data reasonably approximate the definitions, scope, classifications, valuation, and time of recording required}

The budgetary and extrabudgetary charts of accounts are consistent with the GFS categories recommended in the GFSM 1986. There is no automated mechanism for generating GFS items directly from budgetary items, but compilers know the procedures to be followed for 
moving from the primary sources to the concepts in the GFSM 1986. The times of recording and valuation are in conformity with GFS concepts. GFS information is fully reconcilable with that presented in the annual accounts (Public Account) and is the information used for the quarterly reports to the Congress; the main difference is that for the Public Account, programmable expenditure is recorded on an accrual basis, whereas in the GFS it is recorded on a cash basis.

\subsubsection{Source data are timely}

Accounting and administrative records provide comprehensive, up-to-date data on the budgetary and nonbudgetary federal public sector. The information is available 15-30 days after the end of the month, except for investment projects financed by the private sector, on which information is obtained 20 days after the end of every quarter.

No annual, up-to-date information is available in a timely way for GFS compilation on the state governments, local governments, and general government. The information is available 18 months after the end of the reference year.

\subsection{Statistical techniques-Statistical techniques employed conform to sound statistical procedures}

\subsubsection{Data compilation employs sound statistical techniques}

GFS data are based on comprehensive information; as a result, procedures have not been established to allow for the estimation of omissions in the data. Even the data for GFS on the state and local governments are based on comprehensive information.

\subsubsection{Other statistical procedures (e.g., data adjustments and transformations, and statistical analysis) employ sound statistical techniques}

Generally accepted statistical methods are used to adjust GFS. 


\subsection{Assessment and validation of source data-Source data are regularly assessed and results validated}

3.3.1 Source data —including censuses, sample surveys, and administrative records—are routinely assessed, for example, for coverage, sample error, response error, and nonsampling error; the results of the assessments are monitored and made available to guide planning

There are no substantial problems in the coverage or integrity of statistical compilation. As pointed out above, GFS are compiled on the basis of comprehensive information. The main sources of information on the federal public sector are cross-checked with other accounting or administrative records that allow for verification of their accuracy. Similarly, differences are checked between transaction flows and changes in stocks.

Preliminary GFS are compiled using the most up-to-date data that are appropriate for formulating and analyzing fiscal policy. All GFS are preliminary until the last revision is done with final, audited information, and the pertinent tables are labeled as preliminary. If discrepancies are noted later, corrections are made as applicable.

\subsection{Assessment and validation of intermediate data and final statistical outputs- Intermediate results and final statistical outputs are regularly assessed and validated}

\subsubsection{Main intermediate data are validated against other information where applicable}

Information on revenue, expenditure, financing, and debt is routinely reconciled with the budgetary records of various SHCP departments and with the bank balances of the entities in question.

\subsubsection{Statistical discrepancies in intermediate data are assessed and investigated}

Significant statistical discrepancies are investigated and the pertinent series are adjusted or corrected, depending on the result.

\subsubsection{Statistical discrepancies and other potential indicators of problems in final statistical outputs are investigated}

Financing data in the GFS are reconciled every month with the BM's pertinent monetary data. The official overall fiscal balance is derived from the monetary accounts; as a result, any statistical discrepancy remaining after reconciliation is included as an item in the GFS. Such statistical discrepancies relate mainly to temporary operations and exchange rate differences but are generally minimal. 
3.5 Revision studies-Revisions, as a gauge of reliability, are tracked and mined for the information they may provide

\subsubsection{Studies and analyses of revisions are carried out routinely and used to improve statistical processes}

Revisions incorporate all changes resulting from available up-to-date data. The characteristics, reasons, sense, and magnitude of changes in the source data that give rise to revisions are known. Source data reliability is continuously assessed. Studies on GFS revisions are carried out routinely; these are not disseminated but are used to improve GFS quality.

\section{Serviceability—Statistics are relevant, timely, consistent, and follow a predictable revisions policy}

\subsection{Relevance-Statistics cover relevant information on the subject field}

\subsubsection{The relevance and practical utility of existing statistics in meeting users' needs are regularly assessed}

The GFS time frame is the same as that used in budget preparation and monitoring; they serve as the principal statistics for decision making on fiscal policy. The level of detail and timeliness of the GFS enables users to assess the extent to which the government is achieving the financial objectives of fiscal policy. The methodological basis and the classification structure of the GFS generally meet users' needs. Users are consulted regularly, as established in the 1995-2000 Government Modernization Program; the two latest consultations took place in 1998 and 2000.

\subsection{Timeliness and periodicity-Timeliness and periodicity follow internationally accepted dissemination standards}

\subsubsection{Timeliness follows dissemination standards}

Monthly data on central government operations are released 30-35 days after the end of the reference month (30 days for months that are not at the end of a quarter and 35 days for ends of quarters), i.e., exceed the one month period stipulated by the SDDS. For this reason, Mexico has adopted a flexibility option for the timeliness of the GFS for central government.

Annual data on general government operations are not disseminated routinely and are available only 18-24 months after the end of the reference period, i.e., exceed the two months period stipulated by the SDDS. For this reason, Mexico has adopted a flexibility option for the timeliness of the GFS for general government. The data on NFPS operations are disseminated with the same lag as the monthly GFS for central government. 
Quarterly data on central government debt are disseminated 35 days after the end of the reference quarter, i.e., within the period stipulated by the SDDS (one quarter). Monthly data are disseminated with the same lag.

\subsubsection{Periodicity follows dissemination standards}

Data on central government operations are disseminated monthly and annually, data on general government operations are disseminated annually, and data on central government debt are disseminated monthly. Thus, SDDS requirements are met.

\subsection{Consistency-Statistics are consistent within a dataset, over time, and with other major datasets}

\subsubsection{Statistics are consistent within the dataset (e.g., they conform with accounting identities)}

The various accounting identities (deficit/surplus = financing, principal components $=$ sum of the components, functional expenditure = expenditure by economic type, domestic financing = change in domestic debt, external financing = change in external debt, paid transfers $=$ received transfers) are observed in the GFS. The only exception occurs in the case of the GFS for the state and local governments, in which consistency is not verified between domestic financing and the change in domestic debt (these entities have no external debt), and no satisfactory checks can be made of transfers between state and local governments.

\subsubsection{Statistics are consistent or reconcilable over a reasonable period of time}

Statistics are consistent with expected trends and reflect discretionary changes, external shocks, and economic activity. Time series are presented with the methodology and coverage with which they were compiled over the period in question. Breaks in the time series and the reasons for them are clearly identified.

\subsubsection{Statistics are consistent or reconcilable with those obtained through other data sources and/or statistical frameworks}

GFS data on financing are consistent with the monetary accounts following a significant reconciliation effort to clear up problems of classification, recording criteria, and a lack of detailed information in the monetary accounts. Data in the GFS on external debt serve as inputs for the balance of payments and are therefore consistent with the latter. Lastly, there are differences between the GFS data and the national accounts because of differences in the basis of recording and in coverage. 


\subsection{Revision policy and practice-Data revisions follow a regular and publicized procedure}

\subsubsection{Revisions follow a regular, well-established, and transparent schedule}

The main revision of data occurs when the information for the Public Account becomes available. This information is audited and final, and is usually available six to eight months after each year-end. Revisions are also made in the month following publication of the preliminary data. In practice, revisions follow a regular cycle known by users but do not follow an established schedule.

\subsubsection{Preliminary data are clearly identified}

Preliminary data and revised data are clearly indicated in statistics publications. Revised data are disseminated by the same media and with the same level of detail as original data. There is sufficient consistency between the preliminary data and the final data, so preliminary data can be used confidently in policy formulation and analysis.

\subsubsection{Studies and analyses of revisions are made public}

The public is not provided with time series on data revisions, and analyses comparing preliminary data with final data are not disseminated for the principal aggregates.

\section{Accessibility—Data and metadata are easily available, and assistance to users is adequate}

\subsection{Data accessibility-Statistics are presented in a clear and understandable manner, forms of dissemination are adequate, and statistics are made available on an impartial basis}

5.1.1 Statistics are presented in a way that facilitates proper interpretation and meaningful comparisons (layout and clarity of texts, tables, and charts)

The information presented can be used in the process of budget preparation and monitoring and in the formulation of other government economic and fiscal policies. The GFS are presented in such a way as to allow for identification and comparison of the principal aggregates/financing items. Time series are also supplied. The public is provided with a very large volume of information on government finance and public debt. The presentation of the information can be improved to facilitate its comprehension by general users and international comparisons. To this end, the introduction of a few selected tables highlighting the principal results and following the guidelines of the GFSM 1986 would be useful.

Compiled and disseminated GFS focus on the federal government, budgetary public sector, NFPS, and PSBR levels, rather than on consolidated central government and general government. The classification of revenue, expenditure, financing, and debt follows national 
criteria similar to those recommended in the GFSM 1986 but with major presentation differences. In general, a link can be made between the national classifications and those in the GFSM 1986, but this requires access to detailed information on that link, which is not available to the public. As a result, the current presentation of the GFS is not conducive to international comparison.

\subsubsection{Dissemination media and formats are adequate}

Monthly, quarterly, and annual GFS are posted on the SHCP's website. In addition, quarterly and annual GFS are disseminated in quarterly publications.

\subsubsection{Statistics are released on a pre-announced schedule}

A data release calendar is announced one year in advance, on the SHCP's website and in the quarterly publication entitled Timely Government Finance and Public Debt Statistics. The publication date can be adjusted one week in advance, but usually it coincides with the preannounced date.

\subsubsection{Statistics are made available to all users at the same time}

The GFS are released at the same time to all parties concerned, through the SHCP's website, without preferential treatment to any user. In addition, a press release is published, informing the public that the GFS are available, usually from 2 p.m. on the appointed day.

\subsubsection{Nonpublished (and nonconfidential) subaggregates are made available upon request}

Nonpublished, nonconfidential disaggregated data are supplied on request. To this end, users are provided, on the SHCP's website, with a name, telephone number, and e-mail address.

\subsection{Metadata accessibility-Up-to-date and pertinent metadata are made available}

5.2.1 Documentation on concepts, scope, classifications, basis of recording, data sources, and statistical techniques is available, and differences from internationally accepted standards, guidelines, or good practices are annotated

Three methodological notes with concepts, sources, and methods are posted on the SHCP's website: one on nonfinancial public sector operations, one on public sector borrowing requirements, and one on public debt statistics. ${ }^{11}$ In addition, as Mexico is an SDDS

\footnotetext{
${ }^{11}$ In April 2002, the SHCP added to its website the document entitled "Balance Fiscal en México: Definición y Metodología" ["Fiscal Balance in Mexico: Definition and Methodology"], which provides a detailed and comprehensive definition of the various concepts related to the financial obligations of the public sector.
} 
subscriber country, methodological notes are published on the IMF's Dissemination Standards Bulletin Board (DSBB) concerning central government and general government (and NFPS) operations, as well as on central government debt. The documentation indicates some of the differences from internationally accepted standards. Lastly, upon request, bridge tables could be provided, showing the existing links between the source data and the GFS.

The INEGI includes a brief methodological note in its document entitled Mexico State and Municipal Government Finance. Work is under way on a more detailed methodological note, expected to be posted on the INEGI's website soon.

\subsubsection{Levels of detail are adapted to the needs of the intended audience}

General technical descriptions are published on the concepts, sources, and methods used. However, experts may need to seek further information to assess the attributes and shortcomings of the GFS.

\subsection{Assistance to users-Prompt and knowledgeable support service is available}

\subsubsection{Contact person for each subject field is publicized}

The name, telephone number, and e-mail address of the person who can be consulted regarding the GFS are posted on the website. This person provides back-up and efficient advice to all users, regardless of their level of specialization, and can provide technical corrections on any incorrect use of the GFS.

5.3.2 Catalogs of publications, documents, and other services, including information on any charges, are widely available

A detailed catalog of the services provided by the SHCP is posted on the SHCP's website. 


\section{Monetary Statistics}

\section{Prerequisites of Quality}

\section{$0.1 \quad$ Legal and institutional environment}

\subsubsection{The responsibility for collecting, compiling and disseminating statistics is clearly assigned}

The Mexican banking system is governed by the Political Constitution of the United Mexican States (Art. 28, paragraphs 6 and 7) and the following laws that have undergone various amendments and additions: the Bank of Mexico Law, the Law on Credit Institutions, the General Law on Auxiliary Credit Organizations and Activities, the Law on Financial Groups, and the Credit Bureau Law.

The Bank of Mexico (BM) is in practice responsible for collecting, compiling, and disseminating monetary statistics, even though the data source is shared with other institutions, such as the Secretariat of Finance and Public Credit (SHCP) and the National Banking and Securities Commission (CNBV).

The legal right of the BM to compile monetary and financial statistics derives essentially from Art. 62 of the Bank of Mexico Law. That law establishes that the BM may, in coordination with the other aforementioned competent authorities, prepare, compile, and publish economic and financial statistics, as well as operate information systems based on them and collect the data required for those purposes.

Articles 40 and 41 of the BM's By-laws establish guidelines for publication of accounting information. Those articles stipulate that the BM must publish: (1) its general balance sheet within five business days following the date on which it is approved; (2) consolidated statements of accounts for the months that have elapsed in the current fiscal year up to the date of approval of the balance sheet within 15 business days following said approval; (3) the consolidated statement of accounts of the immediately preceding month (except December) within the first 20 business days of each month; and (4) every week, summary information on its assets, liabilities, and net worth in the official gazette Diario Oficial de la Nación, with preliminary figures at close of business each Friday and within the following three business days. That information must be signed by the Director of Accounting, and, in his/her absence, by the Manager of Budget and Accounting. The BM also produces other publications on a daily, weekly, or monthly basis that are directly related to decisions of the BM's Governing Board, in order to disseminate the evolution of indicators and the principal macrofinancial variables, such as the financial and monetary statistics for the banks as a whole and for each group of nonbank financial intermediaries.

The CNBV is an entity separate from the BM, endowed with technical but not budgetary autonomy, given that for budgetary purposes it depends on the SHCP. In addition, the CNBV receives contributions from supervised financial corporations to help cover inspection costs. 
The CNBV (a devolved agency) has its own legal framework known as the National Banking and Securities Commission Law. It has the authority to establish rules regarding accounting information and the criteria to govern its recording, valuation, and presentation. The CNBV publishes statistical data in net figures for each institution pursuant to Art. 4 of its Law. The SHCP does not produce or publish financial statistics.

\subsubsection{Data sharing and coordination among data producing agencies are adequate}

The BM has introduced procedures to guarantee the flow of information between the Office of the Manager of Budget and Accounting (GPC) and the Office of the Manager of Macrofinancial Analysis (GAM) with regard to the BM's statement of accounts. In addition, the BM has an institutional mechanism for sharing information from financial corporations, which is stored in the Economic Information System (SIE) database. The flow of information takes place through automated systems that allow authorized BM staff access to the SIE. There is also information sharing between institutions; that is to say, between the BM, the $\mathrm{CNBV}$, and the SHCP through online communication servers in those institutions. The BM shares information with reporting financial corporations, but only for the whole set of corporations or groups of them.

In order to coordinate on matters related to the information provided by the financial corporations, resolve issues related to data requirements and data sharing, and avoid duplication in reporting requirements, a Committee to Coordinate Information Flows among Authorities (Committee) was established on July 6, 2000, composed of representatives of the SHCP, the BM, the CNBV, the Bank Savings Protection Institute, and the National Commission for the Defense of Customers and Financial Services. The Committee holds periodic meetings, which representatives of the financial corporations may be invited to attend. There are also monthly working meetings with the Mexican Bankers' Association, organized by the Committee on Financial Information and Accounting Matters, which is composed largely of representatives of commercial and development banks.

Until 1999, the BM and the CNBV used the same financial corporation data reporting form, based on a single very detailed chart of accounts, which satisfied the needs of both institutions. After the CNBV decided to change the form to improve bank surveillance, the BM introduced its own data reporting form, known as Accounting and Sectorization Report (Report), in February 2000. Nevertheless, these two institutions continue to collaborate closely with each other and share information whenever the need arises.

\subsubsection{Respondents'data are to be kept confidential and used for statistical purposes only}

The confidentiality of the data that financial corporations provide to the $\mathrm{BM}$ is established in Art. 58 of the BM Law. That article on bank secrecy applies to the BM, the members of its Governing Board, and to its officers and employees. Moreover, Art. 117 of the General Conditions of Employment of the Bank of Mexico (CGT) established that revealing operating secrets or confidential BM matters are grounds for dismissal, without the BM incurring any liability. 
The data included in the presentation of monetary statistics are taken from the detailed information contained in the balance sheets published by the financial corporations; consequently, they are not confidential and do not contravene the provisions of the Banking Law with regard to bank secrecy or the regulations of the Law on Statistical and Geographical Information. ${ }^{12}$ Whenever the BM requests information protected by bank, trustee, or similar secrecy provisions, that information is kept confidential. For instance, the form called List of Liabilities [Relación de Responsabilidades], which contains the name of each borrowing enterprise or individual engaged in business activity cannot be divulged, except as part of some aggregate of the type of debtor or loans characteristics. Furthermore, when information is collected by means of surveys (for instance, bank credit market conditions, factors influencing banks' cash balances, customers' perceptions of bank lending), respondents are informed in advance regarding the nature of the data to be collected and the purpose of the survey. The statistical findings are also shared with respondents.

The BM has some automated procedures to prevent the dissemination of confidential data. Aggregation rules have been established; that is to say, only aggregate information and in the public domain is divulged. Moreover, access to data of individual financial corporations is restricted to authorized BM personnel using access passwords.

\subsubsection{Statistical reporting is supported by legal mandate and/or measures implemented to encourage voluntary response}

The legal provisions underpinning the obligation of financial corporations to report to the BM are contained in the BM Law. Art. 36 stipulates (1) that financial corporations are obliged to provide the BM with the information it requires regarding their operations in order to fulfill its functions appropriately; and (2) that, at the request of the BM, the financial system oversight commissions shall visit the financial corporations to review, verify, and evaluate the information they may have presented. BM staff may take part in those visits. The BM also reaches voluntary agreements with the financial corporations in order to gather information (surveys) on short-term issues related to developments in the principal macrofinancial variables.

Art. 97 of the Law on Credit Institutions establishes that financial corporations must provide the information and documentation requested by the SHCP, the BM, and the CNBV, by the deadlines stipulated by those institutions. Pursuant to this provision, the financial corporations provide the SHCP with their institution's data on operational and financial programs, income and expenditure budgets, integrated indicators, and any other financial information needed to assess the performance and development of the Mexican banking system.

\footnotetext{
${ }^{12}$ Art. 3 of the Law on Statistical and Geographical Information states: "Quantitative and qualitative reports provided by respondents for statistical purposes, referring to a unit of observation, shall be considered confidential statistical information."
} 
In addition, Art. 51-A of the General Law on Organizations and Auxiliary Credit Activities stipulates that those organizations and exchange bureaus shall submit the information and documentation requested by the SHCP, the BM, and the CNBV, by the established deadline. According to Art. 12 of the Credit Bureau Law, Credit Rating Agencies must be governed in their operations and activities by this Law and any general provisions issued by the BM. Art. 17 establishes that these Agencies shall be subject to inspection and supervision by the CNBV, to which they must pay contributions in an amount assessed by the SHCP.

The BM Law contemplates a generic set of sanctions for noncompliance. However, the level of compliance by financial corporations is generally acceptable and it is not necessary to impose sanctions for failure to provide information. The BM maintains close contact with the Mexican Bankers' Association (the professional association for financial institutions) and, when the need arises, this forum is used to discuss problems of noncompliance or information quality with the representatives of the institutions concerned. Nevertheless, in serious cases, fines are levied for reprocessing data, by charging the single account that the BM holds for each institution. Whenever the data provided by an institution substantially distort the statistics published by the BM, the public is informed via a press release and hefty fines are imposed on the institution in breach of the regulations.

The BM provides appropriate support with regard to the preparation and presentation of the forms used by reporting financial corporations. In addition to providing pertinent instructions and procedures for preparation and validation of the data, the BM also appoints an officer of the Bank to assist the financial corporations with all aspects related to the reporting of information. BM fosters the collaboration of respondents by trying to build an atmosphere of good faith. To that end, the BM has tried to convey to the reporting financial corporations the importance of the data they provide as a source for the compilation of financial statistics. The $\mathrm{BM}$ operates a system of certificates to recognize companies that comply with the requirements.

\section{$0.2 \quad$ Resources}

\subsubsection{Staff, financial and computing resources are commensurate with institutional programs}

The monetary statistics are compiled by the BM's macrofinancial analysis team, consisting of 22 professional staff ( 18 accountants, three economists, and one actuary). Each employee has a personal computer and access to the Internet. The human resources directly involved in collecting, validating, and preparing financial and monetary statistics are considered adequate.

On average, the staff engaged in the production of these statistics has had a solid academic education (with at least a degree in accounting or economics), as well as general and specific training provided by the BM. This group consists of persons with (on average) some 15 years of experience. They attend courses taught by the IMF on the methodology of the IMF's Monetary and Financial Statistics Manual (MFSM), other courses offered in cooperation 
with the Center for Latin American Monetary Studies (CEMLA), as well as training courses at various central banks in the European Community. Training is continuous and the BM expects to continue to participate in future training courses. Each analyst in the Financial Information System (SIF) is responsible for all aspects of the financial corporations for which he or she is responsible, and which rotate periodically. Final validation of each institution's figures is done by a coordinator, who is also responsible for incorporating the files in the banking database and assessing the consistency of the data over time.

The BM continuously strives to update systems and programs for compiling and analyzing monetary statistics. Source data collection and the compilation and dissemination of the monetary statistics make use of electronic media. Source data are collected via electronic transfers and centralized in BM servers. Once that phase is completed, the information is stored in the Basic Banking Information System (SBIB) and in the SIE. In the latter, concepts and data series are linked for classification and automated generation of the monetary statistics, including those published on the BM's website. Subsequently, the information is processed in various personal computers and then, when the databases have been integrated, they are also managed by the servers. The procedures guaranteeing data consistency and quality are also fully automated.

GAM has the support of the Office of the Manager of Information Technology (GI) in preparing monetary statistics. These two offices work closely together to establish the requisite budget appropriations and allocate resources in accordance with the priorities agreed upon as part of an annual program. These tasks are adequately funded and requests for additional resources are generally accepted by the Governing Board and other internal organs of the BM.

\subsubsection{Measures to ensure efficient use of resources are implemented}

The managers' offices within the BM's Directorate General of Economic Research that are engaged in compiling monetary statistics follow procedures that guarantee efficient use of resources. They include: (1) informing staff in advance of plans to introduce new statistical tables or improvements to already existing tables; (2) cross-checking macroeconomic data in order to identify and minimize the differences between them, thereby fostering the standardization of methodologies; and (3) applying various validation mechanisms during data processing to ensure that the data are as reliable as possible. Although no cost is imputed to the preparation of monetary statistics, over the years the BM has been able to simplify the structure and reduce the number of staff engaged in these activities. This progress has been achieved largely as a result of the use of the latest technology in data compilation.

At present there is no system for establishing the cost of each area of responsibility. However, program funds are subject to execution priorities, which are analyzed by a committee made up of systems specialists and users. The BM plans to introduce a system of budget allocation per project, which would be exercised in tandem with the progress made and goals achieved in each project. Within this context, more attention will be given to strengthen the co-responsibility of users and the computer systems unit. Recently, an internal 
management review mechanism has been implemented with regard to the monetary statistics preparation process. It is expected that this new procedure will help streamline administrative processes since the purpose of this review is to examine the effectiveness of the controls in place and ensure their application by each analyst.

\subsection{Quality awareness}

\subsubsection{Procedures have been put in place for quality awareness}

The BM recognizes that the quality of the statistics is essential for accurate analysis of the monetary situation and for formulating and implementing monetary policy. In addition, quality fosters users' confidence in the data. Accordingly, BM staff compiling monetary statistics exercise continuous and rigorous control of the coverage, timeliness, and veracity of the data. To that end, the methodology employed in compiling monetary statistics is routinely discussed in working groups in the Directorate General of Economic Research and submitted for approval by the BM's Governing Board.

At the same time, the BM provides appropriate basic infrastructure to foster data quality. For instance, the information on financial corporations is available in automated databases that allow cross-checking of various aspects of a transaction conducted by those corporations.

\subsubsection{Procedures have been established for monitoring the quality of data collection, compilation, and dissemination}

The BM is not subject to internal or external audits of the quality of the monetary statistics or their conformity with international standards. Nevertheless, the SIF makes sure that those standards are observed. An internal administrative audit procedure conducted by staff not directly involved in the preparation of statistics was recently put in place. The BM does not carry out periodic user surveys. However, an electronic mailbox has been set up, which allows direct access to a member of the Governing Board (Deputy Governor) for outside users' comments. Those comments are passed on directly to be dealt with by the staff in charge of the information. There is a procedure for evaluating the quality and timeliness of the replies given to the public.

\subsubsection{Procedures are in place to assess the quality of statistics, to acknowledge and deal with tradeoffs within quality, and to guide planning for existing and emerging needs}

Recognizing the fact that there are alternative dimensions of data quality, the BM's monetary statistics are first described as preliminary. Once quality requirements have been met, they become final. The criterion used with regard to data revision is to maintain the last two observations as preliminary and consider those prior to them as final. 


\section{Integrity}

\subsection{Professionalism}

\subsubsection{Statistics are compiled on an impartial basis}

The Constitution and the BM Law provide a legal framework that ensures the autonomy of the BM. The Constitution establishes that the State shall have a central bank that is autonomous in the exercise of its functions and in its management (Art. 28). The BM Law entrusts the management to a Governing Board and a Governor (Art. 38). Art. 46 of the same Law stipulates that the Governing Board is empowered to establish policies and criteria in carrying out the Bank's operations, while Art. 45 provides for the Secretary and Assistant Secretary of the SHCP to participate in meetings of the Governing Board, but without the right to vote.

The terms and conditions governing the BM are sufficient to ensure its independence and the autonomy of the staff devoted to compiling monetary statistics. The autonomy granted to the BM under the constitution and Art. 62 of the BM Law establishes that it is competent to collect the information needed to compile economic and financial statistics and provides for coordination among financial authorities. Moreover, to reduce the possibility of conflict in the production of statistics, the $\mathrm{BM}$, in agreement with the $\mathrm{CNBV}$, publishes only aggregate data. Legal provisions also safeguard the professional autonomy of BM staff inasmuch as the officers responsible for compiling statistics are appointed by the Governor of the BM.

Professional skills are a prerequisite for the hiring of personnel and they are also a paramount consideration for promotion. The BM encourages professionalism among its staff by providing incentives for the preparation and publication of research papers, subject to revision by officers at different levels in the hierarchy. The BM promotes participation by staff at international meetings in which BM studies are presented. It also encourages professionalism and productivity by awarding bonuses.

\subsubsection{Choices of sources and statistical methods are informed solely by statistical considerations}

The sources selected for the compilation of monetary statistics meet the statistical requirements of the BM's Directorate General of Economic Research. The definitions and methodologies used are those best suited to obtaining the information on financial activities needed for the Board of Governors for decision-making purposes and for publication of internationally comparable figures.

The BM encourages its staff to write papers describing the methodology used in compiling monetary statistics (e.g., monetary aggregates, financing of nonbank sectors, financial statistics developments in Resources and Obligations), duly supported by research, relevant bibliographical sources and including personal or institutional points of view, where necessary. 


\subsubsection{The appropriate statistical entity is entitled to comment on errors of interpretation and misuse of statistics}

Generally speaking, there is no misinterpretation or misuse of monetary statistics.

Nevertheless, the BM does monitor major press coverage of BM and financial activities to detect any inappropriate interpretation of the information. In cases of minor importance, the relevant party is contacted informally. In more important instances, the BM invites the party involved to take part in a review of the matter and provides the pertinent arguments, in some cases in the presence of a Deputy Governor.

\subsection{Transparency}

\subsubsection{The terms and conditions under which statistics are collected, compiled, and disseminated are available to the public}

The public has access to the legislation governing the compilation and dissemination of monetary statistics. The BM Law is published on the BM website and in affordable printed publications. In addition, each employee of the BM has a copy of the CGT, which is also available on the BM's intranet. The BM website also has (1) a mailbox for receiving and dealing with users' questions and comments and (2) a search engine by topic and concept. Through these tools, users can access additional information published by the BM. Furthermore, the form and instructions used by financial corporations to report their data are periodically updated.

\subsubsection{Internal governmental access to statistics prior to their release is made known to the public}

No government agency outside the BM has access to monetary statistics prior to their release.

\subsubsection{Products of statistical agencies/units are clearly identified as such}

All published monetary information bears the BM logo and captions specifying the source of the basic data. There is also a statement to the effect that the statistics are the sole responsibility of the BM. All BM publications cite the data source used.

The BM does not explicitly request acknowledgement of the source when its monetary statistics are reproduced or used by third parties, since it is common practice to identify data sources. 


\subsubsection{Advance notice is given of major changes in methodology, source data and statistical techniques}

Any major change in methodology, data sources, and statistical techniques are announced in advance in articles published in bulletins, briefing sessions, or press releases. ${ }^{13}$

Methodological changes are also announced when revised statistics are published. They are accompanied by a note explaining the changes in methodology and the appropriate link with the historical data. The BM's website has a link for this purpose.

\subsection{Ethical standards}

\subsubsection{Guidelines for staff behavior are made known to staff}

In general, the codes of conduct for staff are found in the BM Law, the Federal Law on the Administrative Responsibilities of Civil Servants, and in the CGT. Art. 46 of the BM Law grants the Governing Board authority to approve the CGT between the Bank and its staff and the Bank's by-laws. Art. 61 of the BM Law establishes that the Federal Law on the Administrative Responsibilities of Civil Servants applies to members of the Governing Board and to BM staff. Art. 8 (section IV) of the same Law requires all civil servants to protect the information to which they have access and to prevent its unlawful use. Furthermore, Art. 24 of the CGT specifies that BM personnel must use discretion in the exercise of their duties, keeping BM matters strictly confidential.

Art. 26 of the BM Law contains specific provisions regarding the operations of financial institutions, including provisions on reporting requirements. These provisions (Circular 2019 of the BM) clearly establish how data are to be presented and the responsibilities incurred by the institutions. Consequently, there is rarely a conflict of interest.

Senior BM management are impartial and make certain that ethical standards are observed in their area of responsibility. Under the BM Bylaws, there are special committees, composed of officers from different departments, to settle cases of breaches of regulations.

Newly hired personnel are provided with a copy of the CGT, which is also available on the BM intranet.

The BM, the SHCP, the CNBC, and the Chamber of Deputies have on their respective websites a link to their legal framework, providing access to current laws governing the financial sector. The Chamber of Deputies website also carried the Federal Law on the Administrative Responsibilities of Civil Servants.

\footnotetext{
${ }^{13}$ In the case of the methodological revision of the monetary aggregates, the previous methodology co-existed for two years with the new one, to facilitate comprehension of the scope of the changes made.
} 


\section{Methodological Soundness}

\subsection{Concepts and definitions}

\subsubsection{The overall structure in terms of concepts and definitions follows internationally accepted standards, guidelines, or good practices}

The concepts and definitions used by the BM in compiling monetary statistics generally follow the guidelines contained in the IMF's Monetary and Financial Statistics Manual (MFSM); for instance, the concept of residency, identification of institutional sectors, valuation of financial assets at market prices, accrual-basis accounting, and presentation of assets and liabilities in gross terms.

In accordance with the MFSM, the BM compiles the BM's sectoral balance sheet, which includes the BM's principal assets and liabilities. This information is published on a weekly basis as Principal Headings in the Statement of Accounts and each month as Resources and Obligations. In this statistical framework, assets are classified as (1) international reserves, as defined in the BM Law (that is to say, net of obligations in foreign currency and gold with a maturity of no more than six months; net international assets are included as a memorandum item); (2) investments in government securities; (3) credit to the federal government; (4) credit to various financial intermediaries, distinguishing between commercial banks, development banks, and development trusts; and (5) credit to government agencies (loans taken over by the Bank Savings Protection Institute). Liabilities are classified as (1) monetary base; (2) monetary regulation bonds; (3) deposits of financial intermediaries (commercial and development banks, Fobaproa, Fameval, and other trust funds); (4) monetary regulation deposits; (5) federal government deposits; (6) obligations to the IMF; and (7) other liabilities and net worth (net of other assets).

The BM also publishes balance sheets for the commercial banks, development banks, and other financial intermediaries, covering asset, liability, and investment operations, and earnings classified by institutional agent of economic activity (especially in the case of banks). The sectoral balance sheets contain detailed information on credit to the private and public sectors, and net foreign assets. The accounts and breakdowns are classified in accordance with the Resources and Obligations statistical framework, in which operations are first distinguished between resident or nonresident. The Resources category shows all gross assets, grouped according to their degree of liquidity, including (1) currency, (2) bank instruments, (3) loans granted, (4) financial instrument holdings, etc. The Obligations category comprises gross liabilities grouped according to maturity, net worth, and outturn. The main headings under Obligations are (1) deposits of the general public, (2) bank loans, (3) obligations derived from rediscounting; and (4) synthetic financial instruments. The BM also publishes balance sheets for a number of other financial intermediaries that either participate in the intermediation process or else play a supporting role for banking intermediaries proper. Their balance sheets are also arranged in accordance with the statistical framework of Resources and Obligations. 
The BM also publishes several measurements of broad money. The MFSM does not prescribe a uniform definition for this indicator since definitions vary from one country to another. The monetary aggregates produced and disseminated by the BM are: (1) Base Money (currency in circulation and current account sight deposits of commercial and development banks in the BM); (2) M1 or narrow money (currency outside banks - currency in circulation minus cash in banks, residents' checking accounts, and current account deposits); (3) M2 (M1 plus residents' accounts - sight deposits other than those in checking and current accounts and local and foreign currency-denominated time deposits of the private sector in banks-, public and private securities held by residents, and other instruments held by pension funds); (4) M3 (M2 plus bank deposits of nonresidents (that is to say, sight and time deposits of persons residing abroad) and federal government securities held by nonresidents; and (5) M4 (M3 plus deposits of residents and nonresidents in foreign branches of local banks). In addition, the BM publishes a series of broader monetary aggregates (M1a, M2a, M3a, and M4a), which add public sector savings (those of the federal, municipal, and state governments; nonfinancial state enterprises; and development trust funds) to the private savings reported in monetary aggregates M1-M4.

The MFSM recommends consolidating data from sectoral balance sheets in surveys containing stock and flow data for the assets and liabilities of the units covered by the respective survey, that is to say, the Central Bank Survey (CBS), Other Depository Corporations Survey (ODCS), and the Depository Corporations (DCS). These surveys contain a basic set of data, that according to the MFSM constitute a valuable tool for macroeconomic analysis. The survey for each subsector provides an analytical presentation of the intermediation performed by the subsector concerned. The BM neither produces nor disseminates the CBS, ODCS, or DCS. Nevertheless, the aforementioned sectoral balance sheets contain sufficient elements to enable the consolidation of the respective subsectors. ${ }^{14}$

In recent years, the $\mathrm{BM}$ has made great efforts to implement the MFSM methodology. Phase one, which consisted of developing a basic data collection system (Accounting and Sectorization Report) for the sectoral balance sheets needed to produce monetary statistics according to MFSM concepts, has been fully and successfully implemented. It is worth pointing out that, for several years now, the BM has been providing the information that the IMF needs to construct, inter alia, the monetary survey and the banking survey, for publication in International Financial Statistics (IFS).

\footnotetext{
${ }^{14}$ Following the mission, the BM initiated a process for compiling and disseminating the surveys in question. Since August 8, 2002, the BM has been disseminating surveys of the central bank, other depository corporations (with full coverage), depository corporations, other financial corporations, and financial corporations on its website. The series are monthly and start from 1997.
} 


\section{$2.2 \quad$ Scope}

2.2.1 The scope is broadly consistent with internationally accepted standards, guidelines, or good practices

The financial system consists of a wide variety of financial intermediaries that operate under different regulatory, legal, and institutional schemes. The financial sector comprises: (1) the BM; (2) the other depository corporations (ODC) (commercial banks and development banks); and (3) other financial corporations known as nonbank financial intermediaries (savings and loan associations, factoring companies, financial leasing companies, bonded warehouses, insurance companies, surety companies, brokerage houses, investment companies, investment companies specializing in retirement funds, exchange bureaus, credit unions, savings associations, specialized lending institutions and economic development funds forming part of Bansefi). Banking financial intermediaries (45 commercial banks, eight development banks) are predominant in the Mexican financial system, with 7,418 branch offices and 10 branches abroad in 2001 . That year there were 856 active nonbank financial intermediaries.

The monetary statistics published by the BM in the sectoral balance sheets comprise both $\mathrm{BM}$ and ODC operations (except exchange bureaus). In the case of the ODC, institutional coverage includes the activities of the head office and all domestic branches. The BM not only collects detailed balance sheets from the ODC, but also collects and publishes quarterly information on the operations of nonbank financial intermediaries.

The complexity and dynamic nature of the Mexican financial system requires constant scrutiny of the functions performed by financial intermediaries in order to ensure correct classification of the monetary accounts. While no nonbank intermediary is authorized to accept checking account deposits, savings and loan associations, factoring companies, financial leasing companies, credit unions, investment funds, and specialized lending institutions receive time deposits from the general public. Therefore, their function is similar to that of other depository corporations, as defined by the MFSM, and they should be included in the ODC survey ${ }^{15}$. Indeed, account is already taken of these instruments in the measurements of broad money.

Nonbank financial intermediaries report data to the BM on a monthly basis, except insurance companies and surety companies which report quarterly. The BM processes the information and publishes the balance sheets on its website. The BM has recently begun to share the ODC data with the IMF's Statistics Department.

\footnotetext{
${ }^{15}$ After the mission, the BM developed and introduced a system with full coverage of the ODCs.
} 


\subsection{Classification/sectorization}

\subsubsection{Classification/sectorization systems used are broadly consistent with internationally accepted standards, guidelines, or good practices}

The sectorization of the economy currently used in compiling the monetary statistics for the $\mathrm{BM}$ and the ODC is largely based on the MFSM recommendations.

For the central bank and the commercial and development banks, assets and liabilities are classified according to the institutional sector of the counterparts. Thus, assets are classified by debtor sectors and liabilities by creditor sectors.

Institutional units are grouped according to their characteristics. In sectorization, first a distinction is made between residents and nonresidents; then the resident units are grouped together in mutually exclusive economic sectors, as follows: (1) Financial Corporations, comprising the BM, commercial banks, development banks, and other public and private financial intermediaries. The latter include financial leasing companies, factoring companies, bonded warehouses, insurance companies, non-bank banks, savings and loan associations, mutual funds, mutual funds specializing in retirement funds, credit unions, brokerage houses, surety companies, and economic development funds; (2) Nonfinancial Corporations, which include agencies and enterprises with State participation, private enterprises, and the Government Workers Security and Social Services Institute (ISSSTE) (Social Security part);

(3) General Government, consisting of the federal government, state governments, municipal governments, and the Mexican Social Security Institute-IMSS (health sector); and (4) Households, which includes the private individuals sector. The nonprofit institutions serving households sector is not identified as a specific sector and is included in Households.

The financial instruments in the sectoral balance sheets (of the central bank, commercial banks, and development banks) are classified according to degree of liquidity and the legal characteristics describing the underlying relationship between creditors and debtors. In commercial bank and development bank balance sheets, repos are shown as a transfer of securities and simultaneously, because of the cash involved, the loans guaranteeing the transactions between the lender and the borrower are also recorded in the accounts. In other words, the purchase or sale of securities is itemized, along with the corresponding settlement rights and duties resulting from the transfer. The BM's gold swap operations are designed to provide coverage of the physical position and the repurchase agreement is posted as a collateralized loan.

\section{$2.4 \quad$ Basis for recording}

\subsubsection{Market prices are used to value flows and stocks}

The securities held by commercial and development banks are classified, first, according to what each bank intends to do with them at the time of purchase. Thus, they may be classified 
as Securities for Trading, Available for Sale, or To be Kept until Maturity. Securities for trading and those available for sale are ascribed a "reasonable value," meaning "the amount for which an instrument may be exchanged between parties disposed to carry out the transaction in a setting free from pressure" (Circular 1448 of the CNBV). This criterion favors valuation at market prices as recommended in the MFSM. Valuation of holdings of precious metal coins is based on their "fair value" (that is, market price), based on the price quoted on the valuation date. Whenever it is not possible to ascertain a market price, the holdings are valued at purchase price plus accrued interest.

As regards loans granted, the balance recorded in the loan portfolio is the amount effectively granted to the borrower plus any uncollected accrued interest: in other words, the book value of the loan. This figure does not include expected losses due to default by the borrowers, which are recorded under liabilities as "provisions against possible loan portfolio losses."

The sectoral balance sheets of commercial banks and development banks do not include any additional information with respect to the market values of stocks and equity participations. Nevertheless, they do record the impact of changes in the general price level.

Financial transactions are recorded at the time of purchase (that is, the date on which ownership is registered), and at market prices (i.e., purchasing cost). In the sectoral balance sheets of the central bank, commercial banks, and development banks, instruments include changes based on valuation and that specific entry is reflected in profits or losses. The valuation criteria are consistent with international standards, but the presentation of the statistics does not include specific notes on those criteria.

Pursuant to Bulletin B-15 of the Mexican Institute of Certified Accountants and in line with the MFSM, foreign currency-denominated assets and liabilities are converted into local currency, using the exchange rate of the day of the transaction, as published by the BM.

\subsubsection{Recording is done on an accrual basis.}

In accordance with the 1993 SNA and in observance of the aforementioned accounting principle, the sectoral balance sheets record the Resources and Obligations concepts on an accrual basis. Transactions are recorded at the time ownership is transferred. Interest on financial assets and liabilities accrues continuously throughout the accounting period.

The sectoral balance sheets contain a specific item for overdue interest. However, in keeping with the accounting criteria applicable to nonperforming loans, interest accrued on loans is suspended once the loan is considered nonperforming.

Restructured overdue loans continue to form part of the nonperforming loan portfolio and they continue to be considered as possible losses until evidence of repayment is forthcoming. For as long as the loan is considered part of the nonperforming portfolio, accrued interest is recorded in suspense accounts. If the overdue interest is collected, it is recorded directly in earnings for the accounting period. 
Arrears in payments of fees or other charges related to financial instruments that are not included in the general balance sheet are posted under accounts receivable in the balance sheet. In line with the MFSM and with the accounting principle of Original Historical Value, operations between intermediaries are recorded simultaneously. Electronic payments systems are in place to ensure simultaneous recording, especially when the BM intervenes in the matching of those operations (through the Bank of Mexico Account Holders Service System and the Expanded Electronic Payments System). When discrepancies arise at the time of recording, it is not possible to make adjustments to achieve consistency, given the difficulty of identifying the exact moment when the counterparties post the operations. Nevertheless, when mismatches do occur in recording dates, an attempt is made to reconcile the accounts in order to detect the nature of the discrepancies, in the following order: central bank, commercial banks, development banks, and other financial intermediaries.

\subsubsection{Grossing/netting procedures are broadly consistent with internationally accepted standards, guidelines, or good practices}

As the MFSM prescribes, data are collected and compiled on a gross basis. This principle is observed in the financial intermediaries reporting form (Report) and in the financial statistics concepts in Resources and Obligations of commercial banks, development banks, and other financial intermediaries, as well as in the BM balance sheet. In this framework, interbank operations are not netted out. The methodology employed to measure macrofinancial variables, such as monetary aggregates and financing to nonbank sectors requires that figures on a net basis. That is, interbank transactions are eliminated in the following order-central bank, commercial banks, development banks, and other financial intermediaries - in order to accurately measure the participation of the nonbank public.

\section{Accuracy and reliability}

\subsection{Source data}

\subsubsection{Source data are collected from comprehensive data collection programs that take into account country-specific conditions}

The available source data for the central bank and the ODC are comprehensive in scope and constitute an adequate basis for the compilation of monetary statistics in accordance with international standards. In the case of the BM, the basic source of information is the BM statement of accounts (Cedula contable), i.e., Bank of Mexico Assets, Liabilities, and Capital Accounts (at the three-digit level) drawn up by the Office of the Manager of Budgets and Accounting (GPC). The statement of accounts is directly linked to the chart of accounts of the institution and is generated by an accounting system known as ARCO on a daily, weekly, and monthly basis.

The source data for compiling the sectoral balance sheet of the ODC is the Report (data reporting forms) that commercial and development banks transmit electronically each month 
to the BM. Each ODC prepares the Report in line with the Detailed Chart of Accounts, making it possible to identify, in considerable detail, the operations associated with the institutional sector with which they were carried out. Thus the Report covers the complete range of financial instruments and institutional sectors, the latter having been included by the $\mathrm{BM}$ as a criterion for classification of operations since 1980. Although, generally speaking, the accounting information provided in the Report is sufficiently extensive and available on a monthly basis, if necessary, it can be supplemented with surveys designed to elicit qualitative factors and other administrative data, such as the Regional Deposits Report (Informe de captación regional), the Deposit by Range Report (Informe de captación por rangos), the Lending Survey (Encuesta de crédito), and the Current Survey of the Credit Market (Encuesta de evaluación coyuntural del mercado crediticio).

The branches of the ODC send the information to the head office, which prepares the Report and submits it to the BM. The Report consolidates the head office data and those of both local branches and offices residing abroad. The BM also receives a separate report on the operations conducted by the offices abroad, which allows it to derive the data corresponding to domestic banks (that includes only the head office and its branches in Mexico).

\subsubsection{Source data reasonably approximate the definitions, scope, classifications, valuation and time of recording required}

The BM has made significant efforts to improve the primary sources of information and to tailor them to meet internationally recommended standards in this area. The structure and degree of detail of the BM balance sheet make it possible to adopt the sectorization standards of the MFSM and to apply them to the BM's asset and liability operations (even for the weekly data).

Regarding the ODC, the reforms recently enacted by the BM in the collection of basic information from financial intermediaries via the Report have facilitated the development of a database that generates monetary statistics that agree for the most part with MFSM principles. Thus, up to end-1999, the BM and the CNBV shared the same financial intermediary data reporting form. In 1999, after the CNBV decided to change the form to improve bank surveillance, the BM started developing its own data collection system and devised the Report, which is principally designed to meet the BM's basic needs, which focus on sectorization of the economy and of all items in the Report. This approach makes it possible to pinpoint the nature of the borrowers and lenders.

Before introducing the Report, the BM elicited comments from the Association of Mexican Bankers and from a sample of banks, and incorporated them into the final format. Tests to fill out the forms were conducted and all intermediaries were given written instructions. The new system got off the ground in 2000. On February 29, 2000, the BM issued circular fax $13 / 2000$, establishing the terms and conditions to be observed by financial corporations in reporting their asset and liability operations to the BM. Although currently the BM and the CNBV each has its own source data, they cooperate closely with one another and share information whenever the need arises. 
Using the Report as a basic source of information for the ODC has resulted in considerable improvements in the quality of monetary statistics. The data obtained via the Report are broadly consistent with the MFSM concepts and definitions; therefore, adjustments to produce monetary statistics are not necessary. The level of "other assets" and "other liabilities" is insignificant. In 2001, commercial banks and development banks declared 6.2 percent and 2.5 percent of their assets, and 6.5 percent and 3.8 percent of their liabilities, respectively, as "not classified."

Although the Report is the principal source of data for the ODC, the BM is aware of possible discrepancies with secondary data sources and continuously strives to identify and reconcile any such differences.

\subsubsection{Source data are timely}

The data compilation system depends on timely reporting of source data that help produce the sectoral balance sheets of the central bank and the ODC by the established deadlines. As regards the central bank, the GAM's Office of the Assistant Manager of Monetary Analysis (SAM) receives specific information from the GPC on a weekly basis and has direct access to the ARCO system, which contains historical and up-to-date (even daily) information. In this way, the Central Bank obtains the information it needs to produce its sectoral balance sheet, published every week on the Internet as Principales Renglones del Estado de Cuenta del Banco de México (Principal Headings in the Statement of Account of the Bank of Mexico) and as Recursos y Obligaciones (Resources and Obligations). The BM's balance sheet is also the source for other analytical tables prepared for in-house use by the BM. Moreover, the GPC provides the GAM with the additional information (not itemized in the balance sheet) that it needs to perform its functions.

Under the terms of circular fax 13/2000, the ODC are required to send their Reports to the $\mathrm{BM}$ within the first 10 business days following the balance sheet cut-off date. Although the $\mathrm{BM}$ monitors reception and is constantly in touch with respondents to ensure that they meet the deadline, an increasingly large portion of the information is received in the first few business days while a smaller portion is received between the tenth and the twentieth day of each month. The compilation of monetary statistics takes approximately two weeks; consequently, itemized monetary statistics are available on the Internet 40 days after the end of the reference month. ${ }^{16}$

\footnotetext{
${ }^{16} \mathrm{After}$ the visit of the mission, the delay was reduced by six days. It is expected that, with the release of the information for January 2003, the delay will be reduced even further (by an additional three days). Moreover, BM expects that, by the end of the second quarter of 2003, the data file will be transmitted to the IMF on the $30^{\text {th }}$ day of each month.
} 


\subsection{Statistical techniques}

\subsubsection{Data compilation employs sound statistical techniques}

The data compiling procedures are fully automated, thereby reducing the number of processing errors that can occur in coding, revising, and tabulating the source data. With respect to the central bank balance sheet, there are various comparison and revision mechanisms that help minimize errors. For the ODC, the Report is an Excel spreadsheet, which is processed electronically by the operating systems of the ODC, without interfering with their respective accounting systems. The Report has built-in validation criteria that are applied when it is prepared by the ODC.

The BM receives the Reports electronically and stores them in the Basic Banking Information System (SBIB) database. The Office of the Assistant Manager of Financial Information verifies the veracity and coherence of the data and, if necessary, consults with the ODC. Since the information comes from the head office of each ODC, there is a high degree of certainty that the data are internally consistent and reflect the whole accounting structure, making possible to fully validate the information.

Once the information has been validated, the Reports are aggregated and sent to the SBIB database, which stores each entity's accounting and sectorization data from 1980 onwards. The data are classified in accordance with the arrangement required for presentation in Resources and Obligations, while the series for each concept are maintained in the SIE database, from which the accounts of the commercial and development banks are compiled and disseminated.

It is unusual that an institution would fail to report its data for a particular date. However, should it happen, established procedure requires: (a) asking the institution to provide preliminary data for the main components of the balance sheet and applying any changes to the previous information or (b) repeating the figures of the previous month.

The GAM has an organizational manual describing the responsibilities and activities of each area, as well as the process for classifying the information, supporting charts, and references to the automated methodology used for data compilation. There is also a description available of the methodology employed for each statistical exercise. A record and progress report of new projects and improvements is kept every year. The manual was last revised in the third quarter of 2001.

\subsubsection{Other statistical procedures (e.g., data adjustments and transformations and statistical analysis) are also based on sound statistical techniques}

Given the accounting basis of the source data, it is unusual to make statistical adjustments or estimates for the central bank balance sheet and the monetary aggregates. The sectoral balance sheets of commercial banks and development banks encompass all intermediaries and are based on their accounting records. 
Currently there are 11 ODC undergoing liquidation; that is under provisional administration by the CNBV. Whenever a financial institution is "intervened," the MFSM recommends maintaining the last information reported prior to the intervention and, once the process has concluded, removing the operations of the intermediary concerned from the monetary accounts. The practice followed in the preparation of Resources and Obligations is to include each month the updated information that the "provisionally administered" institutions report to the BM. There is no provision stating how long the intervention should last.

The information presented by the reporting institutions includes conversion of foreign exchange into local currency, based on the official exchange rate published by the BM. This procedure is reliable because whenever it is necessary to convert a balance back into the original currency, its magnitude is consistent with the corresponding transaction. Thus, although there is no indirect procedure for verifying the conversion, the Report contains foreign currency positions converted into local currency.

\subsection{Assessment and validation of source data}

3.3.1 Source data-including censuses, sample surveys and administrative records-are routinely assessed, e.g., for coverage, sample error, response error and non-sampling error; the results of the assessments are monitored and made available to guide planning

The process of assessing and validating the source data is automated. In the case of the central bank balance sheet, the fact that source data are based on accounting records and the use of a variety of comparison and revision tools minimize errors and ensure the quality of the information. The data provided by the ODC in the Report undergo a series of (15 to 20) automated checks, using several validation and accounting consistency tools. As a priority, the revision of source data is an ongoing process between the SAM and the reporting ODC that require the BM and the ODC to be in close contact. Any doubts about the data are investigated directly with the reporting ODC which are asked to provide written explanations and, if need be, to send in a new Report to update the statistics.

Source data are scrutinized for omissions and reporting errors. The availability of databases facilitates analysis of the historical series and ensures the consistency of the data. The Basic Banking Information System (SBIB) stores the original accounting and sectorization information, and the Economic Information System (SIE) stores the structured information as historical series.

Moreover, when the figures reported by the ODC show major shifts, the information is crosschecked with other sources available in various databases in the BM and with the CNBV. For instance, the flow of funds table is used to check consistency between accounts. The findings are shared with the agency responsible for collecting the relevant data. 


\subsection{Assessment and validation of intermediate and final output data}

3.4.1 Main intermediate results are validated against other information where applicable

In general, the SIF uses secondary sources to verify the information reported by the ODC, with a view to reconcile the counterpart data involving the ODC with the BM and other financial institutions. The Office of the Assistant Manager of Government Finance Analysis also uses securities market data to cross-check the ODC asset holdings data.

\subsubsection{Statistical discrepancies in the intermediate data are assessed and investigated}

Whenever statistical discrepancies are detected in the intermediate data, the SAM investigates their nature and origin.

3.4.3 Statistical discrepancies and other indicators of potential problems with other output data are investigated

The ODC data are checked to prevent statistical discrepancies due to errors in classification or omissions. The SIF investigates any unexplained fluctuation directly with the reporting ODC and crosses information with other institutions and sources.

\subsection{Studies of revisions}

\subsubsection{Studies and analyses of revisions are carried out routinely and used to improve statistical processes}

The SIF and SAM routinely analyze the data and compare the preliminary figures with the final. The findings are kept in a register of changes. When necessary, the ODC are asked to report revisions of their preliminary data. The BM and the reporting institutions remain in close contact to identify discrepancies in the data and their findings are taken into account in the compilation of data for subsequent periods.

\section{Serviceability}

\subsection{Relevance}

4.1.1 The relevance and practical utility of the statistics in meeting users' needs are regularly assessed

The BM considers that it is vital to provide the public with the statistical support it needs to make informed decisions. To this end, whenever there is a change of methodology, consultations and meetings are held with users. Although the BM does not conduct direct, periodic consultations with users via surveys, it frequently invites the financial community to presentations of its statistical bulletins and research papers. Moreover, the BM staff 
responsible for compiling monetary statistics routinely participate in relevant statistical meetings and conferences organized by international and regional agencies.

The BM monitors developments in the financial sector and incorporates any major changes in the statistics. It also keeps track of the financial press and, when called for, explanations are given and published. Access to the Internet pages of the SHCP, the CNBV, the National Insurance and Guarantees Commission, and the BM facilitates tracking the provisions affecting the financial sector. The BM's intranet contains a summary of press cuttings on the financial sector, as well as bulletins and studies generated in the BM.

\subsection{Timeliness and periodicity}

\subsubsection{Timeliness follows dissemination standards}

Central bank data are disseminated monthly on the BM's website within the first five business days following the end of the reference month. In addition, some monetary data, such as monetary base, defined by its uses or currency in circulation, are published every day and the main categories of the BM's balance sheet are published weekly, with a two-day lag. The timeliness of the central bank data surpasses SDDS requirements.

As regards the ODC, a section on the BM's website called Agregados Monetarios $y$ Actividad Financiera [Monetary Aggregates and Financial Activity] contains preliminary summary monthly data with a 25-day lag, which meets SDDS requirements. The information includes the main headings of the ODC balance sheets and changes in monetary aggregates and financing. Subsequently, in Monetary Aggregates and Financial Activity, preliminary itemized monthly statistics are published with a 40-day lag, which exceeds the one-month prescribed by the SDDS. This delay is largely due to the failure of a (dwindling) group of ODC to send their Report on time. The BM is making efforts so that all ODC send the Report between the tenth and the fifteenth of each month so as to gradually to reduce the lag in dissemination of the statistics to 30 days by mid-2002. ${ }^{17}$

\subsubsection{Periodicity follows dissemination standards}

Preliminary monetary statistics on the central bank and the banking system are disseminated on a monthly basis in accordance with SDDS requirements.

\footnotetext{
${ }^{17}$ After the visit of the mission, the delay was reduced by six days. It is expected that, with the release of the information for January 2003, the delay will be reduced even further (by an additional three days). Moreover, BM expects that, by the end of the second quarter of 2003, the data file will be transmitted to the IMF on the $30^{\text {th }}$ day of each month.
} 


\subsection{Consistency}

\subsubsection{Statistics are internally consistent within the dataset (e.g., accounting identities are observed)}

The monetary statistics presented in the sectoral balance sheets of the central bank and the ODC are internally consistent, since assets and liabilities are recorded on an accrual basis. Consistency between the statistics of the BM and the ODC is facilitated by the use of electronic fund transfer systems, which support simultaneity in interbank transactions. Nevertheless, occasionally, and especially towards the end of the month, differences in recording may occur due to operations in transit, but they can be reconciled.

The BM also verifies the internal consistency of the data, by cross-checking the information prepared in the different departments of the BM, taking into account that the source data come from different working groups (accounting, operational) in the reporting institutions. Each year, the BM publishes a flow-of-funds table, in which the monetary accounts are directly derived from the monetary aggregates. Therefore, it is possible to reconcile the monetary aggregates with the flow-of-funds data. Nevertheless, the information published in the flow-of-funds table shows revalued flows (thereby eliminating the effect of changes in the exchange rate), whereas the monetary aggregates information corresponds to current balances.

\subsubsection{Statistics are consistent or reconcilable over a reasonable period of time}

The BM's time series are consistent. The central bank data published since 1985 are based on the same methodology. As regards commercial banks and development banks, time series are available from December 1980 to December 2001, divided into two segments, each of which is based on a different methodology. The first segment covers the 1980-1996 period, while the second begins in January 1997. The second set of data reflects the methodology adapted in accordance with the Report, which was introduced in 2000, so that the historical series since 1997 had to be revised. In this connection, it should be noted that the series common to both datasets are perfectly linked. The methodological changes in the series are indicated in footnotes to the tables in the BM publications.

In general, major fluctuations are explained in the monthly press release on Monetary Aggregates and Financial Activity, which is published on the BM website, as well as in other BM publications, such as Informe Semestral sobre Politica Monetaria [Half-yearly Report on Monetary Policy] and the Annual Report. The SBIB has a module which allows significant comments to be incorporated into the database itself, for internal consultation in the BM.

\subsubsection{Statistics are consistent or reconcilable with those obtained from other data sources or statistical frameworks}

Monetary statistics are reconcilable with balance of payments and public finance data, which are compiled by the BM's Office of the Assistant Manager of External Sector Analysis and 
the Office of the Assistant Manager of Information and Government Finance Analysis, respectively. The transactions and sectorization of foreign assets included in the monetary statistics are compatible with the balance of payments, and the flow of funds table consolidates this information. Any differences between the balance of payments and the monetary accounts are explicitly noted in line 16 ("statistical discrepancy") of the flow of funds table.

Fiscal data on federal government deposits in depository institutions and on the loans it obtains from these institutions are compatible with the corresponding data in monetary statistics. Furthermore, reconciliation exercises are carried out on the data for the public sector financing requirement, which are compiled using alternative information sources. The figures are reconciled monthly and the discrepancies, generally arising from differences in sectorization, are analyzed and the relevant sources are revised accordingly. This reconciliation is conducted by staff of the Office of the Assistant Director General of Financial Statistics in the SHCP and the Office of the Assistant Manager of Information and Government Finance Analysis in the BM. To assist in the sectorization of institutions, the $\mathrm{BM}$ is updating a public sector classification chart for use by the various units that need this information to prepare their accounts.

\subsection{Revision policy and practice}

\subsubsection{Revisions follow a regular, well-established and transparent schedule}

The data revision cycle follows set internal procedures and a schedule, which establish publication dates. Under this arrangement, published figures remain preliminary for two months, after which they are considered final. The contents of the statistics are reviewed on a continuous basis and any change that arises is immediately incorporated into the database, and users are notified by means of footnotes or an explanation in Resources and Obligations, Monetary Aggregates and Financial Activity Bulletin or in the Half-yearly Report on Monetary Policy and the Annual Report, as appropriate.

\subsubsection{Preliminary data are clearly identified}

A general footnote explains to users that the published data are preliminary and subject to revision. The revised data are published with the same level of detail as the previous data.

\subsubsection{Studies and analyses of revisions are made public (see section 3.5.1)}

The BM carries out routine consistency studies between the preliminary and the revised data. These studies are for the BM's internal use and are therefore not published. In principle, users can compare the data since the BM keeps the preliminary data on its website. 


\section{Accessibility}

\subsection{Data accessibility}

\subsubsection{Statistics are presented in a way that facilitates proper interpretation and meaningful comparison (layout and clarity of text, tables and charts)}

The presentation of monetary statistics facilitates their interpretation and enables monitoring of monetary and financial developments. The presentation is flexible enough to allow users to rearrange the statistics to better serve their interests (by issuer of an instrument, holder of an instrument, public sector or private sector, residents and nonresidents, deposits by branch, etc.) The Monetary Aggregates and Financial Activity, the Boletín Semanal sobre Algunos Aspectos del Programa Monetario y el Estado de Cuenta del Banco de México [Weekly Bulletin on Some Aspects of the Monetary Program and Statement of Account of Bank of Mexico], and the whole set of Indicadores Económicos y Financieros [Economic and Financial Indicators] contain charts and tables that provide an efficient way to follow developments in the principal monetary aggregates. On its website, the BM publishes accounts with a more detailed breakdown, while preserving the presentation and structure of the information by means of (1) a table for the last three dates and (2) time series.

Estimates of monetary or credit aggregates are not published, nor are seasonally adjusted series of the monetary accounts. However, the methodology for seasonally adjusting the monetary aggregates is currently being assessed.

\subsubsection{Dissemination media and formats are adequate}

The media and formats used in the dissemination of data are adequate, particularly for users who have access to the Internet, as both recent data and the historical series can be consulted on the BM website. The BM also publishes the information in a timely fashion in press releases.

\subsubsection{Statistics are released on a pre-announced schedule}

Statistics are released according to a pre-announced schedule in keeping with SDDS requirements (it shows exact dates of publication with three month's notice). The schedule is available on the BM website.

\subsubsection{Statistics are made available to all users at the same time}

The $\mathrm{BM}$ has provisions and procedures in place to ensure that monetary statistics are published on the dates specified in the advance release calendar. The statistics are made available to interested users at the same time on the BM website. In addition, weekly BM data are published in the BM Press Release and in the Weekly Bulletin on Some Aspects of the Monetary Program and Statement of Account of Bank of Mexico. Banking sector data are also disseminated on the Internet. The press release includes brief technical commentaries on 
the data, but no commentary on monetary policy. Any significant methodological change is explained via the Internet.

\subsubsection{Non-published (but non-confidential) subaggregates are made available upon request}

The BM provides subaggregates of unpublished data, upon request, provided that the information involved is not confidential.

\subsection{Metadata accessibility}

5.2.1 Documentation on concepts, scope, classifications, basis of recording, data sources and statistical techniques is available, and differences from internationally accepted standards, guidelines, or good practices are noted

The BM publishes brief methodological notes on its website and, in particular, in the Annual Report, but it does not make available to the public extensive documentation of the methodology currently employed in compiling monetary statistics. ${ }^{18}$ To comply with the IMF's Special Data Dissemination Standards, the BM prepared summaries of the methodology, which can be found on the IMF website's for the Dissemination Standards Bulletin Board. However, it should be pointed out that this information does not reflect recent changes in the ODC source data or monetary aggregate and financing methodologies. The BM is aware of the need to update the metadata and has begun working on this. ${ }^{19}$ The $\mathrm{BM}$ is finalizing the incorporation of a metadata and methodologies module in the Economic and Financial Indicators section on its website.

\subsubsection{The degree of detail is adapted to the needs of users, to ensure their satisfaction}

The detail of the monetary statistics available on the BM website is quite extensive, although not always easy to locate due to the abundance of information and the complexity of the site. In recognition of this limitation, the BM has started a project to simplify the search procedure. It is worth noting that the BM discussed the structure of the tables and subaggregates of the series presented with monetary analysts and specialists. Thus, the section entitled "economic and financial information" contains, inter alia, itemized information on (1) assets and liabilities of the BM, commercial banks and development banks; (2) credit granted by commercial and development banks, by type of business activity; (3) regional distribution of commercial bank deposit taking by principal instrument; (4) resources and obligations of other nonbank financial intermediaries; (5) monetary

\footnotetext{
${ }^{18}$ Following the visit of the mission, the BM posted an extensive methodological note on its website.

${ }^{19}$ Following the visit of the mission, the BM updated the metadata.
} 
aggregates; and (6) financing for nonbank sectors. It also contains a historical series of Resources and Obligations of the Bank of Mexico, which provides a more detailed balance sheet consistent with the weekly information.

There is no detailed documentation available to the public describing the methods and sources used to compile the monetary statistics. Nevertheless, the BM makes this information available to data users upon request. Once the metadata and methodologies module is completed, the public will have access to this information.

\subsection{Assistance to users}

\subsubsection{Contact person for each subject field is publicized.}

The BM provides user service via an electronic mailbox, which allows direct access to a member of the Governing Board (Deputy Governor), who passes the queries on to the appropriate area in the BM. Although the BM does not conduct periodic user surveys, its policy is to reply to all the e-mails it receives, and through the replies it keeps track of user satisfaction.

\subsubsection{Catalogs of publications, documents and other services, including information on their cost, are easily obtainable}

The BM has a catalog of publications listing all available titles on macroeconomic sectors and research papers. Access to this information, which includes the advance release calendar, is through the BM's website. All BM publications are free of charge. Occasional meetings are arranged with different groups of private analysts and the media to brief them regarding the information published by the BM and to answer any questions they might have. 


\section{Dimensions and Elements of the Special Data Dissemination Standard (SDDS)}

Data dimension (coverage, periodicity and timeliness)

- the dissemination of 18 data categories, including component detail covering the four main sectors of the economy, with prescribed periodicity and timeliness.

\section{Access dimension}

- $\quad$ the dissemination of advance release calendars (ARCs) providing at least a onequarter ahead notice of approximate release dates, and at least a one-week ahead notice of the precise release dates;

- $\quad$ the simultaneous release of data to all users.

\section{Integrity dimension}

- the dissemination of the terms and conditions under which official statistics are produced and disseminated;

- the identification of internal government access to data before release;

- the identification of ministerial commentary on the occasion of statistical releases;

- the provision of information about revision and advance notice of major changes in methodology.

\section{Quality dimension}

- the dissemination of documentation on statistical methodology and sources used in preparing statistics;

- the dissemination of component detail and/or additional data series that make possible cross-checks and checks of reasonableness.

SDDS subscribers are required:

- $\quad$ to post descriptions of their data dissemination practices (metadata) on the IMF's Dissemination Standards Bulletin Board (DSBB). Summary methodologies, which describe data compilation practices in some detail, are also disseminated on the DSBB.

- $\quad$ to maintain an Internet website, referred to as the National Summary Data Page, which contains the actual data described in the metadata, and to which the DSBB is electronically linked. 
At the March 29, 2000 meeting of the IMF's Executive Board, Directors approved the incorporation of a new SDDS data category on external debt. The transition period for implementing this data category expires in March 2003.

As a result of the IMF Executive Board's Third Review of the SDDS in March 2000, IMF staff began monitoring observance of the Standard through NSDPs maintained on the Internet. Monitoring commenced from July 2000, and is limited to the coverage, periodicity, and timeliness of the data, and to the dissemination of advance release calendars. 
Mexico: General Overview of Data Dissemination Practices in Comparison with the SDDS

\begin{tabular}{|c|c|c|c|c|c|c|}
\hline \multirow{2}{*}{$\begin{array}{l}\text { SDDS Data } \\
\text { Category }\end{array}$} & \multirow{2}{*}{$\begin{array}{l}\text { Coverage } \\
\text { meets } \\
\text { SDDS } \\
\text { requirement }\end{array}$} & \multicolumn{2}{|c|}{ Periodicity } & \multicolumn{2}{|c|}{ Timeliness } & \multirow[b]{2}{*}{ Comments } \\
\hline & & SDDS & Mexico $^{1}$ & SDDS & Mexico $^{1}$ & \\
\hline \multicolumn{7}{|l|}{ Real Sector } \\
\hline National Accounts & Yes & Q & Q & Q & $61 / 2 \mathrm{~W}$ & $\begin{array}{l}\text { Timeliness exceeds SDDS } \\
\text { requirements. }\end{array}$ \\
\hline $\begin{array}{l}\text { Industrial } \\
\text { Production }\end{array}$ & Yes & $\mathrm{M}$ & $\mathrm{M}$ & $\begin{array}{c}6 \mathrm{~W}(\mathrm{M} \\
\text { encour- } \\
\text { aged) }\end{array}$ & Within 6W & \\
\hline Employment & Yes & Q & $\mathrm{M}$ & Q & $3 \mathrm{~W}$ & $\begin{array}{l}\text { Periodicity and timeliness } \\
\text { exceed SDDS requirements. }\end{array}$ \\
\hline Unemployment & Yes & Q & $\mathrm{M}$ & Q & $3 \mathrm{~W}$ & $\begin{array}{l}\text { Periodicity and timeliness } \\
\text { exceed SDDS requirements. }\end{array}$ \\
\hline Wages/Earnings & Yes & Q & $\mathrm{M}$ & Q & $9 \mathrm{~W}$ & $\begin{array}{l}\text { Periodicity and Timeliness } \\
\text { exceed SDDS requirements. }\end{array}$ \\
\hline $\begin{array}{l}\text { Consumer Price } \\
\text { Index }\end{array}$ & Yes & $\mathrm{M}$ & $\mathrm{M}$ & $1 \mathrm{M}$ & $\begin{array}{l}\text { Within } \\
10 \text { days }\end{array}$ & $\begin{array}{l}\text { Timeliness exceeds SDDS } \\
\text { requirements. }\end{array}$ \\
\hline $\begin{array}{l}\text { Producer Price } \\
\text { Index }\end{array}$ & Yes & $\mathrm{M}$ & $\mathrm{M}$ & $1 \mathrm{M}$ & $\begin{array}{l}\text { Within } \\
9 \text { days }\end{array}$ & $\begin{array}{l}\text { Timeliness exceeds SDDS } \\
\text { requirements. }\end{array}$ \\
\hline \multicolumn{7}{|l|}{ Fiscal Sector } \\
\hline $\begin{array}{l}\text { General } \\
\text { Government } \\
\text { Operations }\end{array}$ & Yes & A & A & $2 \mathrm{Q}$ & $\begin{array}{l}1 \text { year } \\
8 \mathrm{M}\end{array}$ & $\begin{array}{l}\text { The flexibility option for the } \\
\text { timeliness of the data is used. }\end{array}$ \\
\hline $\begin{array}{l}\text { Central } \\
\text { Government } \\
\text { Operations }\end{array}$ & Yes & $\mathrm{M}$ & $\mathrm{M}$ & $1 \mathrm{M}$ & 30-35 days & $\begin{array}{l}\text { The flexibility option for the } \\
\text { timeliness of the data is used. }\end{array}$ \\
\hline $\begin{array}{l}\text { Central } \\
\text { Government Debt }\end{array}$ & Yes & Q & Q & $1 \mathrm{Q}$ & 35 days & $\begin{array}{l}\text { Timeliness exceeds SDDS } \\
\text { requirements. }\end{array}$ \\
\hline \multicolumn{7}{|l|}{ Financial Sector } \\
\hline $\begin{array}{l}\text { Analytical } \\
\text { Accounts of the } \\
\text { Banking Sector }\end{array}$ & Yes & $\mathrm{M}$ & $\mathrm{M}$ & $1 \mathrm{M}$ & 25 days & $\begin{array}{l}\text { Timeliness exceeds SDDS } \\
\text { requirements. }\end{array}$ \\
\hline $\begin{array}{l}\text { Analytical } \\
\text { Accounts of the } \\
\text { Central Bank }\end{array}$ & Yes & $\begin{array}{l}\text { M (W } \\
\text { encour- } \\
\text { aged) }\end{array}$ & $\mathrm{W}$ & $\begin{array}{c}2 \mathrm{~W}(\mathrm{~W} \\
\text { encour- } \\
\text { aged })\end{array}$ & $\begin{array}{l}\text { 2BD after } \\
\text { every Friday }\end{array}$ & $\begin{array}{l}\text { Periodicity and timeliness } \\
\text { exceed SDDS requirements. }\end{array}$ \\
\hline Interest Rates & & $\mathrm{D}$ & $\mathrm{D}$ & 2 & $\mathrm{D}$ & \\
\hline Stock Market & Yes & $\mathrm{D}$ & $\ldots$ & ? & $\ldots$ & \\
\hline
\end{tabular}


Mexico: General Overview of Data Dissemination Practices in Comparison with the SDDS

\begin{tabular}{|c|c|c|c|c|c|c|}
\hline \multirow{2}{*}{$\begin{array}{l}\text { SDDS Data } \\
\text { Category }\end{array}$} & \multirow{2}{*}{$\begin{array}{c}\text { Coverage } \\
\text { meets } \\
\text { SDDS } \\
\text { requirement }\end{array}$} & \multicolumn{2}{|c|}{ Periodicity } & \multicolumn{2}{|c|}{ Timeliness } & \multirow[b]{2}{*}{ Comments } \\
\hline & & SDDS & Mexico $^{1}$ & SDDS & Mexico $^{1}$ & \\
\hline \multicolumn{7}{|l|}{ External Sector } \\
\hline $\begin{array}{l}\text { Balance of } \\
\text { Payments }\end{array}$ & Yes & Q & Q & $1 \mathrm{Q}$ & $9 \mathrm{~W}$ & $\begin{array}{l}\text { Timeliness exceeds SDDS } \\
\text { requirements. }\end{array}$ \\
\hline $\begin{array}{l}\text { International } \\
\text { Reserves }\end{array}$ & Yes & $\begin{array}{c}\text { M (W } \\
\text { encour- } \\
\text { aged) }\end{array}$ & $\mathrm{W}$ & $1 \mathrm{~W}$ & 2BD & $\begin{array}{l}\text { Periodicity and timeliness } \\
\text { exceed SDDS requirements. }\end{array}$ \\
\hline Reserves Template & Yes & $\mathrm{M}$ & $\mathrm{M}$ & $1 \mathrm{M}$ & $1 \mathrm{M}$ & \\
\hline Balance of Trade & Yes & $\mathrm{M}$ & $\mathrm{M}$ & $\begin{array}{c}\text { 8W (4-6W } \\
\text { encour- } \\
\text { aged) }\end{array}$ & $3 \mathrm{~W}$ & $\begin{array}{l}\text { Timeliness exceeds SDDS } \\
\text { requirements. }\end{array}$ \\
\hline $\begin{array}{l}\text { International } \\
\text { Investment } \\
\text { Position }\end{array}$ & Yes & $\begin{array}{c}\text { A (Q } \\
\text { encour- } \\
\text { aged) }\end{array}$ & $\ldots$ & $\begin{array}{l}\text { 2Q (Q } \\
\text { encour- } \\
\text { aged) }\end{array}$ & $6 \mathrm{M}$ & Not currently prepared. ${ }^{3 /}$ \\
\hline Exchange Rates & Yes & $\mathrm{D}$ & $\mathrm{D}$ & 21 & $\mathrm{D}$ & \\
\hline $\begin{array}{l}\text { Addendum: } \\
\text { Population }\end{array}$ & Yes & A & $\bar{A}$ & 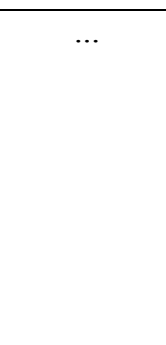 & $1 \mathrm{Q} / 5 \mathrm{M}$ & $\begin{array}{l}\text { For the years in between } \\
\text { censuses, the data are } \\
\text { published in the first quarter } \\
\text { of the reference year. For the } \\
\text { years in which censuses are } \\
\text { taken, the preliminary data } \\
\text { are published five months } \\
\text { after the census. }\end{array}$ \\
\hline
\end{tabular}

Periodicity and timeliness: (D) daily; (BD)with a lag of no more than one banking day; (W) weekly or with a lag of no more than one week from the reference date or the closing of

the reference week; (M) monthly or with a lag of no more than one month; $(\mathrm{Q})$ quarterly or with a lag of no more than one quarter; (A) annually; and (...) not applicable.

${ }^{1}$ Refers to current practices in Mexico.

${ }^{2}$ Given that the data are broadly disseminated by private means, the timeliness with which official data are published is not so important. Although dissemination is recommended via recorded telephone messages or by fax, the dissemination of these data may form part of other dissemination mechanisms (preferably, high frequency).

${ }^{3}$ After the visit of the mission, 2001 data were disseminated for the first time, six months after the end of the reference period. 


\section{The Data Quality Assessment Framework}

For some time now, the IMF Statistics Department has been developing a data quality assessment framework (DQAF). This initiative responds to a number of needs, including enhancing the quality dimension of the Special Data Dissemination Standards (SDDS), focusing more closely on the quality of the data submitted by the IMF countries, which underpins Fund surveillance of countries' economic policies, and systematically evaluating the data quality provided for the IMF Reports on Observance of Standards and Codes (ROSC). Against this background, the IMF Statistics Department developed and assessment methodology that provides a structure and a common language for evaluating data quality. The DQAF that has emerged comprises a generic framework which brings together the internationally accepted core principles for official statistics, and serves as an umbrella for the macroeconomic dataset-specific frameworks (national accounts, consumer price, producer price, balance of payments, government finance, and monetary statistics). The main components of these dataset-specific frameworks are select indicators of quality.

The DQAF covers five dimensions of quality and a set of prerequisites for the assessment of data quality (see below). The coverage of these dimensions recognizes that data quality encompasses the quality of the institution or system behind the production of the data as well as the individual data product. Within this framework, each dimension comprises a number of elements, which are in turn associated with a set of desirable practices. The following are the statistical practices associated with each dimension:

- $\quad$ Prerequisites of quality — the legal and institutional framework is supportive of statistics; resources are commensurate with the needs of the statistical programs; quality is recognized as a cornerstone of statistical work.

- Integrity—professionalism in statistical policies and practices is a guiding principle; statistical policies and practices are transparent; policies and practices are guided by ethical standards.

- Methodological soundness - concepts and definitions used are in accord with accepted statistical frameworks; the scope is in accord with internationally accepted standards; classification and sectorization systems are consistent with internationally accepted standards; flows and stocks are valued and recorded according to internationally accepted standards.

- $\quad$ Accuracy and reliability — source data available provide an adequate basis to compile statistics; statistical techniques employed conform to sound statistical procedures; source data are regularly assessed and results validated; revisions, as a gauge of reliability, are tracked and mined for the information they may provide.

- $\quad$ Serviceability — statistics cover relevant information on the subject field; timeliness and punctuality follow internationally accepted dissemination standards; statistics are 
consistent over time, internally, and with major data systems; data revisions follow a regular and publicized procedure.

- Accessibility — statistics are presented in a clear and understandable manner, forms of dissemination are adequate, and statistics are made available on an impartial basis; up-to-date and pertinent metadata are made available; prompt and knowledgeable support service is available.

One main characteristic of this framework is its structure, which focuses on the principles of quality, organized in an orderly series from the abstract to the specific. Thus, a group of elements has been developed for each of the dimensions and all the prerequisites of quality that indicate desirable practices and a set of indicators and focal points corresponding to those practices. 


\section{Data Quality Assessment Framework: Generic Framework (July 2001 version)}

\begin{tabular}{|c|c|c|}
\hline Quality Dimensions & Elements & Indicators \\
\hline $\begin{array}{l}\text { Prerequisites of } \\
\text { Quality }^{1}\end{array}$ & $\begin{array}{l}\text { 0.1 Legal and } \\
\text { institutional environment } \\
\text { - The environment is } \\
\text { supportive of statistics. } \\
\text { 0.2 Resources } \\
\text { - Resources are } \\
\text { commensurate with needs } \\
\text { of statistical programs. } \\
\text { 0.3 Quality awareness } \\
\text { - Quality is recognized as } \\
\text { a cornerstone of } \\
\text { statistical work. }\end{array}$ & $\begin{array}{l}\text { 0.1.1 The responsibility for collecting, compiling and } \\
\text { disseminating statistics is clearly assigned. } \\
\text { 0.1.2 Data sharing and coordination among data producing } \\
\text { agencies are adequate. } \\
\text { 0.1.3 Respondents' data are to be kept confidential and used } \\
\text { for statistical purposes only. } \\
\text { 0.1.4 Statistical reporting is supported by legal mandate } \\
\text { and/or measures implemented to encourage voluntary } \\
\text { response. } \\
\text { 0.2.1 Staff, financial and computing resources are } \\
\text { commensurate with statistical programs. } \\
\text { 0.2.2 Measures to ensure efficient use of resources are } \\
\text { implemented. } \\
\text { 0.3.1 Procedures have been put in place for quality } \\
\text { awareness. } \\
\text { 0.3.2 Procedures have been established for monitoring the } \\
\text { quality of data collection, compilation, and dissemination. } \\
\text { 0.3.3 Procedures are in place to assess the quality of } \\
\text { statistics, to acknowledge and deal with tradeoffs within } \\
\text { quality, and to guide planning for existing and emerging } \\
\text { needs. }\end{array}$ \\
\hline $\begin{array}{l}\text { 1. Integrity } \\
\text { The principle of } \\
\text { objectivity in the } \\
\text { collection, } \\
\text { compilation, and } \\
\text { dissemination of } \\
\text { statistics is firmly } \\
\text { adhered to. }\end{array}$ & & $\begin{array}{l}\text { 1.1.1 Statistics are compiled on an impartial basis. } \\
\text { 1.1.2 Choices of sources and statistical methods are } \\
\text { informed solely by statistical considerations. } \\
\text { 1.1.3 The appropriate statistical entity is entitled to } \\
\text { comment on errors of interpretation and misuse of } \\
\text { statistics. } \\
\text { 1.2.1 The terms and conditions under which statistics are } \\
\text { collected, compiled, and disseminated are available to the } \\
\text { public. } \\
\text { 1.2.2 Internal governmental access to statistics prior to } \\
\text { their release is made known to the public. } \\
\text { 1.2.3 Products of statistical agencies/units are clearly } \\
\text { identified as such. } \\
\text { 1.2.4 Advance notice is given of major changes in } \\
\text { methodology, source data and statistical techniques. } \\
\text { 1.3.1 Guidelines for staff behavior are made known to } \\
\text { staff. }\end{array}$ \\
\hline
\end{tabular}




\section{Data Quality Assessment Framework: Generic Framework (July 2001 version)}

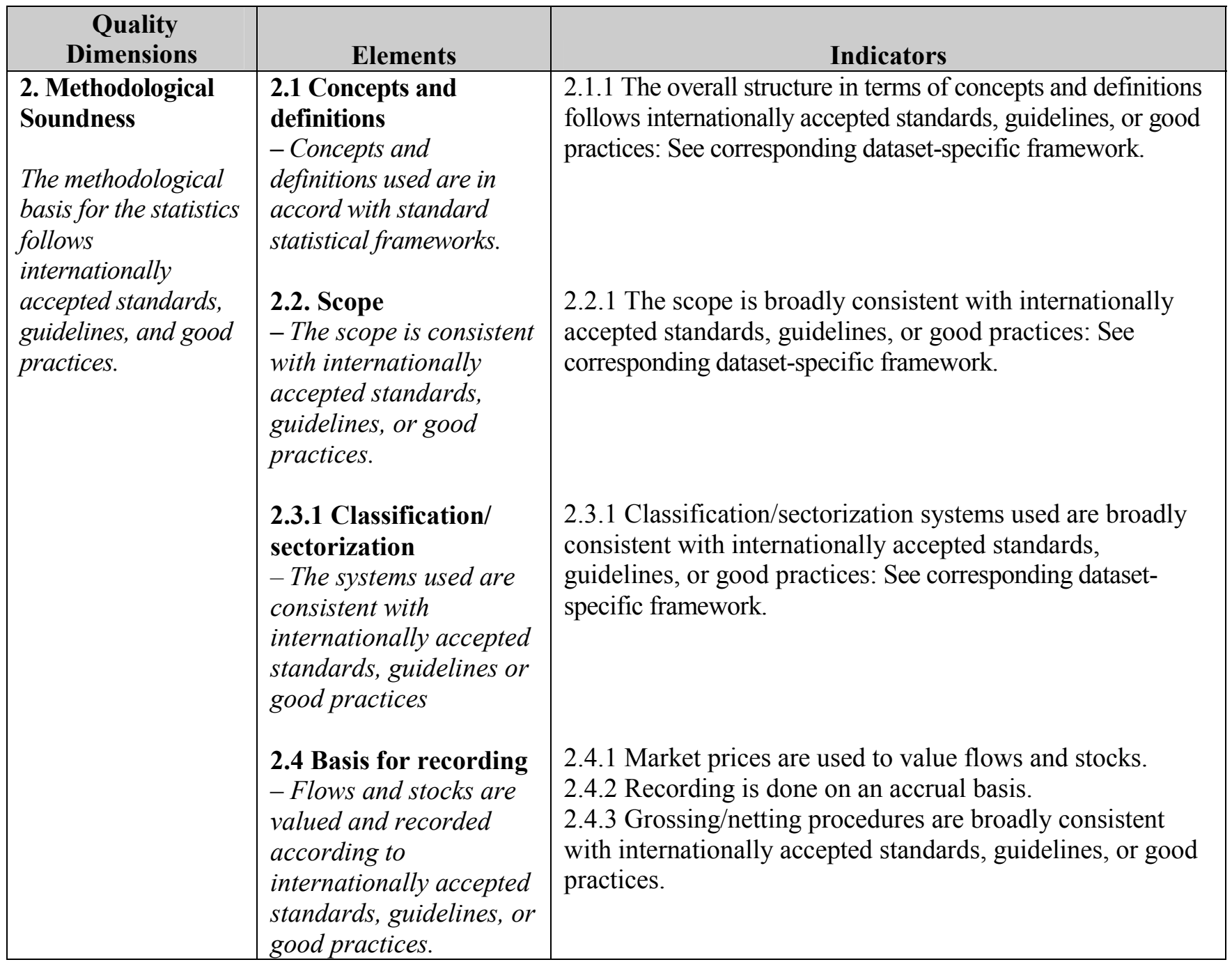




\section{Data Quality Assessment Framework: Generic Framework (July 2001 version)}

\begin{tabular}{|c|c|c|}
\hline $\begin{array}{c}\text { Quality } \\
\text { Dimensions }\end{array}$ & Elements & Indicators \\
\hline $\begin{array}{l}\text { 3. Accuracy and } \\
\text { reliability } \\
\text { Source data and } \\
\text { statistical techniques } \\
\text { are sound, and } \\
\text { output data } \\
\text { sufficiently portray } \\
\text { reality. }\end{array}$ & $\begin{array}{l}\text { 3.3 Assessment and } \\
\text { validation of source data } \\
\text { - Source data are periodically } \\
\text { assessed and validated. } \\
\text { 3.4 Assessment and } \\
\text { validation of intermediate } \\
\text { and output data } \\
\text { - Intermediate and final output } \\
\text { data are periodically assessed } \\
\text { and validated. } \\
\text { 3.5 Revision studies } \\
\text { - Revisions, as a gauge of } \\
\text { reliability, are tracked and } \\
\text { mined for the information they } \\
\text { may provide. }\end{array}$ & $\begin{array}{l}\text { 3.1.1 Source data are collected from } \\
\text { comprehensive data collection programs that } \\
\text { take into account country-specific conditions. } \\
\text { 3.1.2 Source data reasonably approximate } \\
\text { the definitions, scope, classifications, } \\
\text { valuation and time of recording required. } \\
\text { 3.1.3 Source data are timely. } \\
\text { 3.2.1 Data compilation employs sound } \\
\text { statistical techniques. } \\
\text { 3.2.2 Other statistical procedures (e.g., data } \\
\text { adjustments and transformations and statistical } \\
\text { analysis) are also based on sound statistical } \\
\text { techniques. } \\
\text { 3.3.1 Source data-including censuses, sample } \\
\text { surveys and administrative records-are } \\
\text { routinely assessed, e.g., for coverage, sample } \\
\text { error, response error, and non-sampling error; } \\
\text { the results of the assessments are monitored } \\
\text { and made available to facilitate planning. } \\
\text { 3.4.1 Main intermediate results are validated } \\
\text { against other information where applicable. } \\
\text { 3.4.2 Statistical discrepancies in the } \\
\text { intermediate data are assessed and } \\
\text { investigated. } \\
\text { 3.4.3 Statistical discrepancies and other } \\
\text { indicators of potential problems with other } \\
\text { output data are investigated. } \\
\text { 3.5.1 Studies and analyses of revisions are } \\
\text { carried out routinely and used to improve } \\
\text { statistical processes. }\end{array}$ \\
\hline
\end{tabular}




\section{Data Quality Assessment Framework: Generic Framework (July 2001 version)}

\begin{tabular}{|c|c|c|}
\hline $\begin{array}{c}\text { Quality } \\
\text { Dimensions }\end{array}$ & Elements & Indicators \\
\hline $\begin{array}{l}\text { 4. Serviceability } \\
\text { Statistics are } \\
\text { relevant, timely, } \\
\text { consistent, and } \\
\text { follow a predictable } \\
\text { revisions policy. }\end{array}$ & $\begin{array}{l}\text { 4.1 Relevance of the statistics } \\
\text { - Statistics cover relevant } \\
\text { information on the subject field. } \\
\text { 4.2 Timeliness and periodicity } \\
\text { - The timeliness and periodicity } \\
\text { of the statistics follow } \\
\text { internationally accepted } \\
\text { dissemination standards. } \\
\text { 4.3 Consistency } \\
\text { - Statistics are internally } \\
\text { consistent within the dataset and } \\
\text { over time, and are compatible } \\
\text { with other datasets. } \\
\text { 4.4 Revisions policy and } \\
\text { procedures } \\
\text { - Data revisions follow a } \\
\text { regular and publicized } \\
\text { procedure. }\end{array}$ & $\begin{array}{l}\text { 4.1.1 The relevance and practical utility of } \\
\text { the statistics in meeting users' needs are } \\
\text { regularly assessed. } \\
\text { 4.2.1 Timeliness follows dissemination } \\
\text { standards. } \\
\text { 4.2.2 Periodicity follows dissemination } \\
\text { standards. } \\
\text { 4.3.1 Statistics are internally consistent } \\
\text { within the dataset (e.g., accounting } \\
\text { identities are observed). } \\
\text { 4.3.2 Statistics are consistent or reconcilable } \\
\text { over a reasonable period of time. } \\
\text { 4.3.3 Statistics are consistent or reconcilable } \\
\text { with those obtained from other data sources } \\
\text { and/or statistical frameworks. } \\
\text { 4.4.1 Revisions follow a regular, well- } \\
\text { established and transparent schedule. } \\
\text { 4.4.2 Preliminary data are clearly identified. } \\
\text { 4.4.3 Studies and analyses of revisions are } \\
\text { made public. }\end{array}$ \\
\hline
\end{tabular}




\section{Data Quality Assessment Framework: Generic Framework (July 2001 version)}

\begin{tabular}{|c|c|c|}
\hline $\begin{array}{c}\text { Quality } \\
\text { Dimensions }\end{array}$ & Elements & Indicators \\
\hline $\begin{array}{l}\text { 5. Accessibility } \\
\text { Data and metadata } \\
\text { are easily available } \\
\text { and assistance to } \\
\text { users is adequate. }\end{array}$ & $\begin{array}{l}\text { 5.2 Metadata accessibility } \\
\text { - Up-to-date and pertinent } \\
\text { metadata are made available. } \\
\\
\text { 5.3 Assistance to users } \\
\text { - Prompt and knowledgeable } \\
\text { support service is available. }\end{array}$ & $\begin{array}{l}\text { 5.1.1 Statistics are presented in a way that } \\
\text { facilitates proper interpretation and } \\
\text { meaningful comparisons (layout and clarity } \\
\text { of text, tables and charts). } \\
\text { 5.1.2 Dissemination media and formats are } \\
\text { adequate. } \\
\text { 5.1.3 Statistics are released on a pre- } \\
\text { announced schedule. } \\
\text { 5.1.4 Statistics are made available to all users } \\
\text { at the same time. } \\
\text { 5.1.5 Non-published (but non-confidential) } \\
\text { subaggregates are made available upon } \\
\text { request. } \\
\text { 5.2.1 Documentation on concepts, scope, } \\
\text { classifications, basis of recording, data } \\
\text { sources and statistical techniques is available, } \\
\text { and differences from internationally accepted } \\
\text { standards, guidelines, or good practices are } \\
\text { noted. } \\
\text { 5.2.2 The degree of detail is adapted to the } \\
\text { needs of users, to ensure their satisfaction. } \\
\text { 5.3.1 The contact person for each subject } \\
\text { field is publicized. } \\
\text { 5.3.2 Catalogs of publications, documents } \\
\text { and other services, including information on } \\
\text { their cost, are easily obtainable. }\end{array}$ \\
\hline
\end{tabular}

${ }^{1}$ The elements and indicators included here bring together the "pointers to quality" that are applicable across the five dimensions of data quality. 
Table 1. Mexico: Data Quality Assessment Framework

Summary for National Accounts

\begin{tabular}{|c|c|c|c|c|c|c|}
\hline \multirow[b]{2}{*}{ Elements } & \multicolumn{5}{|c|}{ Assessments } & \multirow[b]{2}{*}{ Comments } \\
\hline & NA & $\mathbf{O}$ & LO & LNO & NO & \\
\hline \multicolumn{7}{|l|}{ 0. Prerequisites } \\
\hline $\begin{array}{l}\text { 0.1 Legal and institutional environment } \\
0.2 \text { Resources } \\
0.3 \text { Quality awareness }\end{array}$ & & $\begin{array}{l}X \\
X\end{array}$ & $\mathrm{X}$ & & & $\begin{array}{l}\text { No provisions in law governing } \\
\text { appointment of the President of INEGI } \\
\text { and specifying qualifications for the } \\
\text { position. }\end{array}$ \\
\hline \multicolumn{7}{|l|}{ 1. Integrity } \\
\hline $\begin{array}{l}\text { 1.1 Professionalism } \\
\text { 1.2 Transparency } \\
\text { 1.3 Ethical Standards }\end{array}$ & & $\begin{array}{l}\mathrm{X} \\
\mathrm{X} \\
\mathrm{X}\end{array}$ & & & & \\
\hline \multicolumn{7}{|l|}{ 2. Methodological Soundness } \\
\hline $\begin{array}{l}\text { 2.1 Concepts and definitions } \\
\text { 2.2 Scope } \\
\text { 2.3 Classification/sectorization } \\
\text { 2.4 Basis for recording }\end{array}$ & & $\begin{array}{l}\mathrm{X} \\
\mathrm{X}\end{array}$ & $\mathrm{X}$ & & & $\begin{array}{l}\text { The central product classification } \\
\text { (CPC) has not been implemented. }\end{array}$ \\
\hline \multicolumn{7}{|l|}{ 3. Accuracy and reliability } \\
\hline 3.2 Statistical techniques & & & $\mathrm{X}$ & $\mathrm{X}$ & & $\begin{array}{l}\text { Although the data sources are } \\
\text { extensive, some statistics require } \\
\text { greater scientific rigor. There are also } \\
\text { valuation problems in the surveys and } \\
\text { in the import data. There are } \\
\text { considerable gaps in the quarterly } \\
\text { survey data. } \\
\text { Inappropriate techniques in the } \\
\text { calculation of taxes at constant prices. } \\
\text { Inappropriate techniques in the } \\
\text { calculation of quarterly value added at } \\
\text { current prices and "benchmarking." }\end{array}$ \\
\hline $\begin{array}{l}\text { 3.3 Assessment and validation of } \\
\text { source data }\end{array}$ & & $\mathrm{X}$ & & & & \\
\hline $\begin{array}{l}\text { 3.4 Assessment and validation of } \\
\text { intermediate and final output data }\end{array}$ & & & $\mathrm{X}$ & & & $\begin{array}{l}\text { Sampling errors are not calculated and } \\
\text { the samples are not adjusted. }\end{array}$ \\
\hline 3.5 Revision studies & & & $\mathrm{X}$ & & & $\begin{array}{l}\text { Although revisions are monitored on an } \\
\text { ongoing basis, these studies have not } \\
\text { had a significant effect on the } \\
\text { calculations for later periods. }\end{array}$ \\
\hline \multicolumn{7}{|l|}{ 4. Serviceability } \\
\hline $\begin{array}{l}\text { 4.1 Relevance } \\
\text { 4.2 Timeliness and periodicity } \\
\text { 4.3 Consistency } \\
\text { 4.4 Revisions policy \& practice }\end{array}$ & & $\begin{array}{l}X \\
X \\
X \\
X\end{array}$ & & & & \\
\hline \multicolumn{7}{|l|}{ 5. Accessibility } \\
\hline $\begin{array}{l}\text { 5.1 Data accessibility } \\
\text { 5.2 Metadata accessibility } \\
\text { 5.3 Assistance to users }\end{array}$ & & $\begin{array}{l}\mathrm{X} \\
\mathrm{X} \\
\mathrm{X}\end{array}$ & & & & \\
\hline
\end{tabular}

Note: NA = Not applicable; $\mathrm{O}=$ Practice Observed; $\mathrm{LO}=$ Practice Largely Observed; LNO = Practice Materially Nonobserved; $\mathrm{NO}=$ Practice Non-observed. Comment: Only if different from $\mathrm{O}$. 
Table 2. Mexico: Data Quality Assessment Framework

Summary for the CPI

\begin{tabular}{|c|c|c|c|c|c|c|}
\hline \multirow[b]{2}{*}{ Dimensions/Elements } & \multicolumn{5}{|c|}{ Assessments } & \multirow[b]{2}{*}{ Comments } \\
\hline & NA & $\mathbf{O}$ & LO & LNO & NO & \\
\hline \multicolumn{7}{|l|}{ 0. Prerequisites } \\
\hline 0.1 Legal and institutional environment & & $\mathrm{X}$ & & & & \\
\hline 0.2 Resources & & $\mathrm{X}$ & & & & \\
\hline 0.3 Quality awareness & & $\mathrm{X}$ & & & & \\
\hline \multicolumn{7}{|l|}{ 1. Integrity } \\
\hline 1.1 Professionalism & & $\mathrm{X}$ & & & & \\
\hline 1.2 Transparency & & $\mathrm{X}$ & & & & \\
\hline 1.3 Ethical Standards & & $\mathrm{X}$ & & & & \\
\hline \multicolumn{7}{|l|}{ 2. Methodological Soundness } \\
\hline 2.1 Concepts and definitions & & $\mathrm{X}$ & & & & \\
\hline 2.2 Scope & & $\mathrm{X}$ & & & & \\
\hline 2.3 Classification/sectorization & & & & $\mathrm{X}$ & & COICOP is not used. \\
\hline 2.4 Basis for recording & & $\mathrm{X}$ & & & & \\
\hline \multicolumn{7}{|l|}{ 3. Accuracy and reliability } \\
\hline 3.1 Source data & & & $\mathrm{X}$ & & & $\begin{array}{l}\text { The } 1989 \text { ENIGH was conducted only } \\
\text { during one quarter of the year. }\end{array}$ \\
\hline 3.2 Statistical techniques & & & & $\mathrm{X}$ & & The weights are 13 years old. ${ }^{1}$ \\
\hline $\begin{array}{l}\text { 3.3 Assessment and validation of } \\
\text { source data }\end{array}$ & & $\mathrm{X}$ & & & & \\
\hline $\begin{array}{l}\text { 3.4 Assessment and validation of } \\
\text { intermediate and final output data }\end{array}$ & & $\mathrm{X}$ & & & & \\
\hline 3.5 Revision studies & & & & $\mathrm{X}$ & & $\begin{array}{l}\text { No revision studies are made when } \\
\text { changes of the base period are } \\
\text { introduced. }\end{array}$ \\
\hline \multicolumn{7}{|l|}{ 4. Serviceability } \\
\hline 4.1 Relevance & & & $\mathrm{X}$ & & & $\begin{array}{l}\text { Users are not consulted actively and } \\
\text { systematically. }\end{array}$ \\
\hline $\begin{array}{l}\text { 4.2 Timeliness and periodicity } \\
4.3 \text { Consistency }\end{array}$ & & $\begin{array}{l}X \\
X\end{array}$ & & & & \\
\hline 4.4 Revision policy and practice & & & & $\mathrm{X}$ & & $\begin{array}{l}\text { Data are not revised after publication, } \\
\text { and there is no well- established plan } \\
\text { for changes of base period. }\end{array}$ \\
\hline
\end{tabular}


Table 2. Mexico: Data Quality Assessment Framework

Summary for the CPI

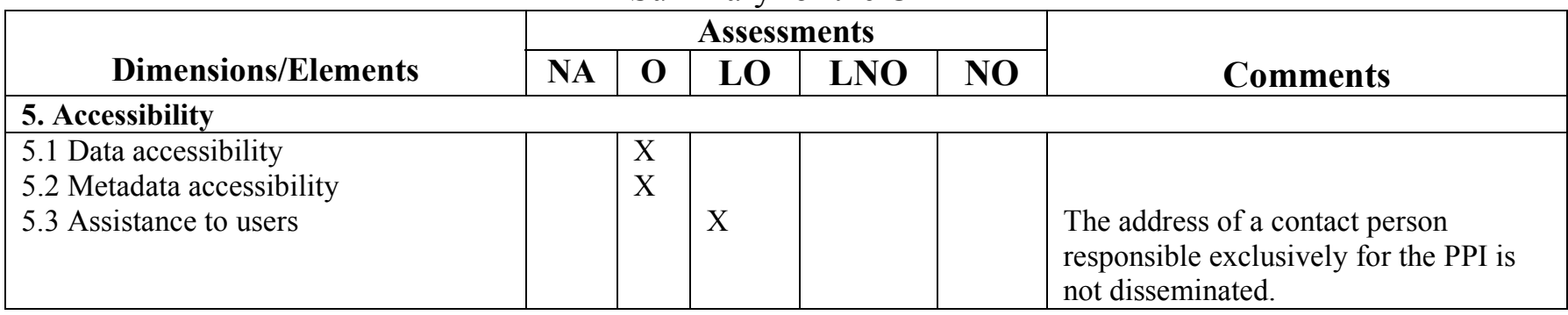

Note: NA = Not Applicable; $\mathrm{O}=$ Practice Observed; $\mathrm{LO}=$ Practice Largely Observed; LNO = Practice Materially Nonobserved (i.e., significant aspects are not observed); $\mathrm{NO}=$ Practice Non-observed.

${ }^{1}$ After the visit of the mission, the BM updated the base period for the NCPI. The index is now compiled with the second half of June 2002 as the price reference period. It uses new expenditure weights from the year 2000, aligned to the second half of June 2002 for relative price changes. 
Table 3. Mexico: Data Quality Assessment Framework

Summary for the PPI

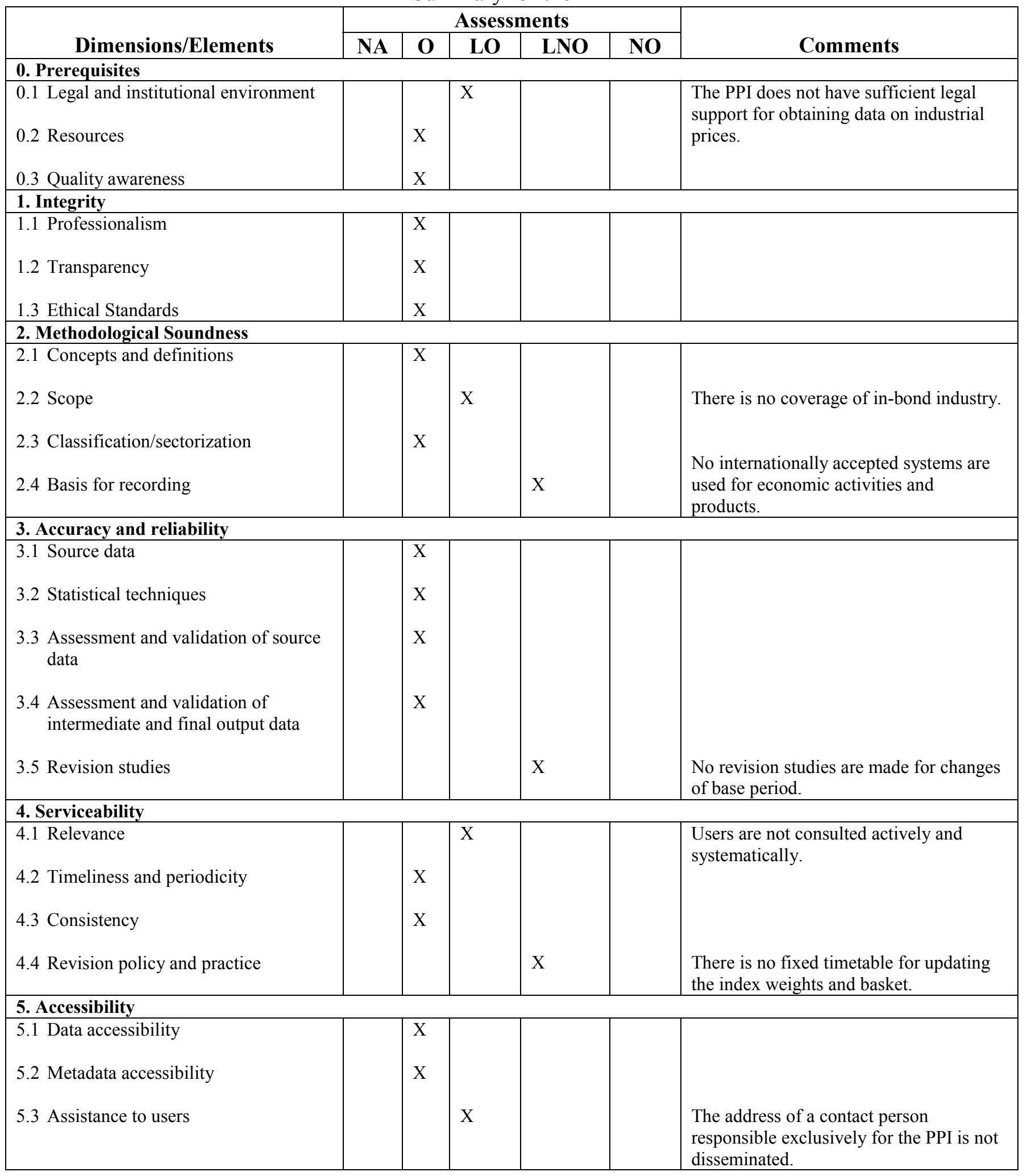

Note: NA = Not Applicable; $\mathrm{O}=$ Practice Observed; LO = Practice Largely Observed; LNO = Practice Materially Nonobserved (i.e., significant aspects are not observed); $\mathrm{NO}=$ Practice Non-observed. 
Table 4. Mexico: Data Quality Assessment Framework

Summary for Balance of Payments Statistics

\begin{tabular}{|c|c|c|c|c|c|c|}
\hline \multirow[b]{2}{*}{ Dimensions/Elements } & \multicolumn{5}{|c|}{ Assessments } & \multirow[b]{2}{*}{ Comments } \\
\hline & NA & $\mathbf{O}$ & LO & LNO & NO & \\
\hline \multicolumn{7}{|l|}{ 0. Prerequisites } \\
\hline 0.1 Legal and institutional environment & & & $\mathrm{X}$ & & & $\begin{array}{l}\text { The Law neither specifically assigns } \\
\text { the task of compiling balance of } \\
\text { payments statistics to the BM nor } \\
\text { authorizes the central bank to request } \\
\text { information from the nonfinancial } \\
\text { private sector. Formal agreements on } \\
\text { statistical revisions with the public } \\
\text { sector are inadequate. }\end{array}$ \\
\hline 0.2 Resources & & $\mathrm{X}$ & & & & \\
\hline 0.3 Quality awareness & & $\mathrm{X}$ & & & & \\
\hline \multicolumn{7}{|l|}{ 1. Integrity } \\
\hline 1.1 Professionalism & & $\mathrm{X}$ & & & & \\
\hline 1.2 Transparency & & $\mathrm{X}$ & & & & \\
\hline 1.3 Ethical Standards & & $\mathrm{X}$ & & & & \\
\hline \multicolumn{7}{|l|}{ 2. Methodological Soundness } \\
\hline 2.1 Concepts and definitions & & & $\mathrm{X}$ & & & $\begin{array}{l}\text { The structure and classification of the } \\
\text { balance of payments use mixed } \\
\text { methodological standards from the } \\
\text { fourth and fifth editions of the Balance } \\
\text { of Payments Manual. }\end{array}$ \\
\hline 2.2 Scope & & & $\mathrm{X}$ & & & $\begin{array}{l}\text { Financial transactions of foreign } \\
\text { branches of Mexican banks are not } \\
\text { recorded on the basis of the residency } \\
\text { criterion. }\end{array}$ \\
\hline 2.3 Classification/sectorization & & & $\mathrm{X}$ & & & $\begin{array}{l}\text { There is no detailed breakdown in the } \\
\text { services account. }\end{array}$ \\
\hline 2.4 Basis for recording & & & $\mathrm{X}$ & & & $\begin{array}{l}\text { Interest on the public external debt is } \\
\text { not recorded on an accrual basis. }\end{array}$ \\
\hline \multicolumn{7}{|l|}{ 3. Accuracy and reliability } \\
\hline 3.1 Source data & & & $\mathrm{X}$ & & & $\begin{array}{l}\text { There are no procedural manuals } \\
\text { documenting management, processing, } \\
\text { and quality control. No data are } \\
\text { collected on some services items. }\end{array}$ \\
\hline 3.2 Statistical techniques & & $\mathrm{X}$ & & & & \\
\hline $\begin{array}{l}3.3 \text { Assessment and validation of } \\
\text { source data }\end{array}$ & & $\mathrm{X}$ & & & & \\
\hline $\begin{array}{l}\text { 3.4 Assessment and validation of } \\
\text { intermediate and final output data }\end{array}$ & & $\mathrm{X}$ & & & & \\
\hline 3.5 Revision studies & & & $\mathrm{X}$ & & & $\begin{array}{l}\text { Revision studies are not performed } \\
\text { regularly. }\end{array}$ \\
\hline
\end{tabular}


Table 4. Mexico: Data Quality Assessment Framework Summary for Balance of Payments Statistics

\begin{tabular}{|c|c|c|c|c|c|c|}
\hline \multirow[b]{2}{*}{ Dimensions/Elements } & \multicolumn{5}{|c|}{ Assessments } & \multirow[b]{2}{*}{ Dimensions/Elements } \\
\hline & NA & $\mathbf{O}$ & LO & LNO & NO & \\
\hline \multicolumn{7}{|l|}{ 4. Serviceability } \\
\hline 4.1 Relevance & & & $\mathrm{X}$ & & & $\begin{array}{l}\text { Users are not consulted actively and } \\
\text { systematically. }\end{array}$ \\
\hline 4.2 Timeliness and periodicity & & $\mathrm{X}$ & & & & \\
\hline 4.3 Consistency & & $\mathrm{X}$ & & & & \\
\hline 4.4 Revision policy and practice & & & $\mathrm{X}$ & & & $\begin{array}{l}\text { The revision studies are not } \\
\text { disseminated. }\end{array}$ \\
\hline \multicolumn{7}{|l|}{ 5. Accessibility } \\
\hline 5.1 Data accessibility & & $\mathrm{X}$ & & & & \\
\hline 5.2 Metadata accessibility & & & & $\mathrm{X}$ & & $\begin{array}{l}\text { Balance of payments methodologies } \\
\text { and statistics are not disseminated. } \\
\text { However, metadata on the debt can be } \\
\text { found on the SHCP website. }\end{array}$ \\
\hline 5.3 Assistance to users & & & $X$ & & & $\begin{array}{l}\text { The name of a contact person } \\
\text { responsible exclusively for balance of } \\
\text { payments statistics is not disseminated. }\end{array}$ \\
\hline
\end{tabular}

Note: NA = Not Applicable; $\mathrm{O}=$ Practice Observed; $\mathrm{LO}=$ Practice Largely Observed; LNO = Practice Materially Nonobserved (i.e., significant aspects are not observed); $\mathrm{NO}=$ Practice Non-observed. Comment: Only if different from $\mathrm{O}$. 
Table 5. Mexico: Data Quality Assessment Framework

Summary for Government Finance Statistics

\begin{tabular}{|c|c|c|c|c|c|c|}
\hline \multirow[b]{2}{*}{ Dimensions/Elements } & \multicolumn{5}{|c|}{ Assessments } & \multirow[b]{2}{*}{ Comments } \\
\hline & NA & $\mathbf{O}$ & LO & LNO & NO & \\
\hline \multicolumn{7}{|l|}{ 0. Prerequisites } \\
\hline $\begin{array}{l}0.1 \text { Legal and institutional } \\
\text { environment }\end{array}$ & & $\mathrm{X}$ & & & & \\
\hline 0.2 Resources & & $\mathrm{x}$ & & & & \\
\hline 0.3 Quality awareness & & $\mathrm{X}$ & & & & \\
\hline \multicolumn{7}{|l|}{ 1. Integrity } \\
\hline 1.1 Professionalism & & $\mathrm{X}$ & & & & \\
\hline 1.2 Transparency & & $\mathrm{X}$ & & & & \\
\hline 1.3 Ethical Standards & & $\mathrm{X}$ & & & & \\
\hline \multicolumn{7}{|l|}{ 2. Methodological Soundness } \\
\hline 2.1 Concepts and definitions & & & $\mathrm{X}$ & & & $\begin{array}{l}\text { The concepts and definitions used are } \\
\text { similar but not identical to the } \\
\text { GFSM } 1986 \text { guidelines. }\end{array}$ \\
\hline 2.2 Scope & & & & $\mathrm{X}$ & & $\begin{array}{l}\text { The definition of consolidated central } \\
\text { government is different from that of the } \\
\text { GFSM } 1986 \text {. General government data } \\
\text { are not disseminated regularly. }\end{array}$ \\
\hline 2.3 Classification/sectorization & & & & $\mathrm{X}$ & & $\begin{array}{l}\text { Classification and sectorization differ } \\
\text { from the GFSM } 1986 \text { presentation. }\end{array}$ \\
\hline 2.4 Basis for recording & & $\mathrm{X}$ & & & & \\
\hline \multicolumn{7}{|l|}{ 3. Accuracy and reliability } \\
\hline 3.1 Source data & & $\mathrm{X}$ & & & & \\
\hline 3.2 Statistical techniques & & $\mathrm{x}$ & & & & \\
\hline $\begin{array}{l}3.3 \text { Assessment and validation of } \\
\text { source data }\end{array}$ & & $\mathrm{X}$ & & & & \\
\hline $\begin{array}{l}3.4 \text { Assessment and validation of } \\
\text { intermediate and final output } \\
\text { data }\end{array}$ & & $\mathrm{X}$ & & & & \\
\hline 3.5 Revision studies & & $\mathrm{X}$ & & & & \\
\hline
\end{tabular}


Table 5. Mexico: Data Quality Assessment Framework

Summary for Government Finance Statistics

\begin{tabular}{|c|c|c|c|c|c|c|}
\hline \multirow[b]{2}{*}{ Dimensions/Elements } & \multicolumn{5}{|c|}{ Assessments } & \multirow[b]{2}{*}{ Comments } \\
\hline & NA & $\mathbf{O}$ & LO & LNO & NO & \\
\hline \multicolumn{7}{|l|}{ 4. Serviceability } \\
\hline 4.1 Relevance & & $\mathrm{X}$ & & & & \\
\hline 4.2 Timeliness and periodicity & & & $\mathrm{X}$ & & & $\begin{array}{l}\text { The timeliness of GFS for central } \\
\text { government, general government, and } \\
\text { the nonfinancial public sector does not } \\
\text { meet SDDS requirements. }\end{array}$ \\
\hline 4.3 Consistency & & $\mathrm{X}$ & & & & \\
\hline 4.4 Revision policy and practice & & & $\mathrm{X}$ & & & $\begin{array}{l}\text { Studies and analyses of the revisions } \\
\text { are not disseminated. }\end{array}$ \\
\hline \multicolumn{7}{|l|}{ 5. Accessibility } \\
\hline 5.1 Data accessibility & & & $\mathrm{X}$ & & & $\begin{array}{l}\text { The presentation of the GFS makes } \\
\text { their comprehension and international } \\
\text { comparisons difficult. }\end{array}$ \\
\hline 5.2 Metadata accessibility & & $\mathrm{X}$ & & & & \\
\hline 5.3 Assistance to users & & $\mathrm{X}$ & & & & \\
\hline
\end{tabular}

Note: NA = Not Applicable; $\mathrm{O}=$ Practice Observed; $\mathrm{LO}=$ Practice Largely Observed; LNO = Practice Materially Nonobserved (i.e., significant aspects are not observed); $\mathrm{NO}=$ Practice Non-observed. Comment: Only if different from $\mathrm{O}$. 
Table 6. Mexico: Data Quality Assessment Framework Summary for Monetary Statistics ${ }^{1}$

\begin{tabular}{|c|c|c|c|c|c|c|}
\hline \multirow{2}{*}{ Dimensions/Elements } & \multicolumn{5}{|c|}{ Assessments } & \multirow{2}{*}{ Comments } \\
\hline & NA & $\mathbf{O}$ & LO & LNO & NO & \\
\hline \multicolumn{7}{|l|}{ 0. Prerequisites } \\
\hline $\begin{array}{l}0.1 \text { Legal and institutional } \\
\text { environment }\end{array}$ & & $\mathrm{X}$ & & & & \\
\hline 0.2 Resources & & $\mathrm{X}$ & & & & \\
\hline 0.3 Quality awareness & & $\mathrm{X}$ & & & & \\
\hline \multicolumn{7}{|l|}{ 1. Integrity } \\
\hline 1.1 Professionalism & & $\mathrm{X}$ & & & & \\
\hline 1.2 Transparency & & $\mathrm{X}$ & & & & \\
\hline 1.3 Ethical Standards & & $\mathrm{X}$ & & & & \\
\hline \multicolumn{7}{|l|}{ 2. Methodological Soundness } \\
\hline 2.1 Concepts and definitions & & & $\mathrm{X}$ & & & $\begin{array}{l}\text { No surveys are prepared or } \\
\text { disseminated for (1) the central bank, } \\
\text { (2) other depository corporations } \\
\text { (ODC), and (3) depository } \\
\text { corporations. }^{2}\end{array}$ \\
\hline 2.2 Scope & & & $\mathrm{X}$ & & & $\begin{array}{l}\text { Coverage of the ODC is not complete. } \\
\text { Some financial corporations classified } \\
\text { as nonbank perform ODC functions. }\end{array}$ \\
\hline 2.3 Classification/sectorization & & $\mathrm{X}$ & & & & \\
\hline 2.4 Basis for recording & & $\mathrm{X}$ & & & & \\
\hline \multicolumn{7}{|l|}{ 3. Accuracy and reliability } \\
\hline 3.1 Source data & & & $\mathrm{X}$ & & & $\begin{array}{l}\text { Delays in the submission of the reports } \\
\text { of some ODC prevents more timely } \\
\text { dissemination of detailed monetary } \\
\text { statistics. (The BM is making efforts to } \\
\text { reduce this lag). }{ }^{4}\end{array}$ \\
\hline 3.2 Statistical techniques & & $\mathrm{X}$ & & & & \\
\hline $\begin{array}{l}\text { 3.3 Assessment and validation of } \\
\text { source data }\end{array}$ & & $\mathrm{X}$ & & & & \\
\hline $\begin{array}{l}\text { 3.4 Assessment and validation of } \\
\text { intermediate and final output data }\end{array}$ & & $\mathrm{X}$ & & & & \\
\hline 3.5 Revision studies & & $\mathrm{X}$ & & & & \\
\hline
\end{tabular}


Table 6. Mexico: Data Quality Assessment Framework Summary for Monetary Statistics ${ }^{1}$

\begin{tabular}{|c|c|c|c|c|c|c|}
\hline \multirow{2}{*}{ Dimensions/Elements } & \multicolumn{5}{|c|}{ Assessments } & \multirow{2}{*}{ Comments } \\
\hline & NA & $\mathbf{O}$ & LO & LNO & NO & \\
\hline \multicolumn{7}{|l|}{ 4. Serviceability } \\
\hline 4.1 Relevance & & & $\mathrm{X}$ & & & $\begin{array}{l}\text { Data users are not consulted actively or } \\
\text { systematically. }\end{array}$ \\
\hline 4.2 Timeliness and periodicity & & $\mathrm{X}$ & & & & \\
\hline 4.3 Consistency & & $\mathrm{X}$ & & & & \\
\hline 4.4 Revision policy and practice & & & $\mathrm{X}$ & & & $\begin{array}{l}\text { Studies and analyses of revisions are } \\
\text { not disseminated. }\end{array}$ \\
\hline \multicolumn{7}{|l|}{ 5. Accessibility } \\
\hline 5.1 Data accessibility & & $\mathrm{X}$ & & & & \\
\hline 5.2 Metadata accessibility & & & & $\mathrm{X}$ & & $\begin{array}{l}\text { No detailed documentation is published } \\
\text { on the methodology used. (The BM is } \\
\text { completing the incorporation of a } \\
\text { metadata and methodologies module. })^{5}\end{array}$ \\
\hline 5.3 Assistance to users & & & $\mathrm{X}$ & & & $\begin{array}{l}\text { The name of a contact person } \\
\text { responsible exclusively for monetary } \\
\text { statistics is not disseminated. }\end{array}$ \\
\hline
\end{tabular}

Note: $\mathrm{NA}=$ Not Applicable; $\mathrm{O}=$ Practice Observed; $\mathrm{LO}=$ Practice Largely Observed; $\mathrm{LNO}=$ Practice Materially Nonobserved (i.e., significant aspects are not observed); $\mathrm{NO}=$ Practice Non-observed. Comment: Only if different from $\mathrm{O}$.

${ }^{1}$ The assessment uses the Depository Corporations Survey as a point of reference.

${ }^{2}$ Since August 8, 2002, the BM has begun to disseminate these surveys on its Internet website.

${ }^{3}$ Since the departure of the mission, the BM has introduced a data system with full coverage of the ODC.

${ }^{4}$ After the visit of the mission, the delay was reduced by six days. It is expected that, with the release of information for January 2003, the delay will be reduced by a further three days. Moreover, BM expects that, by the end of the second quarter of 2003, the data file will be transmitted to the IMF on the $30^{\text {th }}$ day of each month.

${ }^{5}$ After the visit of the mission, the BM updated the metadata and posted an extensive methodological note on its Internet website. 


\section{Users' Views}

With the assistance of the authorities, the mission conducted an informal survey of users to ascertain their views on selected aspects of the quality of Mexico's statistics. The survey used a questionnaire developed by IMF staff. The survey conducted by INEGI targeted users of national accounts statistics and that conducted by SHCP was directed mainly to users of government finance statistics. Those surveys, together with that conducted by BM with a broader range of users, reflected users' views on the quality of official macroeconomic statistics. BM, INEGI, and SHCP provided data compiled from responses by 22, 12, and 9 respondents, respectively. As a complement to the survey and the mission's own assessment of macroeconomic statistics, a meeting with some key users of Mexican economic data was organized by BM.

\section{The survey}

According to the survey results, the methodological soundness and reliability of Mexican macroeconomic data were perceived to be good and to compare favorably with those of other countries in the region. Most respondents thought that the institutional coverage was sufficient, although certain users (roughly 20 percent) disagreed. In general, users were satisfied with the topical range of statistics made available. However, a common denominator in most of the responses was the need to improve the coverage of labor statistics.

Only some 60 percent of respondents were satisfied with the level of detail of the statistics, citing needed improvements in public finance statistics, external and domestic debt data, national accounts (most users agreed on the need for quarterly GDP by activity), and labor statistics. Respondents were partially satisfied with the frequency of the data, calling for improvements in the frequency of labor and industrial production data.

Users appreciated the availability of advance release calendars and thought that in general data releases met the projected dates. A significant number of users noted the lack of information on revisions made to the official statistics. Users mentioned that revisions were not properly identified each time new data were released. They also believed that, to avoid outdated data, historical series needed to be updated each time new data were released, a procedure that has proved to be too costly for the users to undertake.

The survey showed that users were mostly satisfied with accessibility to the official statistics. The data were considered to be reasonably accessible, primarily though electronic means, publications, and press releases. About 45 percent of the respondents felt that methodological concepts and analytical presentations were clearly described, but about 30 percent of the respondents strongly disagreed and noted the lack of supporting methodological documentation. Respondents cited balance of payments and prices data as the two sets of statistics that most obviously lacked publicly available descriptions of methodologies. 
Users indicated that the overall quality of official statistics was appropriate for economic analysis. Virtually all responses regarding the overall quality of the Mexican statistics placed those statistics among the third and fourth quintiles of the rating scale.

\section{The meeting of users}

To complement the user's views of official statistics in Mexico, the mission met with seven key users of macroeconomic statistics represented by economists from the private sector, including economic analysis and forecasting firms. Overall, user's views were consistent with the findings of the survey, and the main areas for improvement identified by users were in line with the findings of the IMF staff.

Even though the group that met with the mission mainly comprised specialists in macroeconomic projection and forecasting, the statistical requirements of this group were similar to those of the more diverse group of users covered by the survey. In general, users expressed the need for a more complete set of metadata (information on statistical sources and methodologies) in all sectors of statistics. Users also wanted more information on revision policies and better coverage, as well as an expanded breakdown, of real sector and public finance statistics.

Specifically on real sector statistics, users cited limited availability of seasonally adjusted series for national accounts prepared by INEGI as well as limited public information on the methodology for the seasonal adjustment of the series. Seasonally adjusted data on national accounts were disseminated only in the form of indices, while the users would like to have available also the absolute figures. Users expressed the need to have more data at the regional level, although they recognized that INEGI had made significant progress in this field regarding annual data. Users would like to have such regional data as existed with a higher frequency and timeliness.

A common view of users was that government finance statistics lacked clarity and were difficult to understand. These statistics appeared to contain ambiguities that were difficult to resolve, and monthly and annual data were not entirely consistent. As in most other statistical sectors, users mentioned that comprehensive metadata were not available to the public. For most off-balance items, available information was very limited or in some cases nonexistent, and there was no information available to the public regarding foreign direct investment projects known as PIDIREGAS.

On balance of payments statistics, users expressed the view that revisions had not been properly explained in the press releases of the BM, thereby creating an extra burden for users in using historic time series. In addition, users would like to have additional data coverage regarding the financial account, particularly the portfolio investment account. In general, users were satisfied with the support given by data providers.

All users regarded monetary statistics compiled by BM as of high quality. However, some users considered that additional breakdowns of credits were needed and that the timeliness of 
monetary statistics could be improved. Users expressed the view that there was a need for more disaggregation of BM's monetary liabilities. 